EUROPEAN CENTRAL BANK WORKING PAPER SERIES

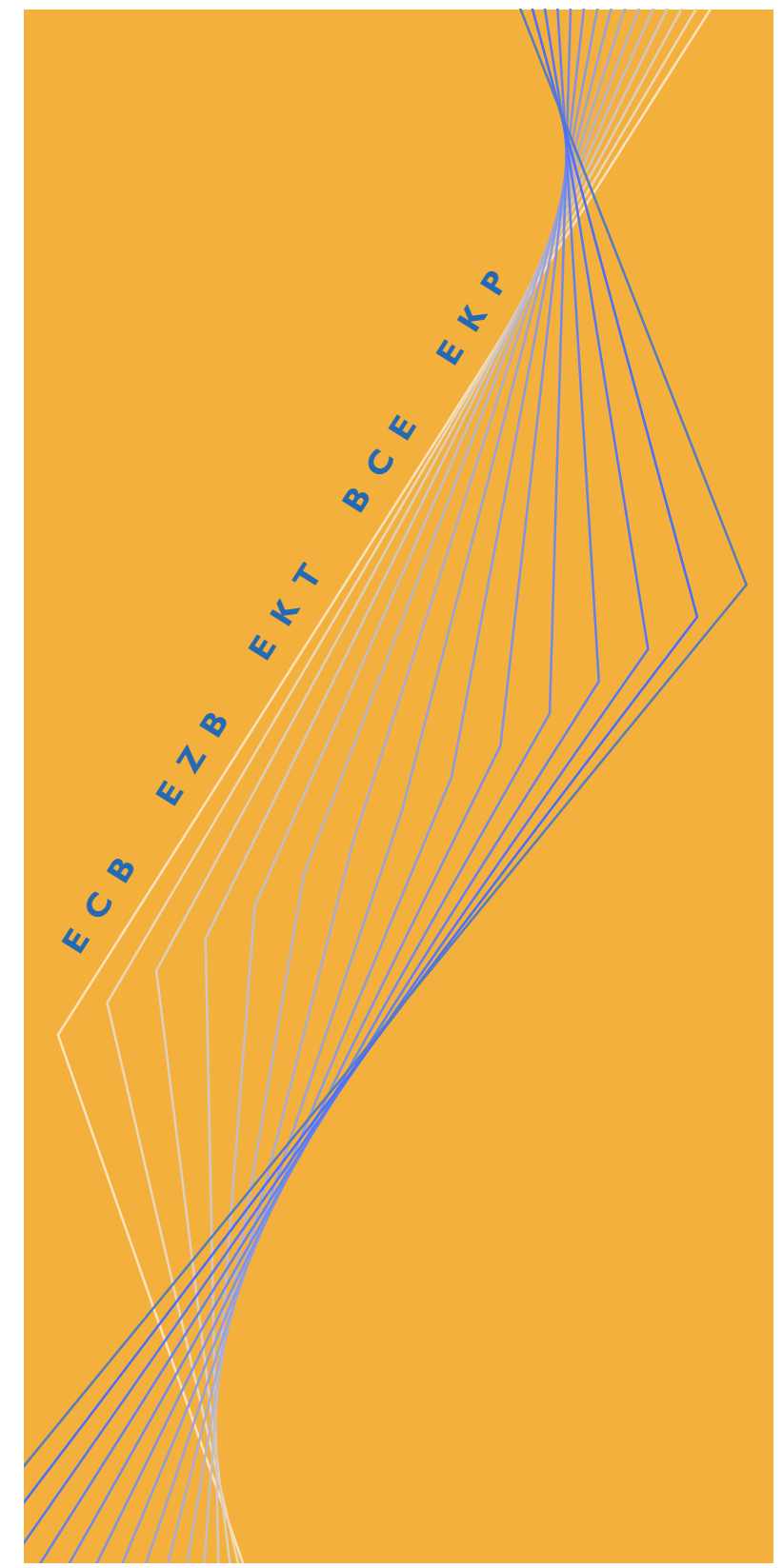

WORKING PAPER NO. 63

$$
\begin{aligned}
& \text { DOES MONEY LEAD } \\
& \text { INFLATION IN THE } \\
& \text { EURO AREA? }
\end{aligned}
$$

BY S. NICOLETTI ALTIMARI

May 200 I 
E U R P E A N C N TRAL BA N K

WORKING PAPER SERIES

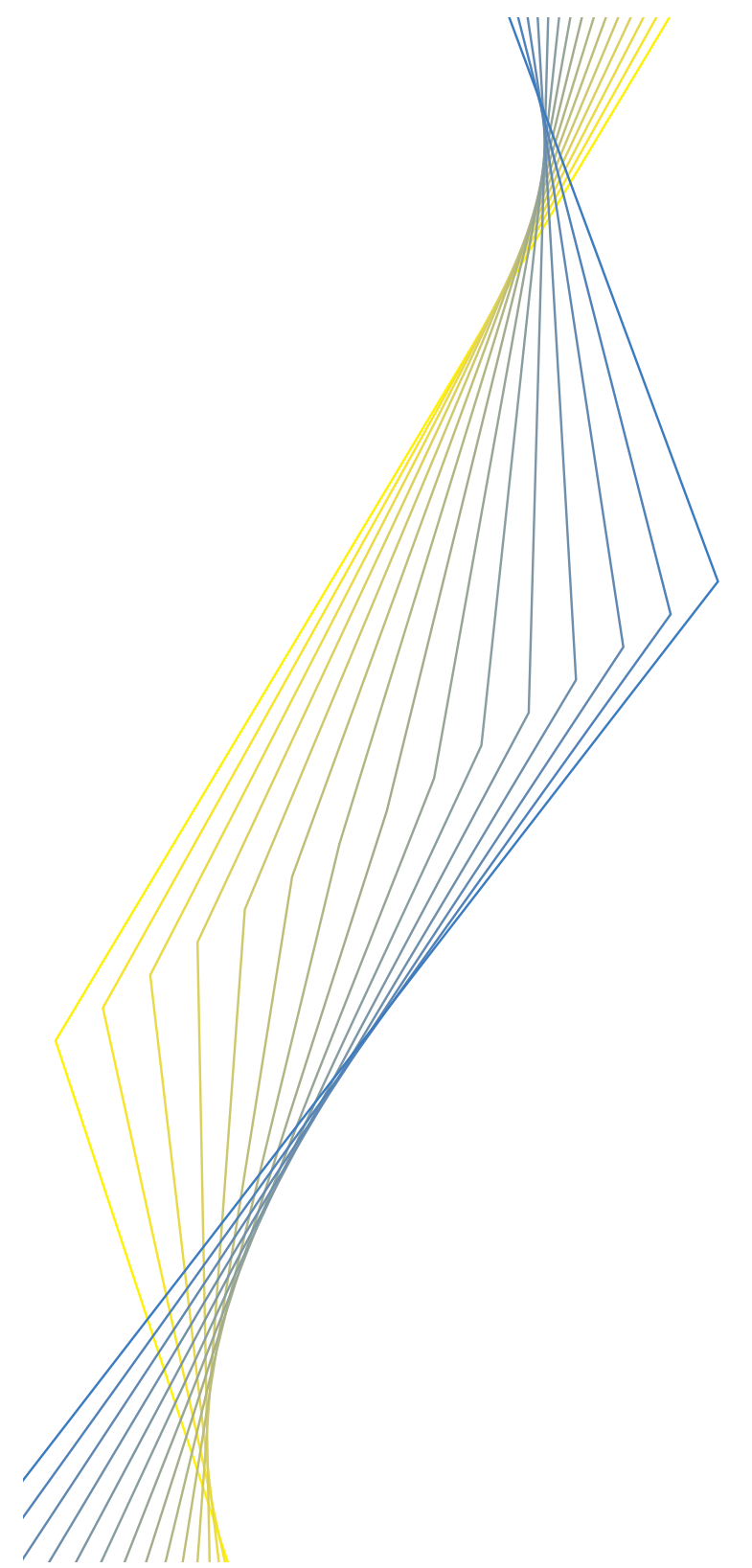

WORKING PAPER N0. 63

DOES MONEY LEAD

INFLATION IN THE

EURO AREA?*

BY S. NICOLETTI ALTIMARI

May 2001 
() European Central Bank, 200 I

Address

Kaiserstrasse 29

D-603 I I Frankfurt am Main

\section{Germany}

Postfach 160319

Postal address

D-60066 Frankfurt am Main

\section{Germany}

+496913440

Telephone

http://www.ecb.int

Internet

+496913446000

Fax

4 I I I44 ecb d

Telex

All rights reserved.

Reproduction for educational and non-commercial purposes is permitted provided that the source is acknowledged.

The views expressed in this paper are those of the authors and do not necessarily reflect those of the European Central Bank.

ISSN I56I-08I0 


\section{Contents}

$\begin{array}{ll}\text { Abstract } & 5\end{array}$

$\begin{array}{lll}1 & \text { Introduction } & 7\end{array}$

2 The data set and the construction of indicators 10

$\begin{array}{ll}2.1 \text { The data set } & 10\end{array}$

2.2 Measures of inflation 11

$\begin{array}{ll}2.3 \text { Money-based indicators } & 12\end{array}$

$\begin{array}{ll}2.4 \text { Other indicators } & 14\end{array}$

3 Bivariate forecasts of inflation 15

$\begin{array}{ll}3.1 \text { The methodology } & 15\end{array}$

3.2 Results for the bivariate forecasts 17

3.2.1 Out-of-sample forecast performance of different indicators 17

3.2.2 Encompassing tests of predictive ability 20

3.2.3 Results for different sample periods $\quad 21$

3.2.4 Results using an alternative model specification $\quad 22$

4 Multivariate forecasts of inflation 23

4.1 The methodology 23

4.2 Results for the multivariate forecasts $\quad 25$

$5 \quad$ Inflation predictability across forecast horizons 27

6 Conclusions 28

$\begin{array}{ll}\text { Appendix } & 30\end{array}$

$\begin{array}{ll}\text { References } & 32\end{array}$

Figures and Tables $\quad 35$

European Central Bank Working Paper Series $\quad 48$

ECB - Working Paper No 63 - May 2001 3 


\begin{abstract}
This paper investigates the properties of monetary and credit aggregates as indicators for future price developments in the euro area. The forecasting performance of models including indicators based on money and credit is assessed in a simulated out-of-sample forecasting exercise for forecast horizons varying from one quarter to three years ahead. The performance of these models is compared with that of models which include indicators based on financial markets, real activity, the labour market and various cost and price measures. The results support the idea that monetary and credit aggregates provide significant and independent information for future price developments in the euro area, especially at medium term horizons.
\end{abstract}

Keywords: euro area, inflation, leading indicators, money, P-Star

JEL classifications: E31, E40, C32 


\section{Non Technical Summary}

The decision by the ECB of assigning a prominent role to money in its monetary policy strategy and the increasing interest on developments at the euro area level have recently stimulated a set of studies which focus on the information content of monetary aggregates for future price developments. So far, however, no systematic investigation has been carried out on the leading indicator properties of different moneybased indicators or on their relative predictive content with respect to other potential leading indicators of inflation.

This paper tries to fill this gap by evaluating, in a systematic manner, the forecasting performance of different models including a broad set of money-based indicators in predicting future inflation in the euro area. The monetary indicators considered include the stocks of M1, M2, M3, loans to the private sector, and a number of other money-based indicator, such as the real money gap and the money overhang measures. The predictive content for future inflation of models including these money-based indicators is compared with that of models including a number of alternative indicators derived from financial markets, real activity measures, labour market indicators and cost and price measures.

The procedure is based on performing a simulated out-of-sample forecasting exercise (i.e. predictions are made using only the information available prior to the forecasting period) to predict inflation for forecast horizons varying from one quarter to three years ahead. In order to check the robustness of the results obtained, the exercise is performed for different measures of inflation, different sample periods and considering both bivariate and multivariate information sets.

The results obtained support the idea that monetary and credit aggregates contain substantial information about future price developments in the euro area. The comparative advantages, in terms of forecasting performance, of models which include money-based indicators tend to increase as the forecast horizon is broadened. This is consistent with the view that money contains information which is especially useful for anticipating medium-term and low-frequency trends in inflation.

Indicators derived within the framework of the P-Star model of inflation, such as the real money gap or rate of change in the P-Star indicator (all based on M3), appear to perform well in forecasting inflation and to add useful information to "headline" monetary aggregates especially for forecast horizons within the two years. It proves useful, in constructing these measures, to clean the signal contained in monetary aggregates (M3) from the distortions caused by the short run portfolio re-allocation due to movements in long-term interest rates, especially for forecast horizons around one and a half years. The models including the rate of growth of M3 and of loans are the best performing models for the longest horizons (beyond two years). The analysis also clearly indicates that, at longer horizons, broad monetary aggregates show better leading indicator properties for future inflation than narrow aggregates.

Overall, the results lend support to the idea that monetary and credit aggregates provide useful additional and independent information on medium-term inflation prospects for the euro area relative to the best nonmonetary indicators, especially at horizons beyond one and a half years. 


\title{
DOES MONEY LEAD INFLATION IN THE EURO AREA?
}

\author{
Sergio Nicoletti Altimari
}

\section{Introduction}

While the long-run close association between the price level and the money stock is the subject of a widespread consensus in the economics profession, the role of money as an information variable for monetary policy is still a very open issue. Does money contain useful information on future price developments and for a horizon which is relevant for taking policy decisions? ${ }^{1}$ The empirical investigations on this question have not provided unambiguous answer and the available evidence seems to vary depending on the country or the historical periods considered.

In the United States, for example, where a large body of empirical literature exists, the evidence is, at best, rather mixed. ${ }^{2}$ The growing scepticism towards monetary aggregates which has emerged in the United States seems to reflect mainly a relative high instability of money demand relationship in this country. It is argued that a number of factors, going from the effects of regulatory changes to unpredictable innovations in financial markets, may obscure the signal that can be extracted from monetary aggregates for both the short and the longer term horizons. Recently, Estrella and Mishkin (1997) have argued that the instability of the relationship between money and nominal income (or velocity shocks) may represent a problem for using money as an information variable to guide monetary policy decisions particularly in a situation of relatively subdued inflation. ${ }^{3}$

In the euro area the empirical evidence points to a somewhat different picture. Most of the evidence produced over the recent years points to the existence of a stable money demand relationship in the euro area. ${ }^{4}$ More recently this evidence has been reconfirmed in a comprehensive manner by the work of Coenen and Vega (1999) and Brand and Cassola (2000).

In 1998, also as a reflection of the more favourable experience with monetary aggregates in the euro area, the ECB decided to assign a prominent role to money in its monetary policy strategy. The prominent role

1 Indeed, both questions, whether and why does money contain useful information for future price developments, are still intensely debated. For an excellent survey of the debate see Engert and Selody (1998).

2 See, among others, Friedman and Kuttner (1992), Estrella and Mishkin (1997), Stock and Watson (1999) and Orphanides and Porter (2000).

3 In the words of Estrella and Mishkin (1997): "The problem with monetary aggregates as a guide to monetary policy is that there frequently are shifts in velocity that alter the relationship between money growth and nominal income. A way of describing this situation is to think of velocity shocks as the noise that obscures the signal from monetary aggregates. In a regime in which changes in nominal income, inflation and the money supply are subdued, the signal-to-noise ratio is likely to be low, making monetary aggregates a poor guide for policy."

4 See Fagan and Henry (1998) and the survey in Browne, Fagan and Henry (1997). 
of money entails a commitment on the part of the ECB to thoroughly analysing developments in monetary aggregates and extracting the information they contain for taking monetary policy decisions. ${ }^{5}$ The decision by the ECB and the increasing interest on developments at the euro area level have naturally stimulated a set of studies which more directly focus on the information content of monetary aggregates for future price developments. Gerlach and Svensson (2000) and Trecoci and Vega (2000) have investigated the information content of money (M3) for inflation in the framework of a P-Star model of inflation. Both studies found broad support to the idea that the real money gap (the deviation of the real money balances from equilibrium real balances) has substantial predictive content for future price developments in the euro area. Gottschalk et al. (2000) have investigated the predictive performance of monetary aggregates by means of bivariate VAR representations and compared it with the performance of simple univariate models of inflation. Their results are less favourable to monetary aggregates, even if some evidence is found of a good predictive content of the broad aggregate M3 for future inflation, particularly at long horizons.

So far, however, no systematic investigation has been carried out on the leading indicator properties of different money-based indicators or on the relative predictive content of these indicators with respect to other potential leading indicators of inflation. The empirical evidence available for the euro area leaves open a number of important questions. First, on a theoretical ground, there are different, competing or complementary, theories of inflation, which suggests that other variables/indicators should play a role in forecasting future price developments. How does the predictive content of monetary aggregates compare with respect to other potential leading indicator of inflation? Second, at a more practical level, a number of different money-based indicators have been proposed in the economics literature. Among these, various measures of "excess liquidity", such as money gaps or overhangs, are commonly used in monetary analysis of various central banks. ${ }^{6}$ Do these indicators provide useful additional information beyond that contained in headline monetary aggregates from which they are derived? Third, the performance of an indicator may vary depending on the forecast horizon at which it is measured. For what forecast horizons should money-based indicators be considered "good" indicators for future inflation and how does the relative predictive content of different money-based indicators vary with changes in the forecast horizon? Finally, money may be considered as a variable which summarises the information contained in other variables (e.g. its determinants in a money demand framework) or as a variable providing additional information. Is there an additional, independent predictive content in money beyond that contained in its determinants, such as real activity and prices?

\footnotetext{
5 The ECB's monetary policy strategy comprises first and foremost a quantitative definition of the primary objective of monetary policy in the euro area, namely price stability. Secondly, two forms of analysis are used to support the assessment by the ECB's Governing Council of the risks to price stability: a prominent role for money (the first pillar), as signalled by the announcement of a quantitative reference value for monetary growth, and a broadly based assessment of a wide range of other indicator variables (the second pillar). See ECB (1999a) and ECB (2000) for a description and explanation of the ECB's monetary policy strategy. See also Issing et al. (2001) for a comprehensive review of monetary policy in the euro area.

6 A broad overview of the use of monetary analysis in central banks' policy making can be found in Klöckers (2001).
} 
This paper tries to address these questions in a systematic way by comparing the forecasting performance of a large number of models based on monetary and non-monetary indicators, using a simulated out-ofsample methodology. In the exercise, all models are recursively estimated and forecasts are performed using only data prior to the forecasting period (and therefore potentially available to a "real time" forecaster). This methodology, certainly not new in the econometric literature, has recently been rigorously laid out and applied using data for the United States by Stock and Watson (1998 and 1999) who have also suggested a number of innovative procedures to forecasting. This study follows closely the work of these authors. Besides the obvious difference of being applied on a different set of data, there are two other differences. First, the focus is on monetary variables: the analysis is extended to a number of indicators which follow in the tradition of the P-Star approach, such as real money gap and overhang indicators. As already mentioned, these indicators have been found to have predictive content for future inflation in previous empirical studies for the euro area. Second, there is an attempt to evaluate how the predictability of inflation varies across prediction horizons and depending on the information set. The predictive content for future inflation of various money-based indicators is compared to that of a number of alternative indicators derived from financial markets, real activity, the labour market and others at forecasting horizons varying from one quarter to three years ahead. Measures of predictability proposed in the literature are evaluated for the models based on varying information sets.

The forecasting performance of the models based on the indicators considered is evaluated over the period 1992 to 2000 Q3 using both bivariate and multivariate forecast techniques. Moreover, the sensitivity of the results obtained is checked with respect to different model specifications, different periods of out-ofsample forecast and different measures of price inflation.

The following main conclusions emerge from the simulated out-of-sample forecasting exercise. Overall, the results give support to the idea that monetary aggregates provide useful additional and independent information on inflation prospects in the medium-term for the euro area. The predictive content of monetary aggregates relative to other indicators increases with the length of the horizon. For longer horizons broad monetary aggregates (M3 and its main counterpart, loans to the private sector) are better indicator for future inflation than narrow aggregates, and are generally the best performing indicators among all indicators considered. Measures of excess liquidity, such as P-Star and money gap/overhang indicators, appear to add useful information with respect to "headline" aggregates especially at horizons comprised between one and two years ahead. Their performance, however, is somewhat sensitive to the money demand specification which is used for their derivation. The above results hold for the different measures of inflation and the different sample periods considered. Moreover, the results would suggest that, relative to monetary aggregates, price and cost variables appear to contain additional predictive ability mainly at short horizons. Real activity variables (including measures of imbalances between demand and supply) appear to add useful information also at longer forecast horizons, even if their relative predictive content tends to be lower than that of monetary aggregates at these horizons and is 
sensitive to the measure of inflation utilised and to the sample period over which the exercise is performed.

It is worth mentioning at the outset that in evaluating the above results particular caution is in order. Firstly, the sample period used for the empirical is relatively short and the data set relatively small, due to the limited availability of aggregated data for the euro area extending sufficiently back in time. Secondly, the methodological choice in this paper implies that the empirical evaluation proceeds within the context of reduced form models. As a consequence, the concept of information variable adopted in this paper, limited to the ex-post out-of-sample predictive ability, is a narrow one. Woodford (1994) rightly points out that the problems in drawing conclusions from a reduced-form analysis are likely to be particularly acute for policy related variables. ${ }^{7}$ These limitations warn against a simple-minded use of the results for policymaking purposes and obviously call for further tests and analyses in the future. Nevertheless, and keeping the drawbacks of the approach in mind, the results may be useful in the sense of providing some stylised facts and reveal empirical regularities in the available data. ${ }^{8}$ Clearly, such empirical regularities have to be tested across historical periods and policy regimes and should be explained and investigated by means of structural models. The latter can benefit from the fact that the empirical findings may suggest particular directions of research.

The remainder of the paper is organised as follows. In Section 2, the data set and the procedures to construct the indicators to be used in the forecasting exercise are described. Section 3 illustrates the empirical methodology and the basic specification of the forecasting models and compares the results of the simulated forecast out-of-sample exercise for bivariate models of inflation. Section 4 considers multivariate forecasts of inflation using all variables or groups of variables in the data set. Section 5 analyses measures of the predictability of inflation across forecast horizons. Section 6 concludes.

\section{The data set and the construction of indicators}

\subsection{The data set}

The data used in the exercise are quarterly data from 1980 Q1 to 2000 Q2 (Q3 for the HICP index). While a detailed description of the variables used is contained in the Appendix, two points are worth noting here. First, the exercise is performed only using aggregate data for the euro area as a whole, and no individual countries' data. Clearly, an investigation of the relative performance of forecasts based on the

7 More specifically, the results outlined above are obviously conditional on the specific policies (or policy reaction functions) followed by the monetary policy authorities in the euro area over the past twenty years. The finding that a variable is not useful in forecasting inflation over this period might simply be a consequence of the fact that central banks have reacted systematically (and in the right way) to the information it revealed. At the same time, absent a structural interpretation, it is not obvious how the central bank should respond to a variable which has proved to perform well in forecasting inflation.

8 Moreover, forecasts produced by reduced-form models which have been selected on the basis of their out-of-sample forecasting performance may represent useful benchmarks for assessing the results from structural models as they may point to likely outcomes under the assumption of an unchanged monetary authorities' reaction function. 
euro area aggregated data with respect to the aggregation of forecasts made for individual countries in the euro area represent a useful and interesting complement to the work in this paper. ${ }^{9}$ Second, only finally revised data are used to perform the exercise. Therefore, the exercise presented in the following sections is a "pseudo" out-of-sample forecasting exercise because, strictly speaking, due to subsequent revisions the data used here were not available to a forecaster (or to a policy maker) at the time the forecast was performed. ${ }^{10}$

\subsection{Measures of inflation}

The forecast exercise was performed using various definitions of price inflation. The HICP index for the euro area is the measure which has been chosen by the ECB for the quantitative definition of its primary objective of price stability and therefore represents a natural focus of the analysis. As explained in the Appendix, the HICP series, which is being officially collected only starting in 1995, was extended backward to 1980 Q1 using backward estimates at the country level by Eurostat or (when this was not possible due to the lack of data) the rate of growth of the CPI index. Given that the backward estimates of the HICP are subject to some degree of uncertainty, the private consumption deflator and the GDP deflator were also used as alternative measure of price developments.

Chart 1 plots the annual inflation rates for the above price indexes. Although the three measures of inflation are generally similar, some differences nevertheless emerge. The annual rate of growth of the HICP is systematically lower than the rate of growth of the consumption deflator over the period 19861998 (with an average difference of about 0.5 percentage points). The reason lies in the different weighting of consumption categories in the two indexes and in the exclusion in the HICP of some categories (especially related to housing expenditures) which have tended to grow faster than the average during this period. The rate of growth of the GDP deflator is normally quite close to that of the consumption deflator with the exception of the 1986-87 and the more recent 1999-2000 periods where the two series diverge substantially, mainly as a result of the oil price shocks which occurred (with opposite sign) in the two periods.

9 In this respect, see the studies by Marcellino et al. (2000) and by Angelini et al. (2001) who employ a "bottom-up" approach by using a country level data set.

10 The construction of a "real time" data set for the euro area would represent a major undertaking as it would entail the acquisition of statistics by time of releases for a large number of countries. 


\subsection{Money-based indicators}

The monetary and credit aggregates considered are the stocks of M1, M2, M3 and loans to the private sector, for which data is available since $1980 .^{11}$

A number of money-based indicators in the tradition of the P-Star approach, first pioneered by Hallman, Porter and Small (1991), have been considered. ${ }^{12}$ As mentioned in the Introduction, recent work for the euro area has found considerable empirical support for the P-Star model. ${ }^{13}$ Using the quantity equation, the P-Star indicator is defined as the long-run equilibrium price level that would result with the current money stock, provided that output was at its potential and velocity at its long-run equilibrium level:

$$
p_{t}^{*} \equiv m_{t}+v_{t}^{*}-y_{t}^{*}
$$

where all variable are in logarithms, $y_{t}^{*}$ denotes potential output, $m_{t}$ is the current money stock and $v_{t} \equiv p_{t}+y_{t}-m_{t}$ is velocity. In the P-Star model of inflation, it is assumed that the price level will return to its long run equilibrium $p_{t}^{*}$ and the inflation dynamics are given by:

$$
\pi_{t+1}=(1-\lambda) \pi_{t}+\lambda \Delta p_{t}^{*}-\alpha\left(p_{t}-p_{t}^{*}\right)+\xi_{t+1}
$$

where $\xi_{t+1}$ is an iid shock with zero mean. In the literature and in empirical applications, various modifications of equation (2) have been considered. ${ }^{14}$

The computation of $p_{t}^{*}$ requires to estimate the long-run velocity of circulation. To this purpose, the long-run relationship of a money demand equation (usually for M3 in applications for the euro area) is normally used. Denoting real money balances as $\hat{m}_{t} \equiv m_{t}-p_{t}$, typically money demand specifications imply a long-run equilibrium for real money balances given by:

$$
\hat{m}_{t}^{L R}=k_{y} y_{t}-k_{i} i_{t}
$$

where $i_{t}$ represents the opportunity cost of holding money. The P-Star indicator, $p_{t}^{*}$, is therefore simply defined as:

$p_{t}^{*} \equiv m_{t}-\hat{m}_{t}^{*}=m_{t}-\left(k_{y} y_{t}^{*}-k_{i} i_{t}^{*}\right)$

11 Quarter-on-quarter rates of change of these variables (or the change in the rate of change depending on the model specification, see below) as well as moving averages of various length of their rate of change, in order to smooth short-run volatile movements in these aggregates, were considered. In the next sections results are reported for the headline monetary aggregates rates of growth as well as for the 2-quarters moving average of the rate of growth of M3 (for which some difference in results emerged when smoothing the series; this variable is labelled M3mv in the tables reporting the results).

12 See also Svensson (1999) for a discussion and a survey of the P-Star model.

13 Gerlach and Svensson (2000), Trecoci and Vega (2000). The evidence for the United States is more mixed; see Christiano (1989). Orphanides and Porter (2000) show that the P-Star model can potentially provide significant information on future inflation developments in the US, once the change in the equilibrium level of velocity are properly accounted for.

14 For example, in the original application of Hallman, Porter and Small (1991) the restriction $\lambda=0$ is imposed to equation 2. 
where $\hat{m}_{t}^{*} \equiv m_{t}^{*}-p_{t}^{*}=k_{y} y_{t}^{*}-k_{i} i_{t}^{*}$ is the long run equilibrium real money balances with output and opportunity cost evaluated at their equilibrium values. The price gap $\left(p_{t}-p_{t}^{*}\right)$ entering in (2) is equivalent to the (negative of) the real money-gap which measures the deviation of real money balances from their long run equilibrium level, which is simply defined as: $:^{15}$

$$
\hat{m}_{t}-\hat{m}_{t}^{*} \equiv-\left(p_{t}-p_{t}^{*}\right)=\hat{m}_{t}-\left(k_{y} y^{*}-k_{i} i_{t}^{*}\right)
$$

In the forecasting exercise the predictive content for future inflation of both the P-star indicator (4) and of the real money-gap indicator (5) are evaluated.

Moreover, the concept of money overhang is also considered. This is defined as the difference between the current real money stock and the long run equilibrium real money stock evaluated at current output and opportunity cost:

$m_{t}^{o v} \equiv \hat{m}_{t}-\left(k_{y} y_{t}-k_{i} i_{t}\right)$

The key difference between this concept and the real money-gap is that while the real money-gap would tend to rise when output exceeds its potential the money overhang would not increase (possibly therefore not signalling an increase in future inflation due to demand pressures). ${ }^{16}$ In other words, the money overhang tends to reflect the additional information in money which is not included in its determinants (output and the opportunity cost), whereas the real money-gap goes in the direction of a summary statistic. $^{17}$

In order to construct the indicators described above two different money (M3) demand models have been considered in order to test the robustness of the results with respect to alternative money demand specifications. First, the Brand and Cassola (2000) (BC hereafter) specification, which implies a long-run equilibrium of the form:

$\hat{m}_{t}^{L R}=\beta_{0}+\beta_{1} y-\beta_{2} l_{t}$

where $1_{t}$ denotes the long-term nominal interest rate.

The second money demand specification is the one provided by Coenen and Vega (1999) (CV hereafter) which gives a long-run equilibrium of the form:

$\hat{m}_{t}^{L R}=\alpha_{0}+\alpha_{1} y_{t}-\alpha_{2}\left(l_{t}-s_{t}\right)-\alpha_{3} \pi_{t}$

15 This is the measure used by Gerlach and Svensson (2000) and Trecoci and Vega (2000).

16 It may be worth noting that the money overhang is the (cointegrating vector) term that would be included in VAR systems including money, output, prices and short and long-term interest rates. See Brand and Cassola (2000), among others.

17 For a detailed description of the use of all these concepts in the context of the monetary analysis undertaken at the ECB, see Masuch, Pill and Willeke (2001). 
where $\left(l_{t}-s_{t}\right)$ denotes the spread between the long-term and the short-term interest rates and $\pi_{\mathrm{t}}$ is the inflation rate. ${ }^{18}$

In constructing the real money gap and the P-Star indicator (defined by equations 4 and 5 above), interest rates were evaluated at the sample (1980 Q1 to 2000 Q3) average level, as a proxy for their equilibrium level, or alternatively, at their current level. The logic behind the latter alternative is that it could be useful to avoid that the real money gap or the P-star measures are affected by the temporary effects on the current money stock of variations in the opportunity cost of holding money. It could be argued in fact that movements in monetary aggregates that are only due to portfolio re-allocation by agents induced by changes in the opportunity costs of holding money do not have implications for future price developments. ${ }^{19}$ The methodology for evaluating potential output for the construction of the P-Star and the real money-gap indicators is explained in the next section below.

\subsection{Other indicators}

A number of other indicators among variables often considered as informative for, or commonly used to make forecasts of, future inflation were also considered. These can be grouped into 5 main categories of variables: a) interest rates (short-term, long-term and the spread); b) stock prices (the stock price index, the dividend yield and price-earnings ratio); c) real activity measures (output growth, measures of the output gap and the capacity utilisation rate); d) labour market indicators (employment growth and the unemployment rate); e) cost and price measures (unit labour costs and wages, import prices, commodity prices and the nominal effective exchange rate).

Potential output used for constructing the output gap measures and for the evaluation of the long run equilibrium money stock was computed using a standard Hodrick-Prescott (HP) filter applied to current output. The HP is a two-sided de-trending method which tends to produce a biased estimate of the underlying trend at the end of the sample. In order to partially overcome this problem, a second measure of potential output was also constructed by forecasting output eight quarters ahead at each step of the exercise and using the HP filter on the series of past output augmented with the forecast output values. ${ }^{20}$ Finally, the rate of change of real output was also considered as an alternative de-trending procedure. ${ }^{21}$

18 It should be noted that the $\mathrm{BC}$ money demand is estimated within a system of equations, while here essentially the $\mathrm{BC}$ longrun money demand solution is imposed in a single equation approach (this is necessary given that the recursive nature of the exercise coupled with the relative short sample available would not allow enough degrees of freedom for a system estimation). Abstracting from this, the main difference between the two money demand models is in the different proxy for the opportunity cost of holding money included in the long-run money demand equation. While the BC model only includes the long-term interest rate, $\mathrm{CV}$ model includes both the level of inflation and the spread between the long-term and the short-term interest rates.

19 The results in this paper provide some support to this idea (see below Section 3).

20 The 8 quarters ahead forecast of output was made using a simple ARIMA model of the rate of change of output with lags selected according to the Schwarz criterion and allowing for a number of lags from 1 to 4.

21 Given the drawbacks of the HP filter methodology, future work will need to evaluate the performance of alternative measures of the output gap, such as those derived from estimates of the production function. 


\section{Bivariate forecasts of inflation}

\subsection{The methodology}

The performance of potential leading indicators in predicting future inflation is evaluated with a simulated out-of-sample forecast exercise. As already mentioned, the methodology follows closely Stock and Watson (1998 and 1999).

Consider the forecasts of inflation in the euro area made using the following linear bivariate model, labelled "model 1":

$\pi_{t+h}^{h}=\phi+\gamma(L) \pi_{t}+\beta(L) x_{t}+\varepsilon_{t+h}$

where $\pi_{t}^{h}=(4 / h) \cdot \ln \left(P_{t} / P_{t-h}\right)$ is the $h$-period inflation in the price level $P_{t}$, annualised (data are quarterly); $\pi_{t}=4 \cdot \ln \left(P_{t} / P_{t-1}\right)$ is quarterly inflation at an annual rate; $x_{t}$ is the indicator variable whose forecasting performance is to be evaluated; $\gamma(L)$ and $\beta(L)$ are polynomials in the lag operator $L$ and $h$ denotes the forecast horizon. The exercise for the evaluation of the performance of the various indicators is conducted for different forecast horizons, with $h$ varying from 1 to 12 . It should be noted that, contrary to the standard approach taken to model dynamic systems, equation (9) does not require to forecast $x_{t}$ when performing the $h$-steps ahead forecast of $\pi_{t}^{h} \cdot{ }^{22}$

As mentioned above, the data set used in the exercise comprises quarterly data for the euro area which span the period from 1980 Q1 to 2000 Q2 (Q3 for HICP inflation). In the exercise, out-of-sample forecasts were made for the period from 1992 Q1 to the end of the sample period. This allows enough observations to be used for the estimation of the models when the first out-of-sample forecast is performed. At the same time the exercise produces a sufficient number of out-of-sample forecast (35 in the case of HICP and 34 in the case of other price measures) to make statistical inference about the forecasting performance of alternative indicators. The out-of-sample forecast exercise was also conducted for more recent subsamples (i.e. starting the out-of-sample forecasts in 1995 Q1 and in 1998 Q1) to check the robustness of the results over the most recent periods.

In the simulated out-of-sample exercise model 1 is estimated and an $h$-period ahead forecast of inflation is performed using only data prior to the forecasting period. To be more specific, consider the forecast of the one and a half year ahead inflation rate $(h=6)$ made in (at the end of) 1990 Q2. To compute the forecast

22 There are both pros and cons in using this approach instead of the standard recursive dynamic system. The relative advantage of (9) is that it minimises the effects of errors in model specification, as they are not propagated forward when performing the out-of-sample forecast. See Angelini et al. (2001) for a discussion. It should also be mentioned that the study by Gottschalk et al. (2000), cited in the Introduction, makes use of a standard dynamic bivariate model (including inflation and money) to perform the exercise on the forecasting performance of monetary aggregates. This implies that the errors produced by their bivariate models will reflect both the failure of forecasting inflation as well as the failure of forecasting the monetary aggregate. Given the limited information set used, the latter errors may be significant and could potentially account for much of the differences in results with respect to the present study. 
all models (using all possible indicators) were estimated and the orders of lag polynomials $\gamma(L)$ and $\beta(L)$ were selected using data through 1990 Q2, and a forecast for the (annualised) inflation rate from 1990 Q2 to 1992 Q1 was made (the first out-of-sample forecast in the exercise). Moving forward one quarter, all models were re-estimated and the number of lags selected using data through 1990 Q3, and a new forecast of inflation over the period 1990 Q3 to 1992 Q2 were performed, and so on until the end of the sample period. For each model including the indicator $x_{t}$ considered, this produces a single series of forecast errors based on simulated out-of-sample (or recursive) estimation and model selection. The mean square error (MSE) of the forecast over the period 1992 Q1 to 2000 Q2 is then used to compare the forecasting performance of the different indicators.

It is important to note that, consistently with the logic of the out-of-sample forecast exercise outlined above, the money demand equations, their long-run equilibrium, and therefore the money gap, money overhang, P-Star and the output gap measures were estimated recursively at each step of the exercise using only data prior to the forecasting period.

The orders of the lag polynomials $\gamma(L)$ and $\beta(L)$ in (9) are determined separately using the Schwarz information criterion at each date. In the exercise, the number of lags in $\gamma(L)$ and $\beta(L)$ are allowed to vary from 1 to 4 , i.e. at maximum 1 year of past information about the inflation rate and the indicator was allowed to be included in the model to make the forecast. ${ }^{23}$ This implies that at each step of the forecast exercise 16 different models were compared and a single model was chosen according to the Schwarz criterion.

It is also worth noting here that no attempt was made to distinguish indicators according to the timing of the release. That is, all indicators $x_{t}$ are assumed to be known with certainty at (the end of) time $t$ when the forecast for period $t+h$ is performed. Clearly this is a simplification which is likely to bias the results in favour of indicators (such as, for example, those based on real activity measures) which tend to be available with a substantial delay of time with respect to other indicators (such as money and financial indicators) which are available with little or no delay.

Finally, an alternative specification of the forecasting model 1 was also considered in the exercise. Model 1 above allows inflation and the indicator considered to be $\mathrm{I}(0)$ or, alternatively, inflation and the indicator to be I(1) processes and cointegrated, with the cointegrating vector being estimated by recursive least squares. However, there are substantial uncertainties on the time series properties of inflation (and of

23 A preliminary investigation showed that, when allowing for a larger number of lags, in some few cases the Schwarz criterion resulted in a selection of a number of lags larger than four. However, it was also observed that the overall forecasting performance of models including a relatively large number of lags was substantially worse than that of more parsimonious models, hinting to the possibility that some overfitting bias was emerging. 
the indicators) in the euro area over the period considered. ${ }^{24}$ In particular, model 1 specification would not represent a correct specification in the case when inflation is a I(1) process while the indicator variable is a $\mathrm{I}(0)$ process. In this latter case a correct specification requires to express the model in first differences of inflation. This amounts to imposing the restriction $\gamma(1)=1$ to model 1 . The resulting forecasting model therefore transforms into "model 2" specification:

$$
\pi_{t+h}^{h}-\pi_{t}=\phi+\mu(L) \Delta \pi_{t}+\beta(L) x_{t}+\varepsilon_{t+h}
$$

where the indicator $x_{t}$ is an $\mathrm{I}(0)$ process. When combined with the previous specification, the exercise therefore covers most of the possible combinations of alternative a priori beliefs about the time series properties of the variables involved. The results obtained in terms of forecasting performance of different model specifications, could therefore also shed some lights on the time series properties of the variables used.

\subsection{Results for the bivariate forecasts}

\subsubsection{Out-of-sample forecast performance of different indicators}

Tables 1.a, 1.b and 1.c report the results for the out-of-sample forecasts of the HICP, consumption deflator and GDP deflator, respectively, using the specification in model 1 described above.

Transformations (level, first difference etc.) of the variables included in the bivariate forecasting model are shown in the tables. Monetary and credit aggregates were considered to be of the same order of integration as consumer prices, and therefore introduced in the form of rate of growth in model 1 . The same applies for the P-Star indicator. Some variables, such as the real money gap and overhang measures, the output gap and the unemployment rate, were considered both in levels and in differences. Only results from the best-performing specifications are reported in the tables. Transformations of other variables follow common practice.

The exercise was performed for forecasts of inflation from 1 to 12 quarters ahead and the forecasting performance of the models based on the various indicators is evaluated for the period 1992Q1-2000Q3. In the tables 1.a-1.c, the forecasting performance of each alternative indicator is measured relatively to a simple univariate model. The first row of each table reports the root MSE (in percentage points) of the univariate model used as a benchmark. All other rows show the ratio of the forecast MSE of a bivariate model including the indicator considered (as well as lagged inflation), with respect to the forecast MSE produced by the benchmark univariate model. A number less than one therefore indicates that the model

24 Normally, unit root tests performed over the entire sample would tend to favour the hypothesis that inflation is a I(1) process (prices are I(2)). However, the power of these tests may be low given the short span of data and the results may be biased by the presence of a strong downward trend in the period. Moreover, the findings by Cassola (2001), who conducts the analysis within an approach that allows for regime-switching, would suggest that the inflation generating process in the euro area over the past twenty years could be characterised by a structural break which delimits two different "inflation regimes" (a "high mean" and a "low mean" regime). Within the two different regimes (and around the two different means) inflation could be described as a stationary variable. 
using the indicator performs better (i.e. produces a lower MSE of the forecast) than the univariate model in forecasting inflation over the period considered and at the indicated horizon. Standard errors for the ratio of the mean square forecast error are reported in parenthesis. ${ }^{25}$ Results are reported for models including P-Star and real money gap indicators constructed by evaluating the long-run equilibrium money demand at the current level of interest rates (or spread) since these measures performed better than the alternative measures based on equilibrium (sample period average) interest rates (or spread) ${ }^{26}$ In the case of the output gap only the results using the simple HP filter estimate (which does not use out-of-sample forecasts of future output) are reported as it resulted in a better forecast performance than the alternative measure.

The following results emerged from the bivariate exercise.

Starting with the short-run forecasts of inflation, the bivariate models of inflation based on a single indicator do not perform particularly well. For horizons up to one year ahead in only a few cases the introduction of a single indicator results in a significant improvement with respect to the simple univariate model of inflation in terms of mean square error of the forecast. Looking across the different measures of inflation only an unemployment-based Phillips curve and the P-Star indicator derived from the BC money (M3) demand framework produce systematically a relative MSE of the forecast below one (though the reduction in the MSE is minor and the hypothesis of a forecast MSE equal to that of the univariate model cannot generally be rejected on statistical ground). Among cost and price variables, models based on the unit labour cost and wages perform relatively well only for the forecast of the consumption deflator, while in the case of HICP the import deflator appears to have some limited predictive power. In a few cases, models based on the rate of change of stock prices outperform the univariate model.

As the forecast horizon is enlarged, however, many indicators, especially those based on monetary aggregates, gradually improve their relative performance and eventually outperform the forecast based on the simple univariate model. At forecasting horizons beyond one year and a half the improvement is substantial producing in some cases a forecast MSE which is almost a half of that produced by the simple univariate model.

For forecast horizons between one and two years the money gap and the P-star (both based on the BC demand for M3 specification) are normally the best performing indicators among all indicators considered and across all measures of inflation. In the case of the P-Star indicator the reduction in the MSE of the forecast reaches almost $40 \%$ at the two years horizons for all inflation measures. The performance of other

25 A heteroschedastic and autocorrelation consistent (HAC) estimate of the variance-covariance matrix (estimated using a Bartlett kernel with $h$ lags) of the forecast errors was utilised and the $\delta$-method was applied to compute the standard errors of the MSE ratio. West (1996) provides an asymptotic justification of this procedure when using recursively estimated models. See also the notes to Table 1.a.

26 This tends to support the view that changes in long-term interest rate mainly cause portfolio shifts which are unrelated to future price developments. 
monetary indicator such as M2, and even more, loans to the private sector is also remarkable, especially for the HICP and the consumption deflator cases.

On the contrary, the forecast performance of the model based on nominal M3 growth alone is not particularly satisfactory, especially for horizons around 1 and a half years, being close to that of the univariate model. The forecast errors are somewhat mitigated by the smoother 2-quarters moving average measure of M3 growth (denoted as M3mv in the tables). A closer inspection of the forecast errors reveals that this result depends mainly on the relatively large underprediction of inflation in 1996, which is due to the sharp decline in M3 growth over the previous two years. This is shown in Chart 2 where also the forecast error from the M3-based forecasting model is plotted. In the period 1994-1995, M3 was possibly downward distorted by some special factors and, more importantly, was strongly affected by a portfolio shift caused by a significant increase in the long term interest rates at the euro area level. ${ }^{27}$ The importance of this latter factor is confirmed by noting the very good performance at the one and a half year ahead of the real money-gap and the P-star measures obtained with the BC money demand model, where equilibrium real money balances were measured at the current level of the long-term interest rate (i.e. M3 is implicitly adjusted for portfolio shifts caused by changes in long-term interest rates). Chart 2 also plots the (rate of change of) the P-Star indicator from the $\mathrm{BC}$ money demand and the relative forecast error. The increase in the long-term interest rate depresses the real money equilibrium level (and therefore increases the gap between current developments and the long run equilibrium) helping in moderating the underestimation error of M3 in 1996.

Among real activity variables the output gap and the rate of change of real output are the best performing indicators for forecast horizons between one year and two years. The rate of change of employment also shows a good relative forecasting performance in the case of HICP inflation. Among price and cost measures, only unit labour cost and wage growth rates appear to contain predictive power for future inflation beyond that contained in current price developments (this result does not hold however for the GDP deflator).

At forecast horizons between two and three years the best models, in terms of MSE of forecast, are those based on nominal M3 growth, and its main counterpart credit, together with the M3-based real money-gap measures derived from the $\mathrm{BC}$ model of money demand. At forecasting horizons close to three years ahead these M3-based models result in a substantial reduction of the forecast MSE, in some cases up to or even exceeding $50 \%$ of that produced by the simple univariate model. The nominal M3 growth based model is the best performing model among the ones considered at the longest ( 3 years ahead) forecast horizon for all measures of inflation.

27 See ECB (1999). The exchange rate crisis in the European Monetary System, the substantial movements in interest rates and also special factors - such as major changes in the taxation of interest income in some countries - appear to have been the main factors which have distorted monetary developments during 1992-1995. 
In general, broader aggregates show better leading indicator properties with respect to future price developments, with the models based on M3 and loans outperforming the M2-based model, which in turn outperforms the M1-based model. The model based on the M3 money overhang measure performs very well for the HICP and the consumption deflator, but not for the GDP deflator.

At these longer horizons the relative performance of non-monetary aggregates varies somewhat across measures of inflation. The best performing models are probably the ones based on the output gap which performs relative well across all three measures of inflation. The simple unemployment-based Phillips curve performs very well for the consumption deflator (the reduction of the forecast MSE relative to the univariate model reaches $40 \%$ ), but is not particularly satisfactory for the other inflation measures. Models based on the rate of change of wages also perform well at forecast horizons between two and three years in the case of the HICP and the consumption deflator. Finally the model based on the long-term interest rate seems to have some predictive power for long-term inflation forecasts in the case of the GDP deflator.

To summarise the above results, bivariate models based on monetary aggregates appear to score relatively well in forecasting inflation especially at the medium-term horizon. Among monetary aggregates, M3based P-Star and real money gap measures appear to be the particularly useful to forecast inflation at horizons up to two years ahead, while M3 growth itself and its main counterpart, loans, are the best indicators for the longest horizons. These results are consistent across the different price measures utilised. Among real activity variables the output gap and the unemployment rate are the best performing indicators even though their relative performance changes somewhat with the measure of inflation considered. The same is true for models based on wages and unit labour costs. Very little evidence is found of a predictive content of interest rates (especially the long-term interest rate and the spread are commonly considered to be leading indicators of future inflation $)^{28}$ and stock prices.

Finally, it is worth noting that there are some differences in the predictability of the alternative measures of inflation. In particular, the percentage root MSE of the forecasts produced by the models for the GDP deflator is normally larger than that of the univariate model for the private consumption deflator, which is in turn slightly larger than in the HICP case.

\subsubsection{Encompassing tests of predictive ability}

Forecast encompassing tests are an important complement to the analysis of the relative predictive content of non-nested models based on different indicators conducted above. ${ }^{29}$ In our set up, such tests can be used to evaluate whether a candidate variable gives a useful contribution in forecasting inflation, relative

28 These findings are consistent with recent results by Berk and Bergeijk (2000).

29 See Ericsson (1992) for a discussion of a number of measures of forecast performance, including encompassing, parameter constancy and mean square forecast errors. 
to a variable chosen as a benchmark. A simple forecast encompassing test can be carried using the forecast combining regression:

$\pi_{t+h}^{h}=\lambda f_{t}^{x}+(1-\lambda) f_{t}^{b}+\varepsilon_{t+h}$

where $f_{t}^{x}$ is the forecast of $\pi_{t+h}^{h}$ made at time $t$ and based on the variable $x$ (and past inflation), $f_{t}^{b}$ is the corresponding forecast based on the benchmark indicator (and past inflation), and $\varepsilon_{t+h}$ is the forecast error. In equation (11) $\lambda=0$ implies that the forecasts based on $x$ do not add any useful information to the forecasts based on the benchmark indicator, while if $\lambda=1$ the reverse would be true. A value of $\lambda$ close to 0.5 would indicate that the best forecast would tend to attribute approximately the same weight to the forecasts made using the two indicators.

Tables 2.a and 2.b report the coefficient $\lambda$ of equation (11) and its standard error when the forecast produced by the bivariate model including the rate of growth of M3 (2-quarters moving average) is chosen as the benchmark. (To save space results are shown only for the HICP and consumption deflator forecasts; the results for the GDP deflator forecasts do not change the qualitative conclusions).

The results of the forecast encompassing tests confirm the previous analysis.

Among money-based indicators, some of the best-performing indicators (loans, the real money-gap and the P-Star indicators from BC money demand) appear to contain useful additional information with respect to M3 for forecasting horizons up to two years ahead. For forecasts based on models including loans or the P-Star indicator the value of $\lambda$ remains close to 0.5 also beyond the two years horizons. Nonmonetary indicators based on real activity or price and costs measures appear to provide useful additional information relative to $\mathrm{M} 3$ to forecast inflation at shorter-term horizons (up to 1 and a half year). ${ }^{30}$ While some non-monetary indicators (especially among real activity variables, and, in the case of the HICP, unit labour costs and wages) maintain some additional predictive content relative to M3 even at long horizon, the weight assigned to the M3-based forecasts at horizons beyond the two years is generally significantly smaller than $50 \%$ and often not statistically different from zero.

\subsubsection{Results for different sample periods}

It is also important in this analysis to evaluate how the forecasting properties of the different indicators change across different sub-samples. Given the limited availability of aggregate back data for the euro area, only results obtained for more recent sub-samples are reported. Table 3 shows the results obtained when the simulated out-of-sample exercise was performed over the periods 1995-2000 Q3 and 1998-2000 Q3. Clearly these sub-samples are too short to permit a sound statistical inference (standard errors for relative MSE are not reported in this case). Nevertheless it is worth checking whether the previous results

30 However, it should be noted that also the weight assigned to the univariate model is larger than zero at short horizons, suggesting that the benchmark M3-based model relies too heavily on M3. 
hold also when considering the more recent periods. In particular, the most recent sub-sample is of particular interest because it covers the completion of the process of convergence to Stage III of the Monetary Union, the start of the single monetary policy in the euro area and include the upturn of inflation since early 1999 , the strongest upturn since the early 90 's in the euro area.

The following indications emerge from Table 3. Firstly, the best money-based indicators continue to perform very well, especially at longer horizons, also over the more recent sub-samples. In general the relative forecast performance of the models based on these indicators is maintained. M3 and M3-based money gap and P-Star measures perform extremely well and are unambiguously the best performing indicators among monetary indicators. Secondly, among non-monetary variables, it is worth noting the progressive improvement of the relative forecast performance of the simple "Phillips curve" specification of inflation based on the level of the unemployment rate for all forecast horizons, a result also found by Angelini et al. (2001). ${ }^{31}$ When evaluated over the 1995-2000 period, the simple Phillips curve's performance is very close to the best money-based models. Over the most recent 1998-2000 period this model produces the smallest forecast errors of all models. Finally, over the most recent period, many leading indicator models outperform the univariate model also at the short-run horizon. The latter in fact simply tends to prolong the downward trend in inflation over the past twenty years and, therefore, to severely underpredict the inflation upturn since early 1999. The models based on import prices, on the effective exchange rate and on commodity prices perform very well at short horizons.

\subsubsection{Results using an alternative model specification}

Table 4 reports the results obtained using model 2 specification (equation 10 above). The table shows the forecast MSE relative to the forecast MSE of the univariate model of inflation under specification of model 1 (whose root MSE of the forecast is shown in Table 1) so that the two sets of results are directly comparable. The transformations adopted for the different indicators under the model 2 specification are also shown in the table. Results are shown only for the HICP case since the basic conclusions do not change when considering the other measures of inflation.

It appears clearly from the results in Table 4 that the model 2 specification of inflation performs worse than model 1 specification in most cases. The percentage root MSE of the univariate model is always larger than in the case of model 1 specification at all horizons, with the only exception of the one-quarterahead horizon. Moreover, most indicators fail to perform better than the simple univariate process under

31 Angelini et al. (2001) find, using country level data, that the unemployment rate is often one of the best performing indicator for two-years ahead forecasts for out-of-sample forecast exercises starting at different dates. They also find a general deterioration of forecasting performance of various indicators when the exercise is started in 1992. M3 is found to be a good indicator for HICP inflation for all recursive-starting dates, while its performance for the forecast of the consumption or the GDP deflators is reasonable but less striking. When comparing their results to those presented here two considerations have to be kept in mind. First, as already stressed, the relative performance of (headline) M3 is found to improve markedly only beyond the two years horizon (at this horizon other money-based indicators, such as the rate of change in the P-Star and the real money gap perform better). Secondly, the relatively better performance of models based on money in the present study may be a reflection of the result that money demand relationship may be more stable when aggregated across countries with financially integrated markets that at the individual country level, a result first pioneered by McKinnon (1982). 
model 2 specification, with a few exceptions for the forecast horizons up to two years ahead. In general, the forecasting performance of the models based on different indicators is very similar under model 2 specification (no statistical difference in forecast performance can be detected) and no clear patterns are discernible for the different indicators. Most importantly, with the exception of the forecasts for the one quarter ahead horizon, no indicator model performs better (and in fact they usually perform quite worse) than the best leading indicator models under model 1 specification.

In summary, the evidence suggests that imposing the restriction implied by model 2 specification (i.e. imposing a unit root to inflation when the indicator is believed to be an $\mathrm{I}(0)$ process) does not help in forecasting inflation in the euro area over the period under consideration. ${ }^{32}$ The results may be taken as suggestive of the possibility, put forward by Cassola (2001), that the inflation process in the euro area entered a new regime around the mid 90 s and, taking into account this regime shift, is better described as a stationary, mean reverting process.

\section{Multivariate forecasts of inflation}

\subsection{The methodology}

The analysis conducted so far has shown that many of the variables considered provide useful information for predicting inflation. This section addresses the issue of whether it is possible to combine the information contained in different indicators to improve the accuracy of the forecasts of future inflation. Clearly, since the number of indicators is quite large, including more than a few of them in unrestricted regressions would likely result in overfitting bias and poor forecast performance. Following again Stock and Watson (1999), two alternative methods to construct multivariate forecasts are considered. The first method relies on forecast combination techniques, which implies treating the bivariate forecasts of the previous section as data and combine them using various forecast combination procedures. The second procedure consists in constructing composite indexes from a large group of indicators, following the tradition of dynamic factor analysis, and then using these indexes to construct multivariate forecasting models. $^{33}$

Denoting by $f_{i, t}$ the (bivariate) forecast produced at time $t$ by the model based on the indicator $i(i=1, \ldots$, n) considered in the previous Section, the combined forecasts are simply constructed as:

32 Stock and Watson (1999) find that for the US the results depend on the sample period on which the forecasts are performed. In particular, imposing the unit root restriction leads to more accurate predictions of inflation (using the best forecasting model) over the period 1970-1983 and to less accurate predictions over the period 1984-1996. In our case, the sample period is too short to conduct sound statistical experiments. However, it should be mentioned that when evaluating the forecasting performance over the most recent sub-sample 1998-2000 Q3 (results are not shown) the univariate model 2 specification performs better than the univariate model 1 for forecasting horizons beyond two years (with a forecast MSE which is close to the best performing models under specification 1). Again the relative forecasting performances of models based on different indicators is very similar to each other and no clear pattern can be identified.

33 See Stock and Watson (1998 and 1999) and Forni and Reichlin (1998), among others, for recent contributions. 


$$
f_{c, t}=\sum_{i=1}^{n} \omega_{i t} f_{i, t}
$$

As in Stock and Watson (1999) the weights $\omega_{i t}$ were chosen using three alternative methods: as the mean of all forecasts made at time $t$ (and therefore equal $1 / n$ ), as the median of the forecasts made at time $t$ and, finally, obtained from the regression:

$\pi_{s+h}^{h}=\sum_{i=1}^{n} \omega_{i t} f_{i, s}+\varepsilon_{s+h}, \quad s=1, \ldots \ldots, t$

Because $n$ is large equation (12) was estimated using a ridge regression opportunely modified so that the weights shrink towards equal weighting as:

$\hat{\omega}_{t, \text { Ridge }}=\left(c I_{n}+\sum_{s=1}^{t} F_{s} F_{s}^{\prime}\right)^{-1}\left(\sum_{s=1}^{t} F_{s} \pi_{s+h}^{h}+c / n\right)$

where $F_{s}=\left(f_{1, s} \ldots . . f_{n, s}\right)$ and $c=k \times T R\left(n^{-1} \sum_{s=1}^{t} F_{s} F_{s}^{\prime}\right) .{ }^{34}$

Consistently with the recursive design of the exercise outlined in the previous section, the forecasts $f_{i, t}$ are computed only using data up to time $t$ and the ridge regression estimates of the weights are computed only using forecasts and inflation data available on dates $t$ and earlier.

The second approach makes use of estimated factors constructed from the set of variables available to the forecaster at each time $t$ when the forecast is performed. Denoting with the $(T \times N)$ matrix $X$ such a set of variables, then the factors are estimated as the principal component of $X$ as $P=X \Lambda / N$ where $\Lambda$ consists of $\mathrm{N}^{1 / 2}$ times the eigenvectors of $X X{ }^{35}$ Denoting by $P_{s}^{t}, s=1, \ldots, t$, the vector of factor time series extracted at time $t$, the forecasts of inflation are constructed as:

$\pi_{t+h}^{h}=\phi+\gamma(L) \pi_{t}+\beta(L)^{\prime} P_{s}^{t}+\varepsilon_{t+h}$

At each date $\mathrm{t}$ factors are computed using only data up to time $t$ and, as done in the previous Section, the number of lags in the polynomials $\gamma(L)$ and $\beta(L)$ are selected using the Schwarz information criterion allowing for a number of lags ranging from 1 to 4 . Two dynamic factor models were estimated. The first factor model includes only one factor. A second model allows up to three factors to enter in (15) recursively choosing the number of factors (and the number of lags in $\beta(L)$ for each factor) using the Schwarz criterion.

34 See Stock and Watson (1999). The parameter $k$ governs the amount of shrinkage $(k=0$ corresponds to OLS estimates of equation (13), while weights converge to the sample mean as $k$ grows large). In the exercise various values of $\mathrm{k}$ were used ranging from 0.25 to 20 . To save space only results for $\mathrm{k}=10$ are reported as they were generally the most accurate.

35 Stock and Watson (1998) provide an asymptotic justification for this approach when the time series dimension $T$ and the cross-section dimension $N$ both go to infinity. The approach is useful when the number of predictors is large (i.e. all of the variables considered in the previous section. In what follows, also smaller groups of variables are considered in which case the rationale for this approach is simply that it provides a procedure for summarising the data. 


\subsection{Results for the multivariate forecasts}

Tables 5.a and 5.b report the results for the multivariate forecasts of the HICP and the consumption deflator, respectively. ${ }^{36}$ The tables report the ratio between the forecast MSEs of the multivariate forecasts and the univariate model already used as a benchmark in the bivariate analysis (the forecast root MSE for this model is reported also in tables 5.a and 5.b), so that the results are comparable with those obtained in section 3. Multivariate forecasts following the methods described above were computed for five groups of variables: a) all variables considered in section 4 (i.e. all variables appearing on tables 1.a-1.c) with the exclusion of the P-Star and the money gap/overhang measures; b) monetary and credit aggregates; c) real activity variables; d) wage and (domestic and international) price variables; e) interest rates and stock prices. $^{37}$

The following conclusions emerge from tables 5.a and 5.b. Considering the pooling of all variables in the data set and forecasts horizons up two years ahead, the results are quite satisfactory for the forecast combination methods (mean, median and ridge regression combination of the bivariate forecasts) while they are less satisfactory for the single factor and the multi-factors models. The forecast combination methods produce forecasts which are often close to, and in some cases even more accurate than, those of the best bivariate models for horizons within the two years. Between one and two years ahead the forecast obtained with the ridge regression combination are normally better than the mean and the median, while the reverse is true for longer horizons. ${ }^{38}$ Considering forecast horizons beyond two years, the results are quite different for the HICP and the consumption deflator. While for the HICP little or no improvement in forecast accuracy with respect to the univariate model can be detected, for the consumption deflator the performance of the single and multi-factor models is quite satisfactory. This probably reflects the better performance of models based on real activity variables in forecasting future developments in the consumption deflator than in the HICP, already detected in the bivariate analysis.

The results of the multivariate forecasts for the group comprising only monetary (and credit) aggregates are generally very satisfactory for both measures of inflation. ${ }^{39}$ In general, this is true, with only minor differences, for all multivariate methods utilised. Relative to the best money-based bivariate models considered in the previous section, the improvement consists mainly in a reduction of the forecast MSE at

36 Results for the GDP deflator are not reported to save space. The main differences in results are mentioned in the text below.

37 Results including the P-Star and money gap/overhang measures are similar to those presented here and are not reported.

38 This is generally true also for forecasts using other sub-groups of variables. It should be noticed that by decreasing the value of $k$, the parameter governing the shrinking towards equal weighting in the ridge regression, it is possible to improve somewhat the performance of the ridge regression combined models at longer horizons. However, the improvement is relatively minor and occurs at the expenses of the forecast performance at shorter horizons.

39 This group is very small (only four variables are included). The forecast combinations and the factor models should be mainly seen in this context as different methods to attribute different weights to the various components of the balance sheets of the financial intermediary sector. 
short-term horizons. However, the money-based multivariate forecasts perform close to the best performing money-based bivariate models at all forecast horizons. It is also worth noting that the multifactor model perform extremely well at the longest forecast horizons for both the HICP and the consumption deflator (in the latter case being the best of all models considered). As it was the case for the bivariate analysis the money-based multivariate models are the best performing at long horizons among all multivariate models considered.

Looking at the group containing real activity variables, the improvement in the forecast performance from the multivariate analysis (with respect to both the simple univariate model and the best performing bivariate models) is significant and can be seen mainly at horizons comprised between one and two years ahead. The advantages of aggregating information of different indicators are larger than it was the case for monetary aggregates. As was the case for the bivariate models, real activity-based models perform well at longer horizon (beyond two years) only in the case of the consumption deflator. For real activity variables, the forecast combination methods appear to work better than the models based on the estimated factors.

Considering wages and price measures (including international prices and the effective exchange rate), there is a marked improvement over the bivariate models especially at short-term horizons (within one year). This is especially true in the case of the multiple factor models. At horizons between one and two years some of the multivariate models - especially the Ridge-regression combination of forecasts perform satisfactorily (close to best-performing bivariate counterparts). At longer horizon no wage and price-based multivariate model performs well. ${ }^{40}$

Finally, the results from combining the information from interest rates and stock markets are not very satisfactory, similarly to what found in the case of models based on individual indicators. The only exception to this general picture is given by the model based on a single estimated factor in the case of the consumption deflator, which shows a good relative forecasting performance for long horizons.

In summary, the multivariate analysis conducted in this section broadly confirms the previous findings. Monetary and credit aggregates appear to have a significant predictive content for future price development. The performance of multivariate forecasts based on monetary indicators also tends to increase with the length of the horizon. Multivariate forecasts combining the information from all available indicators do not appear to improve significantly over the best forecasts based on simple bivariate models. However, the results would suggest that there are advantages, relatively to simple bivariate forecasts, in combining the information contained in different indicators within given categories

40 A relatively poor performance of wage and cost indicators is also found by Stock and Watson (1999) in the US case (although their analysis is limited to the one year ahead forecast horizon). However, the results have to be taken with caution. As recalled in the introduction, the whole exercise is conditional to the monetary authorities' reaction functions. The central banks of the euro area countries may have reacted systematically to risks stemming from cost-push factors over the period under consideration thereby reducing their ex-post information content especially over longer horizons (when the effects of the monetary policy reactions unfold). Moreover, real-time forecasters normally make use of much more information, such as that included in wage-bargaining agreements, than the one used in this exercise. 
of variables (say money or real activity variables). These advantages are particular evident for the forecast horizons within two years ahead. However, there is not a single method of combining this information which outperforms the others and different methods of multivariate forecasts appear to give relative advantages depending on the variables used and the prediction horizon considered. ${ }^{41}$

\section{Inflation predictability across forecast horizons}

To conclude the empirical investigation, it is interesting to ask what the results obtained tell about the predictability. Obviously, the predictability of inflation varies with the prediction horizon and the information set considered. Some statistical measures of predictability that have been proposed in the literature can be used to evaluate what information is best used for different prediction horizons. Two different measures of predictability were considered.

A first, commonly used measure of predictability is the one proposed by Granger and Newbold (1986), which represents a natural extension of the familiar $\mathrm{R}^{2}$ of linear regression:

$$
G N=1-\frac{\operatorname{var}\left(\varepsilon_{t+h}^{x}\right)}{\operatorname{var}\left(\pi_{t+h}\right)}
$$

where $\varepsilon_{t+h}^{x}$ is the $h$-steps ahead forecast error produced using the (bivariate or multivariate) optimal forecasts (i.e., conditional mean) on the basis of model using information $x$. Therefore, $G N$ measures predictability relatively to the long-run variability of a variable (inflation in the case at hand), i.e. it shows what fraction of the variance of inflation is "explained" by the model at the given prediction horizon $h$.

An alternative measure of inflation predictability, which is similar in spirit to the one just described, is the statistic proposed by Diebold and Kilian (1999). This measures predictability as (one minus) the ratio of the expected loss of a short-run forecast to the expected loss of a long-run forecast. Assuming a quadratic expected loss function, this is given by:

$D K=1-\frac{\operatorname{var}\left(\varepsilon_{t+h}^{x}\right)}{\operatorname{var}\left(\varepsilon_{t+k}^{b}\right)}$

41 This seems also to be a feature of the results by Angelini et al. (2001) using diffusion indexes constructed from data panels of euro area countries. In particular, they find that HICP and the consumption deflator are best forecast using only nominal factors (constructed using only nominal variables) while the GDP deflator is best predicted using non-nominal factors. On the contrary, Stock and Watson (1999) find that the model based on a single factor, based on a large number of indicators of real economic activity, is the best-performing model among all models considered for forecasting inflation in the US at the one year ahead horizon. This is the only model in their investigation that outperforms systematically a simple Phillips curve specification. At the one year forecast horizon, models that add monetary aggregates to the Phillips curve are found to lead to some marginal improvements for some sample periods and some inflation measures, but to a serious deterioration in accuracy for forecasts of others sample periods or inflation measures. 
where $\varepsilon_{t+k}^{b}$ is the forecast error for a long-run benchmark forecast, with $k>h$. Therefore, $D K$ shows how predictable is a series at horizon $h$ relative to horizon $k .{ }^{42}$ In what follows the benchmark long-run forecast $(k=12)$ of the univariate model was chosen as a benchmark to compute $D K$.

Chart 3.a shows the $G N$ and $D K$ measures of predictability for some selected inflation (HICP) forecasts based on bivariate models considered in the previous sections. It should be recalled that what is measured is predictability of average inflation over the period form $t$ to $t+h$. The chart shows that the explained variance from the forecasting models based on the best indicators is substantial and generally reaches a peak at around the two years horizons, when in some cases it is larger than $60 \%$. It then deteriorates thereafter, in some cases very sharply at the three years horizon. ${ }^{43}$ At this longest horizon, however, the proportion of the variance of inflation explained by the M3 and the loans-based models is still substantial, around $40 \%$. Measures of $D K$ show how the reduction in predictability of inflation when the forecast horizon is enlarged is much slower when predictions are made with an information set which includes money-based measures.

Charts 3.b and 3.c show, respectively, the $G N$ and $D K$ measures for combinations of forecasts produced using selected bivariate models (mean and Ridge-regression techniques) and for the forecasts produced using dynamic factor indexes (single and multi-factor techniques). The pattern already observed for the bivariate forecasts does not change substantially when considering multivariate information sets. Predictability of average future inflation is still highest at around the two-year-ahead horizon and diminishes quite sharply thereafter (again a very drastic deterioration can be noticed at the three years horizon). It is noteworthy, however, that predictability remains very high even beyond the two years horizon when the forecasts are based on a single factor and, especially, on multiple factors extracted from monetary and credit aggregates.

\section{Conclusions}

Three main conclusions emerge from this study.

First, the results support the idea that there is substantial information in monetary and credit aggregates for future price developments in the euro area. The comparative advantages, in terms of forecasting performance, of models which include money-based indicators relative to other, non-monetary models tend to increase for longer forecast horizons. This conclusion emerges when evaluating forecasts of inflation using both bivariate and multivariate information sets. The evidence is consistent with the view

42 The Diebold and Kilian measure of predictability is more general than the Granger-Newbold measure as it can be used for measuring predictability of series which are not covariance stationary and can be applied to multivariate information set. The Granger-Newbold measure emerges as a special case of the Diebold-Kilian measure, i.e. when the series is covariance stationary, the loss function is quadratic, the information set is univariate and $k=\infty$.

43 Besides reflecting the decline in the predictability of inflation at around the three years horizon an additional problem may come from the fact that we are dealing with a small sample. In particular, the sample period over which the models are estimated when starting the out-of-sample forecasting exercise becomes very short when the forecast horizon is long, which might affect the stability of parameters. 
inflation using both bivariate and multivariate information sets. The evidence is consistent with the view that money contains information which is useful to anticipate medium-term and low frequency trends in inflation.

Second, indicators derived within the framework of the P-Star model of inflation, such as the real money gap or the real money overhang (all based on M3), appear to perform well in forecasting inflation and to represent useful complements to headline monetary aggregates especially for forecast horizons within the two years. For example, it proves useful to clean the signal contained in monetary aggregates (M3) from the distortions caused by the short run portfolio re-allocation due to movements in long-term interest rates, especially for forecast horizons around one and a half years. The results appear consistent with previous findings by Trecoci and Vega (2000) and Gerlach and Svensson (2000). However, the claim by the latter authors that the real money gap (as opposed to nominal money growth) should be the focus of monetary policy in the euro area, is not supported by the results in this paper. Models based on (the rate of growth of) the headline monetary and credit aggregates normally perform better than those based on the real money gap for forecast horizons beyond two years. Moreover, a nominal concept, the rate of change of the P-Star indicator which measures the deviation of nominal money growth from equilibrium real money balances (and could therefore be interpreted as a measure of equilibrium inflation), appears to outperform the real money gap also at shorter horizon. Finally, the performance of money gap/overhang indicators appears to be somewhat sensitive to the specific money demand framework from which they are derived.

Third, the evidence presented appears also to suggest that there is additional, independent information in money, beyond the information contained in its determinants (such as output and prices) in money demand relationships. One possibility is that monetary aggregates are measured more accurately than output. A second possibility is that money is a leading indicator of the cycle and that prices are positively correlated (with some lags) with output. ${ }^{44}$ Moreover, money may reflect also other determinants (such as the level of wealth) not considered in the analysis. Finally, the findings might be suggestive of an independent, active role of money in the transmission mechanism. Clearly, the approach adopted cannot discriminate among these possibilities and further investigation is needed on this issue. ${ }^{45}$

Some caveats to the above results are also in order. First, as mentioned in the Introduction, the findings are conditional to the specific monetary policies followed by monetary authorities in the euro area. To the extent that the shift to the single monetary policy in the euro area represents a departure from the (average of) monetary policies in the euro area over the recent past, the performance of some of the models considered in the study may be affected. More generally, while the recursive structure of the exercise provides some safety net against, and helps detecting, model instability, it cannot be excluded that the

44 Some evidence of such relationships is found for the US by King and Watson (1996).

45 This is the sense in which the approach used in this study can stimulate further analysis. For example, general-equilibrium, sticky price models of the transmission mechanism are difficult to reconcile with the finding of an independent information content in money. See Svensson and Woodford (2000) and Dotsey and Hornstein (2000). 
regime shift associated with start of the single currency area can have an impact on the performance of some of the indicator-based models. ${ }^{46}$ Second, only linear models have been considered. Future work should also consider the possibility that the relationship between inflation and some of the variables considered is non-linear. Finally, the exercise was performed on a data set comprising only finally revised series. Clearly, the relative performance of the various indicators, if a "real time" data set was used, may change in a way which is difficult to predict on a priori basis. ${ }^{47}$

46 For example, some model instability was detected in Section 3 for the simple "Phillips-curve" forecast model based on the unemployment rate which was found to perform not very satisfactorily over the 1992 to 2000 sample period, but to perform extremely well over the more recent periods.

47 For example, real activity variables are normally more affected by frequent revisions, while monetary aggregates are the subject of infrequent, but perhaps larger, changes in classifications and definitions. 


\section{Appendix: Data Description}

The HICP index for the euro area was computed aggregating individual countries not seasonally adjusted indexes using consumption expenditure weights at irrevocable fixed conversion rates of 31 December 1998. Eurostat backward estimates of national HICP indexes have been used as far as available. They were then extended backward up to January 1980 using growth rates in CPI (national definition). The procedure for constructing the euro area HICP index follows the method used by Eurostat. The reconstructed index has been then seasonally adjusted using the methodology described in the Technical Notes contained in the "Euro area Statistics" section of the ECB Monthly Bulletin, April 2001 issue. Quarterly data are averages of monthly data.

M1, M2, M3 and loans to the private sector data used are "adjusted stocks". The adjusted stocks are calculated using the data on seasonally adjusted month-end stocks and flows from the ECB database (release data end-September 1999). For the period January 1980 to September 1997 the adjusted stock series consist of month-end stocks. From October 1997 onwards, where flow data are available, the adjusted stocks are calculated via compounded month-on-month growth rates (calculated from the flows). The percentage change between any two dates (after October 1997) corresponds to the change in the stock excluding the effect of reclassifications, other revaluations, exchange rate variations etc.. ${ }^{48}$ The quarterly data are compiled as averages of the monthly data.

The euro area interest rates used are weighted averages of national interest rates calculated with fixed weights based on 1995 (1999 if you used data after the Sept. 2000 release) GDP at PPP rates. National short-term rates are three-month market rates. For short-term interest rates from January 1999 onwards, the three-month Euribor is used. Long-term interest rates correspond to ten-year government bond yields, or the closest available maturity. The total stock market index, the dividend yield and price-earnings ratio are from DATASTREAM.

Regarding the money demand model, log-level indices for real GDP ('stocks' at market prices, taken 1995 as the base year) and the GDP deflator are used. The log-level indices of the euro area real GDP and GDP deflator are a weighted sum of the logarithms of the national seasonally adjusted series using fixed weights based on 1999 GDP at PPP exchange rates. The national GDP series are to the widest extend possible based on ESA 95 data and are adjusted for German unification. Observations for 1999 Q1 onwards are constructed via the quarter-on-quarter growth rates calculated using the ESA 95 data for the euro-11 area published by Eurostat.

The rest of the variables used in the exercise (the private consumption deflator, the unemployment rate, employment, unit labour costs and wages, import prices and the effective exchange rate) are taken from the Area Wide Model estimation database (see Fagan, Henry and Mestre (2000)).

48 The method corresponds to the one used to calculate the index shown in the "Euro area Statistics" section of the ECB Monthly Bulletin. 


\section{References}

Angelini, E., J. Henry and R. Mestre (2001), "Diffusion Index-Based Inflation Forecasts for the Euro Area," ECB Working Paper n. 61.

Berk, J.M. and P. Van Bergeijk (2000), "Is the Yield Curve a Useful Information Variable for the Eurosystem?," ECB Working Paper n.11.

Brand, C. and N. Cassola (2000), “A Money Demand System for the Euro Area M3," ECB Working Paper n. 39.

Browne, F.X., G. Fagan and J. Henry (1997), "Money Demand in EU Countries: A Survey," Staff Paper n. 7, European Monetary Institute, Frankfurt am Main.

Cassola, N. (2001), "Inflation and M3 Growth in the Euro Area As Regime-Switching Processes," ECB, mimeo.

Christiano, L.C. (1989), “P* Is Not the Inflation Forecaster's Holy Grail,” Federal Reserve Bank of Minneapolis Quarterly Review 13, pp. 3-18.

Coenen, G. and J.L. Vega (1999), “The Demand for M3 in the Euro Area,” ECB Working Paper Series n. 6.

Diebold, F.X. and L. Kilian (1999), "Measuring Predictability: Theory and Macroeconomic Applications," New York University, mimeo.

Dotsey, M. and A. Hornstein (2000), "Is the Behavior of Money Useful to a Discretionary PolicyMaker?," Federal Reserve Bank of Richmond, mimeo.

ECB (1999a), “The Stability-Oriented Monetary Policy Strategy of the Eurosystem," ECB Monthly Bulletin, January, pp. 39-50.

ECB (1999b), "Euro Area Monetary Aggregates and Their Role in the Eurosystem's Monetary Policy Strategy," ECB Monthly Bulletin, February, pp. 29-46.

ECB (2000), “The Two Pillars of the ECB's Monetary Policy Strategy,” ECB Monthly Bulletin, November, pp. 37-48.

Engert, W. and J. Selody (1998). "Uncertainty and Multiple Paradigms of the Transmission Mechanism". Bank of Canada Working Paper n. 98/7.

Ericsson, N.R. (1992), "Parameter Constancy, Mean Square Errors, and Measuring Forecast Performance: An Exposition, Extensions and Illustration,” Journal of Policy Modelling 14 (4), pp. 465-495. 
Estrella, A. and F.S. Mishkin (1997), "Is There a Role for Monetary Aggregates in the Conduct of Monetary Policy?," Journal of Monetary Economics 40, pp. 279-304.

Fagan, G. and J. Henry (1998), "Long Run Money Demand in the EU: Evidence for Area-Wide Aggregates," Empirical Economics 23, 483-506.

Fagan, G., Henry, J. and R. Mestre (1999), “An Area-Wide Model for the EU11,” ECB Working Paper n. 42.

Forni, M. and L. Reichlin (1998), "Let's Get Real: A Factor Analytical Approach to Disaggregated Business Cycle Dynamics,” Review of Economic Studies, 65 (3), pp. 453-473.

Friedman, B.M. and K.N. Kuttner (1992), "Money, Income, Prices and Interest Rates," American Economic Review 82 (3), pp. 472-492.

Gerlach, S. and L.E.O. Svensson (2000), "Money and Inflation in the Euro Area: A Case for Monetary Indicators?," NBER Working Paper n. 8025.

Gottschalk, J. F. Martinez Rico and W. Van Zandweghe (2000), "Money As an Indicator in the Euro Zone," Kiel Working Paper n. 984.

Granger, C.W.J. and P. Newbold (1986), "Forecasting Economic Time Series,” 2n ed., Academic Press: Orlando.

Hallman J., Porter R.D. and D.H. Small (1991), "Is the Price Level Tied to the M2 Monetary Aggregates in the Long Run?," American Economic Review 81, pp. 841-858.

Issing O., V. Gaspar, I. Angeloni and O. Tristani (2001), "Monetary Policy in the Euro Area: Strategy and Decision-Making at the European Central Bank," Cambridge University Press, Cambridge.

King, R.G. and M.W. Watson (1996), "Money, Prices, Interest Rates and the Business Cycle," Review of Economics and Statistics, pp. 35-53.

Klöckers, H.J. (2001), ed., “Seminar on Monetary Analysis: Tools and Applications,” ECB’s web-site.

Marcellino, M., J.H. Stock and M.W. Watson (2000), "Macroeconomic Forecasting in the Euro Area: Country Specific versus Area-Wide Information," mimeo.

Masuch K., Pill H.R. and C. Willeke (2001), "The Role of Monetary Analysis in the ECB's Monetary Policy," in Klöckers, H.J. (2001), ed., "Seminar on Monetary Analysis: Tools and Applications," ECB's web-site.

McKinnon, R.I. (1982), "Currency Substitution and Instability in the World Dollar Standard," American Economic Review 72, pp. 320-333.

Orphanides, A. and R.D. Porter (2000), "P* Revisited: Money-Based Inflation Forecasts with a Changing Equilibrium Velocity," Journal of Economics and Business 52, pp. 87-100.

Stock, J.H. and M.W. Watson (1998), “Diffusion Indexes,” NBER Working Paper n. 6702. 
Stock, J.H. and M.W. Watson (1999), "Forecasting Inflation," Journal of Monetary Economics 44, pp. 293-335.

Svensson, L.E.O. (1999), “Does the P* Model Provide Any Rationale for Monetary Targeting,” NBER Working Paper n. 7178.

Svensson, L.E.O. and M. Woodford (2000), “Indicator Variables for Optimal Policy,” NBER Working Paper n. 7953.

Trecoci C. and J.L. Vega (2000), "The Information Content of M3 for Future Inflation,” ECB Working Paper n. 33.

West, K.D. (1996), “Asymptotic Inference About Predictive Ability,” Econometrica 64, pp. 1067-1084.

Woodford, M. (1994), "Non-standard Indicators for Monetary Policy: Can Their Usefulness Be Judged From Forecasting Regressions?," in N. G. Mankiw ed., Monetary Policy, University of Chicago Press for NBER. 


\section{Figures and Tables}

Chart 1: Annual inflation rates

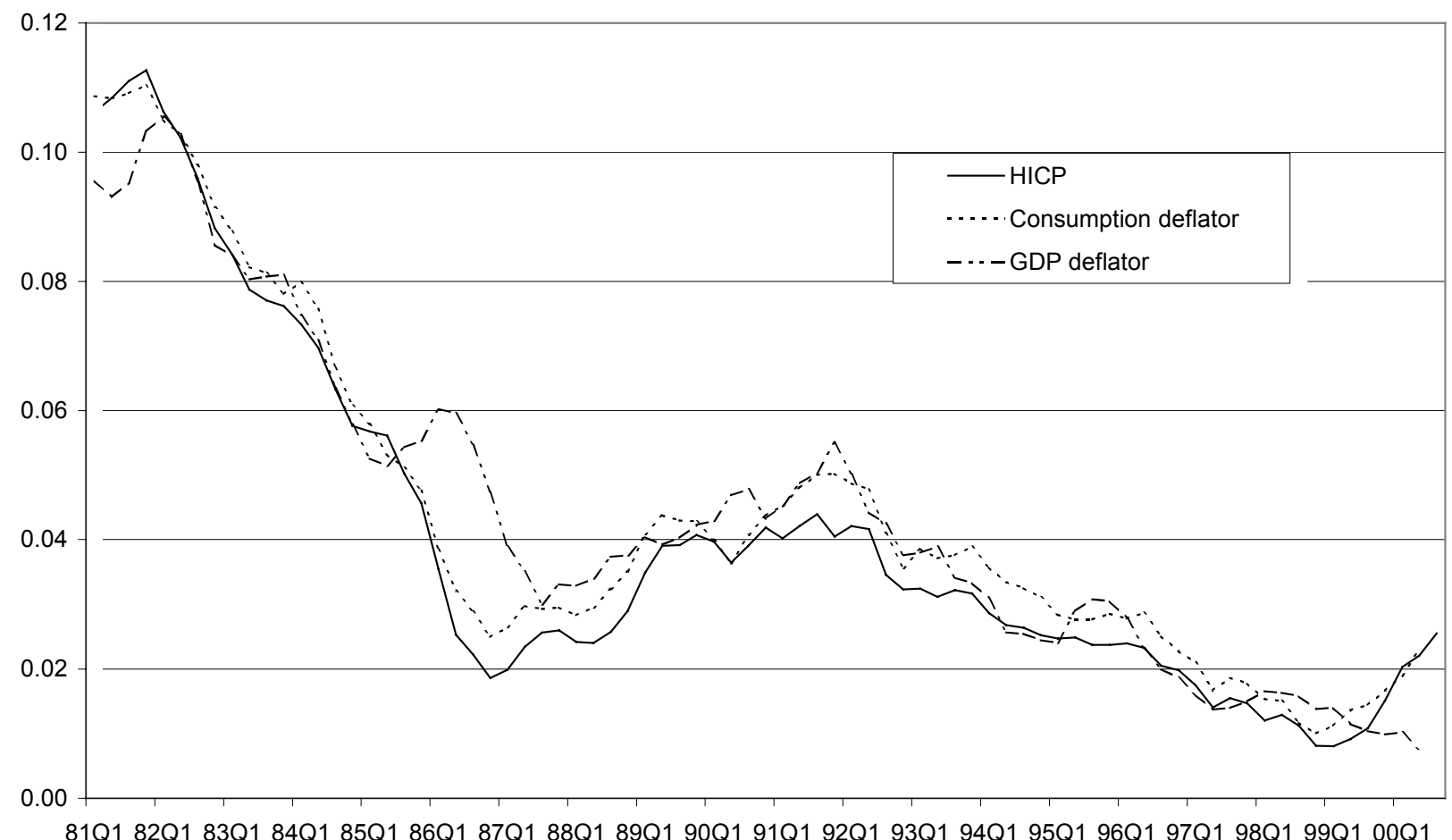

Chart 2: M3, P-Star and forecast errors

(annual growth rates)

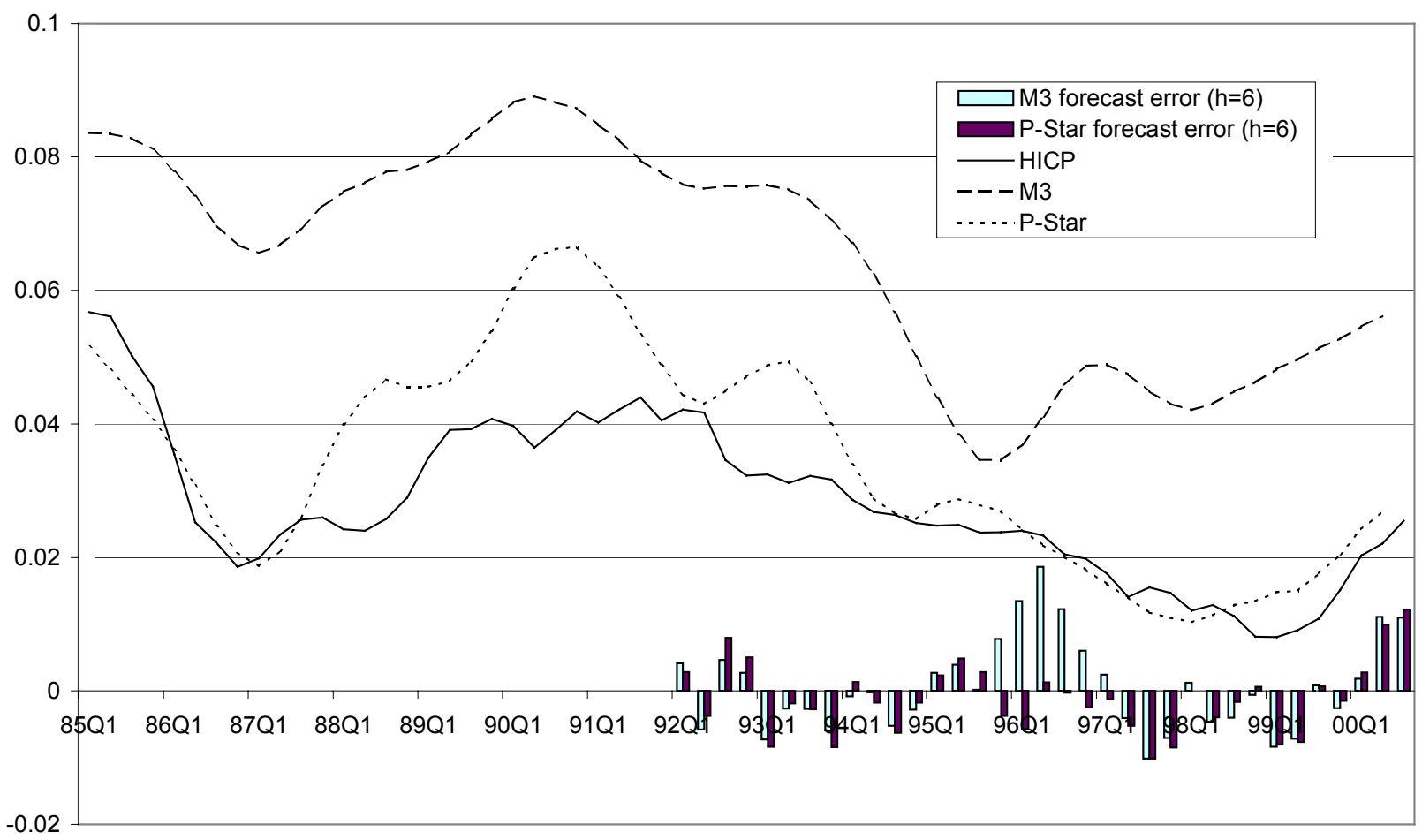


Chart 3.a: Measures of inflation predictability (selected bivariate models)
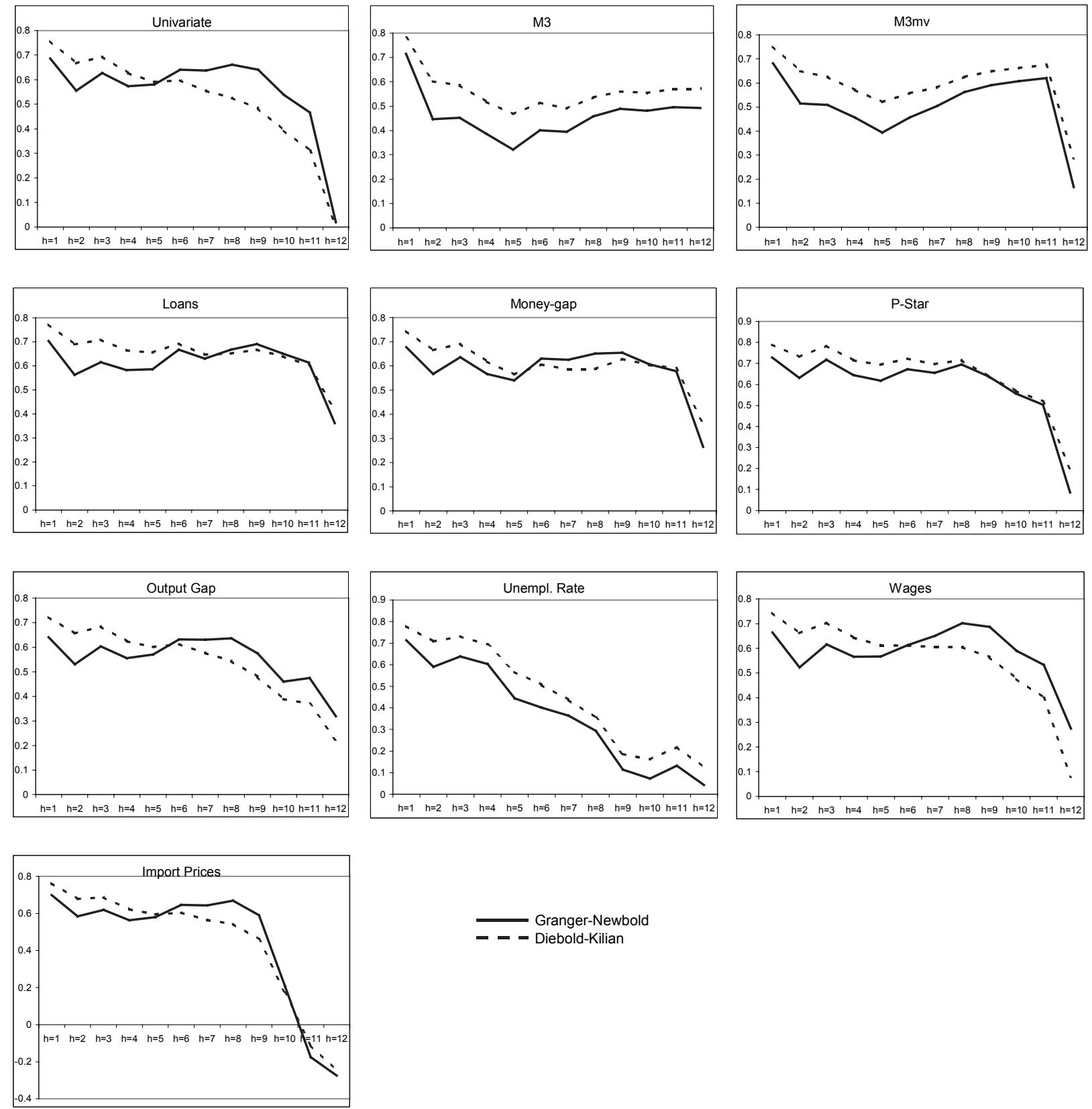

Granger-Newbold

- - - Diebold-Kilian 
Chart 3.b: Measures of inflation predictability (Mean and Ridge regression forecasts combination)
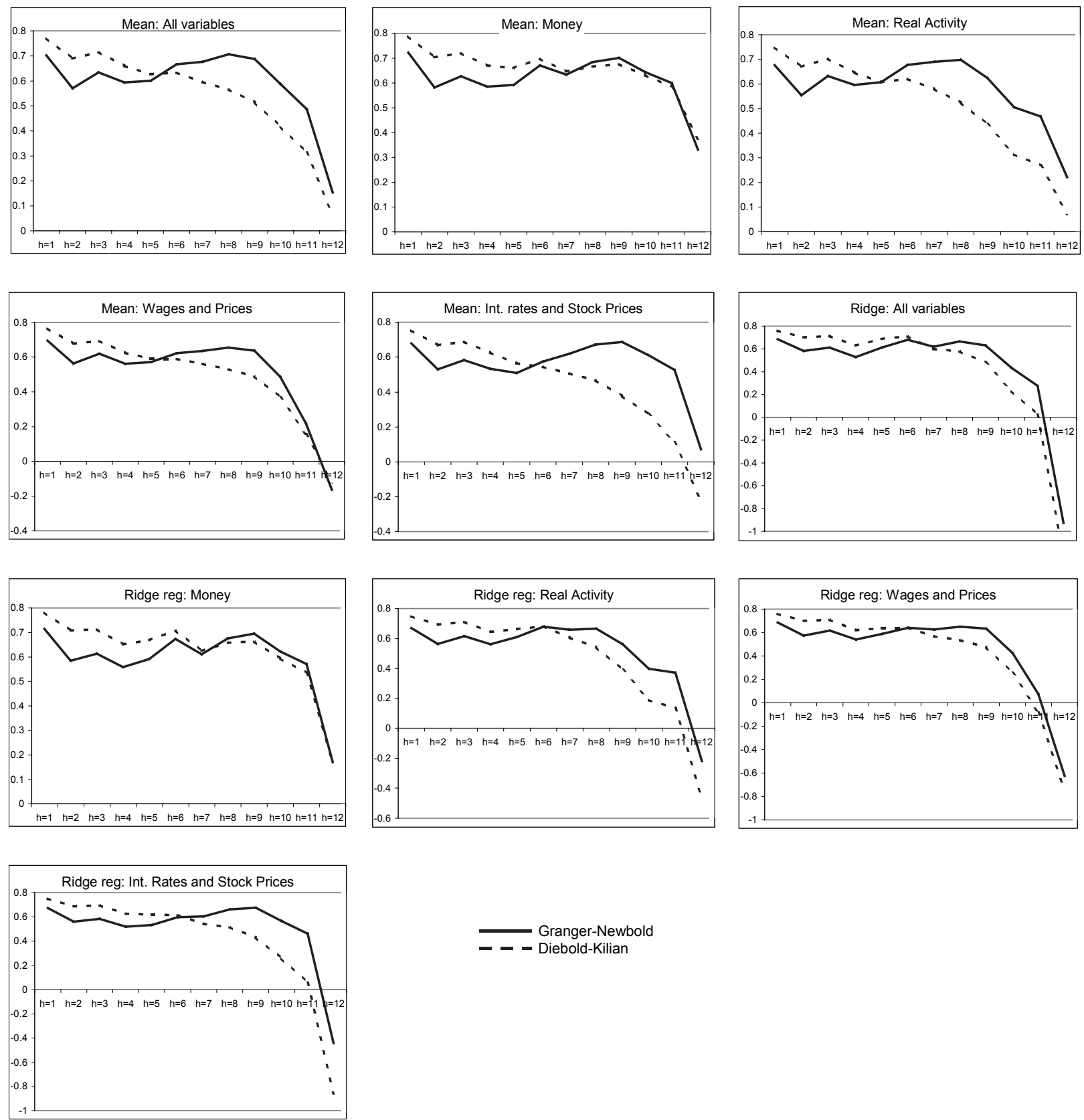

Granger-Newbold 
Chart 3.c: Measures of inflation predictability (Single factor and multi-factor forecasts)
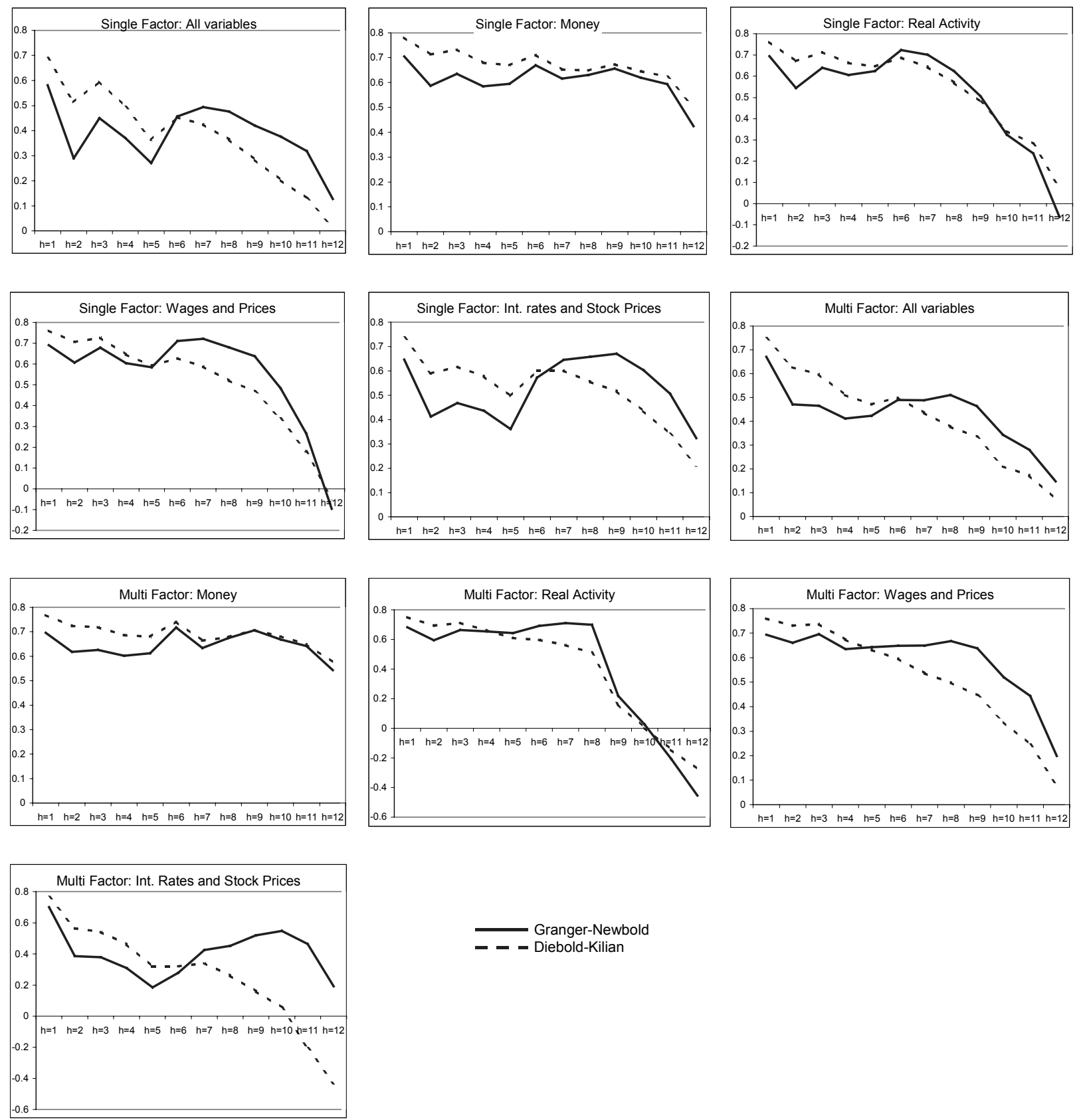

Granger-Newbold 
Table 1.a: HICP - forecast MSE relative to the univariate model

(Model 1 - Period: 1992.1 - 2000.3)

\begin{tabular}{|c|c|c|c|c|c|c|c|c|c|c|c|c|c|}
\hline & Transf. & $\mathrm{h}=1$ & $\mathrm{~h}=2$ & $\mathrm{~h}=3$ & $\mathrm{~h}=4$ & $\mathrm{~h}=5$ & $\mathrm{~h}=6$ & $\mathrm{~h}=7$ & $\mathrm{~h}=8$ & $\mathrm{~h}=9$ & $\mathrm{~h}=10$ & $\mathrm{~h}=11$ & $\mathrm{~h}=12$ \\
\hline univariate (\% RMSE) & & 0.50 & 0.59 & 0.56 & 0.62 & 0.65 & 0.65 & 0.68 & 0.70 & 0.73 & 0.79 & 0.84 & 1.02 \\
\hline \multicolumn{14}{|l|}{ Money aggregates: } \\
\hline M1 & DLN & $\begin{array}{l}0.98 \\
(.18)\end{array}$ & $\begin{array}{l}1.05 \\
(.02)\end{array}$ & $\begin{array}{l}1.07 \\
(.04)\end{array}$ & $\begin{array}{l}1.04 \\
(.04)\end{array}$ & $\begin{array}{l}1.05 \\
(.04)\end{array}$ & $\begin{array}{l}1.01 \\
(.05)\end{array}$ & $\begin{array}{l}1.06 \\
(.05)\end{array}$ & $\begin{array}{l}1.05 \\
(.06)\end{array}$ & $\begin{array}{l}1.04 \\
(.06)\end{array}$ & $\begin{array}{l}1.04 \\
(.05)\end{array}$ & $\begin{array}{l}1.07 \\
(.07)\end{array}$ & $\begin{array}{l}0.95 \\
(.10)\end{array}$ \\
\hline \multirow[t]{2}{*}{ M2 } & DLN & 0.98 & 0.95 & 0.93 & 0.92 & 0.89 & 0.82 & 0.92 & 0.89 & 0.84 & 0.83 & 0.83 & 0.90 \\
\hline & & $(.22)$ & $(.08)$ & $(.09)$ & $(.08)$ & $(.06)$ & $(.06)$ & $(.06)$ & $(.06)$ & $(.06)$ & $(.07)$ & $(.07)$ & (.10) \\
\hline \multirow[t]{2}{*}{ M3 } & DLN & 0.90 & 1.19 & 1.35 & 1.29 & 1.30 & 1.21 & 1.14 & 0.98 & 0.85 & 0.73 & 0.62 & 0.43 \\
\hline & & (.18) & $(.30)$ & (.43) & $(.41)$ & $(.47)$ & $(.46)$ & $(.33)$ & $(.29)$ & $(.26)$ & (.19) & $(.14)$ & (.11) \\
\hline \multirow[t]{2}{*}{$\mathrm{M} 3 \mathrm{mv}$} & DLN & 1.02 & 1.05 & 1.22 & 1.15 & 1.17 & 1.10 & 0.94 & 0.79 & 0.68 & 0.56 & 0.47 & 0.71 \\
\hline & & (.18) & $(.27)$ & $(.42)$ & $(.41)$ & $(.47)$ & $(.46)$ & $(.33)$ & $(.28)$ & $(.24)$ & $(.17)$ & $(.10)$ & (.23) \\
\hline \multirow[t]{2}{*}{ Loans } & DLN & 0.93 & 0.93 & 0.95 & 0.90 & 0.84 & 0.76 & 0.79 & 0.74 & 0.64 & 0.59 & 0.58 & 0.58 \\
\hline & & $(.07)$ & $(.13)$ & $(.13)$ & $(.15)$ & $(.14)$ & $(.16)$ & $(.13)$ & $(.14)$ & $(.14)$ & $(.13)$ & $(.13)$ & (.11) \\
\hline \multicolumn{14}{|l|}{ BC M3-demand } \\
\hline money-gap & LN & $\begin{array}{l}1.05 \\
(.08)\end{array}$ & $\begin{array}{l}1.00 \\
(.06)\end{array}$ & $\begin{array}{l}1.01 \\
(05)\end{array}$ & $\begin{array}{l}1.02 \\
(04)\end{array}$ & $\begin{array}{l}1.06 \\
(08)\end{array}$ & $\begin{array}{l}0.98 \\
(06)\end{array}$ & $\begin{array}{l}0.93 \\
(07)\end{array}$ & $\begin{array}{l}0.87 \\
(09)\end{array}$ & $\begin{array}{l}0.72 \\
(16)\end{array}$ & 0.65 & $\begin{array}{l}0.60 \\
(18)\end{array}$ & 0.64 \\
\hline \multirow[t]{2}{*}{ P-Star } & DLN & $\begin{array}{l}1.00) \\
0.86\end{array}$ & 0.81 & 0.71 & 0.76 & $\begin{array}{l}.00) \\
0.75\end{array}$ & 0.69 & 0.68 & 0.60 & 0.70 & 0.71 & 0.70 & 0.80 \\
\hline & & (.14) & (.14) & (.11) & $(.08)$ & $(.08)$ & $(.08)$ & (.13) & (.12) & (.11) & (.12) & $(.12)$ & (.14) \\
\hline \multirow[t]{2}{*}{ money-overhang } & LN & 1.12 & 1.18 & 1.14 & 1.13 & 1.12 & 1.00 & 0.88 & 0.78 & 0.69 & 0.62 & 0.54 & 0.65 \\
\hline & & $(.14)$ & $(.14)$ & $(.11)$ & $(.11)$ & $(.11)$ & $(.07)$ & $(.05)$ & $(.05)$ & $(.07)$ & $(.09)$ & $(.09)$ & (.18) \\
\hline \multicolumn{14}{|l|}{ CV M3-demand } \\
\hline gap & LN & 1.11 & 1.10 & 1.06 & 1.10 & 1.24 & 1.21 & 1.24 & 1.31 & 1.36 & 1.40 & 1.87 & 1.46 \\
\hline & & (.11) & $(.07)$ & $(.05)$ & $(.07)$ & $(.10)$ & $(.11)$ & $(.15)$ & (.19) & $(.21)$ & $(.21)$ & $(.56)$ & (.22) \\
\hline P-Star & DLN & 1.08 & 0.99 & 0.98 & 0.99 & 0.98 & 0.99 & 0.98 & 0.97 & 0.99 & 0.96 & 1.00 & 1.08 \\
\hline & & $(.06)$ & $(.04)$ & $(.02)$ & $(.01)$ & $(.02)$ & $(.01)$ & $(.01)$ & $(.01)$ & $(.02)$ & $(.03)$ & $(.02)$ & $(.08)$ \\
\hline mone & LN & 1.06 & 1.07 & 1.07 & 1.11 & 1.20 & 1.11 & 1.08 & 1.02 & 1.03 & 1.01 & 0.95 & 0.83 \\
\hline & & (.12) & $(.08)$ & $(.07)$ & $(.08)$ & $(.13)$ & $(.09)$ & $(.08)$ & $(.06)$ & (.11) & (.19) & $(.18)$ & (.16) \\
\hline Interest rates: & & & & & & & & & & & & & \\
\hline spread & L & 1.07 & 1.09 & 1.06 & 1.05 & 1.44 & 2.39 & 2.86 & 3.18 & 3.83 & 3.69 & 4.45 & 3.81 \\
\hline & & $(.04)$ & (.05) & $(.07)$ & (.09) & $(.28)$ & $(.85)$ & $(1.22)$ & (1.52) & (2.06) & $(2.08)$ & (2.59) & (2.35) \\
\hline short-term & L & 1.10 & 1.14 & 1.14 & 1.12 & 1.09 & 1.04 & 0.93 & 0.85 & 0.82 & 0.81 & 0.87 & 1.04 \\
\hline & & $(.25)$ & (.18) & $(.28)$ & $(.33)$ & $(.33)$ & $(.33)$ & $(.30)$ & $(.29)$ & $(.26)$ & $(.21)$ & $(.18)$ & (.14) \\
\hline long-term & L & 1.07 & 1.11 & 1.19 & 1.21 & 1.17 & 1.30 & 1.18 & 1.14 & 1.16 & 1.21 & 1.29 & 1.38 \\
\hline & & (.16) & $(.22)$ & $(.37)$ & $(.46)$ & $(.48)$ & $(.44)$ & $(.32)$ & $(.26)$ & $(.24)$ & (.19) & $(.20)$ & (.17) \\
\hline Stock prices: & & & & & & & & & & & & & \\
\hline ndex & DLN & 0.91 & 0.94 & 0.99 & 1.06 & 1.15 & 1.19 & 1.17 & 1.22 & 1.25 & 1.24 & 1.23 & 1.20 \\
\hline & & $(.09)$ & $(.07)$ & $(.08)$ & $(.07)$ & (.12) & (.13) & (.11) & (.11) & .12) & (.11) & .11) & $(.08)$ \\
\hline price-earnings ratio & L & 1.49 & 1.19 & 1.26 & 1.14 & 1.12 & 1.05 & 0.96 & 0.94 & 0.97 & 0.99 & 1.01 & 1.08 \\
\hline & & $(.36)$ & $(.21)$ & $(.32)$ & $(.30)$ & $(.27)$ & (.19) & (.09) & $(.06)$ & $(.08)$ & (.09) & $(.13)$ & (.13) \\
\hline dividend yield & L & 1.17 & 1.11 & 1.17 & 1.11 & 1.14 & 1.16 & 1.16 & 1.20 & 1.44 & 1.51 & 1.61 & 1.27 \\
\hline & & $(.18)$ & (.15) & $(.20)$ & (.19) & $(.18)$ & (.15) & $(.13)$ & (.15) & (.34) & $(.38)$ & (.43) & (.35) \\
\hline divity. & & & & & & & & & & & & & \\
\hline real output & DLN & 1.01 & 1.00 & 0.97 & 0.98 & 0.96 & 0.94 & 0.94 & 0.91 & 0.94 & 1.02 & 1.17 & 1.01 \\
\hline & & $(.06)$ & $(.03)$ & $(.02)$ & $(.02)$ & $(.03)$ & $(.04)$ & $(.04)$ & $(.03)$ & $(.05)$ & (.10) & $(.22)$ & $(.07)$ \\
\hline output gap & LN & 1.14 & 1.03 & 1.03 & 1.01 & 0.97 & 0.96 & 0.95 & 0.96 & 1.01 & 1.01 & 0.92 & 0.78 \\
\hline & & $(.11)$ & $(.09)$ & $(.07)$ & $(.06)$ & $(.06)$ & 6) & $(.07)$ & $(.07)$ & $(.07)$ & $(.09)$ & $(.08)$ & (.10) \\
\hline unempl. rate & L & 0.90 & 0.87 & 0.88 & 0.82 & 1.06 & 1.22 & 1.26 & 1.36 & 1.57 & 1.38 & 1.13 & 0.88 \\
\hline & & (.13) & $(.16)$ & $(.22)$ & $(.25)$ & $(.37)$ & $(.56)$ & $(.61)$ & $(.74)$ & $(.93)$ & $(.85)$ & $(.75)$ & $(.53)$ \\
\hline employment & DLN & 1.16 & 1.03 & 0.98 & 0.92 & 0.86 & 0.82 & 0.80 & 0.77 & 0.75 & 1.18 & 1.30 & 1.41 \\
\hline & & $(.11)$ & $(.12)$ & $(.12)$ & (07) & $(.07)$ & 7) & $(.07)$ & $(.08)$ & $(.08)$ & $(.39)$ & $(.46)$ & (.49) \\
\hline Capacity utilization & $\mathrm{L}$ & 1.06 & 1.12 & 1.31 & 1.47 & 1.64 & 1.80 & 2.06 & 2.70 & 2.97 & 2.93 & 2.83 & 2.28 \\
\hline & & & $(.13)$ & $(.25$ & $(.41)$ & 45 & $(.66)$ & $(.81$ & (1.19) & (1.42) & (1.47) & $(1.47)$ & $(1.17)$ \\
\hline Nages and prices: & & & & & & & & & & & & & \\
\hline ULC & DLN & 1.09 & 1.01 & 0.95 & 0.94 & 0.91 & 0.92 & 0.87 & 0.87 & 0.88 & 0.97 & 1.34 & 1.20 \\
\hline & & (.15) & $(.08)$ & $(.07)$ & $(.06)$ & $(.06)$ & $(.06)$ & $(.03)$ & $(.03)$ & $(.04)$ & (.12) & $(.47)$ & (.22) \\
\hline wages & DLN & 1.05 & 1.02 & 0.97 & 0.95 & 0.95 & 0.97 & 0.88 & 0.83 & 0.84 & 0.86 & 0.87 & 0.92 \\
\hline & & (.14) & $(.10)$ & $(.09)$ & $(.10)$ & $(.10)$ & $(.10)$ & $(.06)$ & $(.04)$ & $(.03)$ & $(.03)$ & $(.03)$ & $(.06)$ \\
\hline eff. exch. rate & DLN & 1.20 & 1.10 & 1.16 & 1.14 & 1.09 & 1.09 & 1.05 & 1.03 & 1.02 & 1.09 & 1.04 & 1.04 \\
\hline & & $(.21)$ & (.13) & $(.09)$ & $(.09)$ & $(.06)$ & $(.04)$ & $(.03)$ & $(.03)$ & $(.03)$ & $(.08)$ & $(.06)$ & $(.05)$ \\
\hline import deflator & DLN & 0.97 & 0.96 & 1.02 & 1.01 & 0.99 & 0.98 & 0.98 & 0.96 & 1.04 & 1.36 & 1.62 & 1.25 \\
\hline & & $(.16$ & $(.04)$ & $(.02$ & $(.02)$ & $(.02$ & $(.02)$ & $(.0$ & $(.02)$ & $(.07)$ & $(.34)$ & $(.59)$ & (.22) \\
\hline commodity price & DLN & 1.07 & 0.91 & 0.99 & 1.10 & 1.27 & 1.36 & 1.35 & 1.47 & 1.42 & 1.31 & 1.27 & 1.09 \\
\hline & & (.12) & $(.04)$ & $(.03)$ & (.11) & (.17) & (.15) & (.13) & (.13) & (.13) & (.10) & $(.07)$ & $(.12)$ \\
\hline oil prices & DLN & 1.37 & 1.18 & 1.05 & 1.05 & 0.99 & 1.00 & 0.97 & 0.99 & 0.98 & 0.99 & 2.11 & 1.81 \\
\hline & & $(.23)$ & $(.13)$ & $(.05)$ & $(.06)$ & $(.03)$ & $(.03)$ & $(.02)$ & $(.01)$ & $(.01)$ & $(.01)$ & $(1.09)$ & $(.61)$ \\
\hline
\end{tabular}

Notes: All results are for simulated out of sample forecasts according to equation (9) in the text. $h$ denotes the forecast horizon in quarters. The first row shows the forecast percentage RMSE for the univariate model. All other rows show the ratio between the forecast MSE of the bivariate model which uses the variable indicated and the forecast MSE of the univariate model. HAC standard errors (estimated using a Bartlett kernel with $h$ lags) are shown in parenthesis. Transformations of series are: level (L), first difference of $L$ (DL), logarithm (LN), first difference of $L N(D L N)$, first difference of DLN (DDLN). BC and CV refer to Brand and Cassola (2000) and Coenen and Vega (2000) money demand specifications,

respectively. 
Table 1.b: Private Consumption deflator - forecast MSE relative to the univariate model

(Model 1 - Period: 1992.1 - 2000.2)

\begin{tabular}{|c|c|c|c|c|c|c|c|c|c|c|c|c|c|}
\hline & Transf. & $\mathrm{h}=1$ & $\mathrm{~h}=2$ & $\mathrm{~h}=3$ & $\mathrm{~h}=4$ & $\mathrm{~h}=5$ & $\mathrm{~h}=6$ & $\mathrm{~h}=7$ & $\mathrm{~h}=8$ & $\mathrm{~h}=9$ & $\mathrm{~h}=10$ & $\mathrm{~h}=11$ & $\mathrm{~h}=12$ \\
\hline univariate (\% RMSE) & & 0.80 & 0.68 & 0.60 & 0.61 & 0.64 & 0.66 & 0.71 & 0.79 & 0.88 & 0.96 & 0.99 & 1.08 \\
\hline \multicolumn{14}{|l|}{ Money aggregates: } \\
\hline \multirow[t]{4}{*}{ M1 } & DLN & 1.07 & 1.10 & 1.14 & 1.08 & 1.13 & 1.11 & 1.22 & 1.11 & 1.13 & 1.12 & 1.18 & 1.15 \\
\hline & & $(.04)$ & $(.06)$ & $(.09)$ & $(.05)$ & $(.08)$ & $(.07)$ & $(.18)$ & $(.10)$ & $(.10)$ & $(.11)$ & $(.13)$ & $(.12)$ \\
\hline & DLN & 1.04 & 1.00 & 0.97 & 0.98 & 0.96 & 0.94 & 1.09 & 0.96 & 0.88 & 0.85 & 0.86 & 0.84 \\
\hline & & $(.08)$ & $(.05)$ & $(.05)$ & $(.05)$ & $(.05)$ & $(.05)$ & (.15) & $(.10)$ & $(.07)$ & $(.08)$ & $(.09)$ & $(.08)$ \\
\hline \multirow[t]{2}{*}{ M3 } & DLN & 1.06 & 1.11 & 1.31 & 1.45 & 1.40 & 1.63 & 1.45 & 1.10 & 0.86 & 0.68 & 0.56 & 0.52 \\
\hline & & $(.17)$ & $(.30)$ & (.48) & $(.58)$ & $(.71)$ & $(.94)$ & $(.72)$ & (.49) & (.30) & (.19) & (.13) & (.10) \\
\hline \multirow[t]{2}{*}{$\mathrm{M} 3 \mathrm{mv}$} & DLN & 1.09 & 1.07 & 1.19 & 1.44 & 1.45 & 1.50 & 1.22 & 0.91 & 0.67 & 0.50 & 0.42 & 0.39 \\
\hline & & $(.16)$ & $(.23)$ & $(.40)$ & $(.62)$ & $(.74)$ & $(.84)$ & $(.60)$ & $(.41)$ & $(.26)$ & (.15) & $(.09)$ & $(.05)$ \\
\hline \multirow[t]{2}{*}{ Loans } & DLN & 0.97 & 0.95 & 0.95 & 0.91 & 0.88 & 0.88 & 0.81 & 0.66 & 0.56 & 0.48 & 0.47 & 0.45 \\
\hline & & $(.13)$ & $(.14)$ & $(.15)$ & $(.16)$ & $(.18)$ & $(.20)$ & $(.19)$ & $(.19)$ & $(.15)$ & $(.12)$ & $(.11)$ & $(.09)$ \\
\hline \multirow{3}{*}{$\begin{array}{l}\text { BC M3-demand } \\
\text { money-gap }\end{array}$} & & & & & & & & & & & & & \\
\hline & LN & 1.06 & 0.96 & 0.97 & 1.18 & 1.03 & 0.89 & 0.78 & 0.65 & 0.62 & 0.57 & 0.69 & 0.85 \\
\hline & & (.15) & (.13) & (.14) & (.18) & $(.22)$ & (.19) & $(.17)$ & (.13) & (.15) & (.16) & $(.28)$ & $(.42)$ \\
\hline \multirow[t]{2}{*}{ P-Star } & DLN & 1.00 & 0.72 & 0.83 & 0.76 & 0.68 & 0.59 & 0.69 & 0.62 & 0.69 & 0.68 & 0.71 & 0.71 \\
\hline & & (.18) & (.14) & (.16) & (.15) & (.14) & (.09) & $(.21)$ & $(.18)$ & $(.12)$ & (.14) & (.15) & (.14) \\
\hline \multirow[t]{2}{*}{ money-overhang } & LN & 1.43 & 1.16 & 1.26 & 1.68 & 1.65 & 1.45 & 1.16 & 0.79 & 0.54 & 0.48 & 0.38 & 0.43 \\
\hline & & $(.27)$ & $(.11)$ & $(.20)$ & $(.52)$ & $(.65)$ & $(.60)$ & $(.42)$ & $(.24)$ & $(.15)$ & $(.17)$ & $(.15)$ & $(.20)$ \\
\hline \multirow{3}{*}{$\begin{array}{r}\text { CV M3-demand } \\
\text { money-gap }\end{array}$} & & & & & & & & & & & & & \\
\hline & LN & 1.06 & 1.09 & 1.12 & 1.22 & 1.29 & 1.25 & 1.49 & 1.51 & 1.38 & 1.52 & 2.04 & 1.78 \\
\hline & & $(.08)$ & (.09) & $(.09)$ & (.09) & $(.11)$ & (.14) & $(.32)$ & $(.29)$ & $(.25)$ & $(.21)$ & $(.56)$ & $(.29)$ \\
\hline \multirow{2}{*}{ P-Star } & DLN & 1.01 & 0.99 & 0.98 & 0.99 & 0.98 & 1.11 & 1.00 & 0.98 & 1.01 & 0.99 & 1.05 & 1.03 \\
\hline & & $(.01)$ & $(.02)$ & $(.02)$ & $(.01)$ & $(.02)$ & $(.08)$ & $(.03)$ & $(.03)$ & $(.02)$ & $(.02)$ & $(.04)$ & $(.06)$ \\
\hline money-overhang & LN & 1.01 & 0.99 & 1.13 & 1.22 & 1.18 & 0.92 & 1.03 & 1.13 & 0.96 & 0.88 & 1.19 & 1.28 \\
\hline & & $(.02)$ & $(.05)$ & $(.12)$ & (.19) & $(.19)$ & (.15) & $(.20)$ & $(.23)$ & $(.15)$ & $(.15)$ & (.19) & $(.21)$ \\
\hline Interest & & & & & & & & & & & & & \\
\hline spread & L & 1.15 & 1.26 & 1.78 & 2.21 & 3.06 & 3.67 & 4.19 & 4.03 & 3.61 & 3.35 & 3.64 & 3.63 \\
\hline & & $(.18)$ & $(.22)$ & $(.47)$ & $(.68)$ & (1.07) & (1.58) & (2.03) & (2.02) & (1.92) & $(1.95)$ & (2.19) & (2.14) \\
\hline short-term & L & 1.12 & 1.10 & 1.04 & 1.15 & 1.12 & 1.02 & 0.89 & 0.79 & 0.65 & 0.61 & 0.68 & 0.80 \\
\hline & & $(.18)$ & $(.23)$ & $(.30)$ & $(.40)$ & $(.45)$ & $(.48)$ & $(.48)$ & $(.44)$ & $(.37)$ & $(.32)$ & $(.30)$ & $(.25)$ \\
\hline long-term & L & 1.05 & 1.13 & 1.13 & 1.22 & 1.42 & 1.30 & 1.00 & 0.82 & 1.00 & 1.07 & 1.49 & 1.80 \\
\hline & & $(.20)$ & $(.29)$ & $(.39)$ & $(.60)$ & $(.64)$ & $(.56)$ & $(.38)$ & $(.29)$ & $(.23)$ & $(.25)$ & (.49) & $(.49)$ \\
\hline Stock prices: & & & & & & & & & & & & & \\
\hline total market index & DLN & 1.09 & 0.89 & 0.98 & 1.06 & 1.12 & 1.11 & 1.15 & 1.18 & 1.12 & 1.12 & 1.15 & 1.14 \\
\hline & & $(.17)$ & $(.13)$ & (.11) & $(.09)$ & $(.09)$ & $(.09)$ & $(.06)$ & $(.08)$ & $(.07)$ & $(.07)$ & $(.06)$ & $(.05)$ \\
\hline price-earnings ratio & $\mathrm{L}$ & 1.12 & 1.16 & 1.18 & 1.12 & 1.09 & 0.94 & 0.97 & 0.90 & 0.89 & 0.79 & 1.14 & 1.09 \\
\hline & & $(.14)$ & $(.26)$ & $(.32)$ & $(.35)$ & $(.35)$ & $(.23)$ & $(.14)$ & $(.14)$ & $(.12)$ & $(.08)$ & $(.35)$ & $(.24)$ \\
\hline dividend yield & L & 1.18 & 1.11 & 1.25 & 1.28 & 1.33 & 1.32 & 1.34 & 1.27 & 1.15 & 1.13 & 1.19 & 1.19 \\
\hline & & $(.22)$ & $(.21)$ & $(.21)$ & $(.21)$ & $(.22)$ & $(.20)$ & (.16) & $(.13)$ & $(.09)$ & $(.09)$ & $(.12)$ & $(.08)$ \\
\hline Real activity: & & & & & & & & & & & & & \\
\hline real output & DLN & 0.99 & 1.04 & 1.05 & 0.99 & 0.94 & 0.92 & 0.90 & 0.86 & 0.88 & 1.06 & 1.25 & 1.24 \\
\hline & & $(.12)$ & $(.17)$ & $(.07)$ & $(.06)$ & $(.05)$ & $(.05)$ & $(.05)$ & $(.04)$ & $(.03)$ & $(.17)$ & $(.36)$ & $(.32)$ \\
\hline output gap & LN & 1.13 & 1.16 & 1.09 & 1.07 & 1.06 & 1.04 & 0.99 & 0.92 & 0.84 & 0.75 & 0.75 & 0.67 \\
\hline & & $(.26)$ & $(.27)$ & $(.17)$ & (.15) & $(.13)$ & (.10) & $(.10)$ & $(.13)$ & $(.13)$ & $(.17)$ & $(.17)$ & $(.19)$ \\
\hline unempl. rate & L & 0.94 & 0.95 & 1.00 & 1.45 & 1.06 & 1.11 & 1.36 & 1.18 & 1.05 & 0.80 & 0.66 & 0.56 \\
\hline & & (.16) & $(.22)$ & $(.27)$ & $(.58)$ & $(.43)$ & (.52) & $(.71)$ & (.63) & $(.56)$ & $(.47)$ & $(.43)$ & $(.36)$ \\
\hline employment & DLN & 1.10 & 1.11 & 1.07 & 1.00 & 1.06 & 1.47 & 1.18 & 1.62 & 1.73 & 1.63 & 1.76 & 2.10 \\
\hline & & $(.07)$ & $(.20)$ & $(.24)$ & $(.18)$ & $(.27)$ & $(.56)$ & $(.27)$ & $(.54)$ & (.66) & $(.68)$ & $(.80)$ & $(1.02)$ \\
\hline Capacity utilization & L & 1.23 & 1.72 & 2.08 & 2.01 & 2.41 & 2.36 & 2.51 & 2.49 & 2.32 & 2.12 & 2.13 & 1.98 \\
\hline & & $(.18)$ & $(.39)$ & $(.61)$ & $(.72)$ & $(.91)$ & $(1.07)$ & $(1.20)$ & (1.19) & (1.12) & $(1.16)$ & (1.23) & (1.10) \\
\hline Wages and prices: & & & & & & & & & & & & & \\
\hline ULC & DLN & 1.02 & 0.97 & 0.83 & 0.89 & 0.92 & 0.87 & 1.01 & 0.81 & 0.72 & 0.79 & 1.16 & 1.28 \\
\hline & & (.05) & $(.05)$ & $(.05)$ & (.09) & $(.09)$ & (.08) & $(.19)$ & $(.05)$ & $(.06)$ & (.08) & $(.35)$ & $(.36)$ \\
\hline wages & DLN & 1.04 & 0.95 & 0.89 & 0.85 & 0.92 & 0.87 & 0.82 & 0.76 & 0.80 & 0.77 & 0.93 & 0.98 \\
\hline & & $(.09)$ & $(.09)$ & $(.08)$ & (.09) & $(.10)$ & $(.07)$ & $(.05)$ & $(.08)$ & $(.05)$ & $(.04)$ & (.16) & $(.16)$ \\
\hline eff. exch. rate & DLN & 1.09 & 1.06 & 1.13 & 1.11 & 1.06 & 1.05 & 1.04 & 1.05 & 1.02 & 1.01 & 1.01 & 1.02 \\
\hline & & $(.21)$ & (.11) & $(.10)$ & $(.08)$ & $(.05)$ & $(.02)$ & $(.03)$ & $(.04)$ & $(.03)$ & $(.03)$ & $(.02)$ & $(.02)$ \\
\hline import deflator & DLN & 1.08 & 1.04 & 1.04 & 1.04 & 1.05 & 1.07 & 1.07 & 1.06 & 1.04 & 1.31 & 1.46 & 1.29 \\
\hline & & (.09) & $(.07)$ & $(.05)$ & $(.03)$ & $(.03)$ & $(.03)$ & $(.03)$ & $(.03)$ & $(.02)$ & $(.23)$ & $(.40)$ & $(.21)$ \\
\hline commodity price & DLN & 1.02 & 1.01 & 0.97 & 1.08 & 1.27 & 1.18 & 1.14 & 1.16 & 1.19 & 1.06 & 1.16 & 1.22 \\
\hline & & $(.05)$ & $(.04)$ & $(.06)$ & (.11) & (.16) & (.13) & $(.09)$ & (.13) & (.11) & $(.08)$ & (.10) & $(.05)$ \\
\hline oil prices & DLN & 1.03 & 1.00 & 1.01 & 1.00 & 0.99 & 1.00 & 1.01 & 1.03 & 0.98 & 1.01 & 1.84 & 1.68 \\
\hline & & $(.02)$ & $(.01)$ & $(.01)$ & $(.01)$ & $(.02)$ & (.03) & $(.03)$ & $(.04)$ & $(.02)$ & $(.03)$ & $(.85)$ & (.62) \\
\hline
\end{tabular}

Notes: see notes to Table 1.a 
Table 1.c: GDP deflator - forecast MSE relative to the univariate model

(Model 1 - Period: 1992.1 - 2000.2)

\begin{tabular}{|c|c|c|c|c|c|c|c|c|c|c|c|c|c|}
\hline & Transf. & $\mathrm{h}=1$ & $\mathrm{~h}=2$ & $\mathrm{~h}=3$ & $\mathrm{~h}=4$ & $\mathrm{~h}=5$ & $\mathrm{~h}=6$ & $\mathrm{~h}=7$ & $\mathrm{~h}=8$ & $\mathrm{~h}=9$ & $\mathrm{~h}=10$ & $\mathrm{~h}=11$ & $\mathrm{~h}=12$ \\
\hline univariate (\% RMSE) & & 0.94 & 0.80 & 0.76 & 0.79 & 0.86 & 0.87 & 0.90 & 0.94 & 1.02 & 1.12 & 1.25 & 1.33 \\
\hline \multicolumn{14}{|l|}{ Money aggregates: } \\
\hline \multirow{2}{*}{ M1 } & DLN & 1.00 & 1.05 & 1.30 & 1.38 & 1.36 & 1.38 & 1.50 & 1.54 & 1.51 & 1.47 & 1.24 & 1.16 \\
\hline & & $(.15)$ & $(.10)$ & $(.25)$ & $(.26)$ & $(.28)$ & $(.24)$ & $(.31)$ & $(.32)$ & $(.33)$ & $(.30)$ & $(.22)$ & $(.17)$ \\
\hline \multirow[t]{2}{*}{ M2 } & DLN & 1.19 & 1.37 & 1.50 & 1.44 & 1.30 & 1.15 & 1.03 & 0.82 & 0.65 & 0.60 & 0.54 & 0.53 \\
\hline & & $(.23)$ & $(.34)$ & $(.49)$ & $(.52)$ & $(.43)$ & $(.37)$ & $(.31)$ & $(.22)$ & $(.14)$ & $(.11)$ & $(.08)$ & $(.07)$ \\
\hline \multirow[t]{2}{*}{ M3 } & DLN & 1.27 & 1.81 & 2.40 & 2.25 & 2.07 & 1.64 & 1.32 & 1.00 & 0.75 & 0.60 & 0.44 & 0.37 \\
\hline & & $(.12)$ & (.31) & $(.50)$ & $(.60)$ & (.55) & $(.51)$ & $(.38)$ & $(.38)$ & (.48) & $(.34)$ & $(.19)$ & $(.15)$ \\
\hline \multirow[t]{2}{*}{$\mathrm{M} 3 \mathrm{mv}$} & DLN & 1.23 & 1.81 & 2.21 & 2.23 & 1.79 & 1.60 & 1.18 & 0.86 & 0.69 & 0.54 & 0.39 & 0.33 \\
\hline & & $(.18)$ & $(.85)$ & (1.34) & (1.43) & $(1.10)$ & $(.94)$ & $(.57)$ & (.31) & (.18) & $(.11)$ & $(.10)$ & $(.10)$ \\
\hline \multirow[t]{2}{*}{ Loans } & DLN & 1.12 & 1.34 & 1.50 & 1.47 & 1.35 & 1.17 & 1.09 & 1.07 & 1.03 & 0.77 & 0.50 & 0.45 \\
\hline & & $(.12)$ & (.31) & $(.50)$ & $(.60)$ & (.55) & $(.51)$ & $(.38)$ & (.38) & (.48) & $(.34)$ & $(.19)$ & $(.15)$ \\
\hline \multirow{3}{*}{$\begin{array}{l}\text { BC M3-demand } \\
\text { money-gap }\end{array}$} & & & & & & & & & & & & & \\
\hline & LN & 1.30 & 1.29 & 1.40 & 1.16 & 1.03 & 0.78 & 0.75 & 0.63 & 0.49 & 0.52 & 0.55 & 0.56 \\
\hline & & $(.11)$ & $(.23)$ & $(.37)$ & $(.33)$ & (.34) & $(.23)$ & $(.22)$ & $(.22)$ & (.19) & $(.21)$ & $(.21)$ & $(.21)$ \\
\hline \multirow[t]{2}{*}{ P-Star } & DLN & 1.05 & 0.87 & 0.71 & 0.62 & 0.64 & 0.67 & 0.70 & 0.62 & 0.52 & 0.52 & 0.54 & 0.55 \\
\hline & & $(.16)$ & (.19) & $(.17)$ & $(.13)$ & (.10) & $(.12)$ & $(.12)$ & $(.08)$ & $(.05)$ & $(.05)$ & $(.05)$ & $(.04)$ \\
\hline \multirow[t]{2}{*}{ money-overhang } & LN & 1.77 & 2.85 & 3.86 & 3.74 & 3.37 & 3.14 & 2.52 & 2.17 & 1.85 & 1.63 & 1.44 & 1.37 \\
\hline & & $(.33)$ & $(.88)$ & $(1.65)$ & $(1.72)$ & (1.51) & $(1.40)$ & (1.11) & $(.84)$ & $(.53)$ & $(.39)$ & $(.36)$ & $(.27)$ \\
\hline \multirow{3}{*}{$\begin{array}{l}\text { CV M3-demand } \\
\text { money-gap }\end{array}$} & & & & & & & & & & & & & \\
\hline & LN & 1.38 & 1.25 & 1.63 & 1.53 & 1.31 & 1.61 & 1.89 & 1.98 & 2.06 & 2.00 & 1.89 & 1.94 \\
\hline & & $(.10)$ & (.15) & $(.28)$ & $(.24)$ & $(.24)$ & $(.30)$ & $(.48)$ & $(.55)$ & $(.59)$ & $(.55)$ & $(.48)$ & $(.51)$ \\
\hline P-Star & DLN & 1.04 & 0.88 & 0.91 & 0.99 & 0.87 & 0.85 & 0.91 & 0.93 & 0.88 & 0.93 & 0.87 & 0.86 \\
\hline & & $(.05)$ & (.15) & $(.16)$ & $(.09)$ & $(.09)$ & $(.09)$ & $(.09)$ & $(.10)$ & $(.10)$ & $(.10)$ & $(.07)$ & $(.07)$ \\
\hline money-overhang & LN & 1.33 & 1.37 & 1.74 & 1.57 & 1.43 & 1.38 & 1.39 & 1.31 & 1.31 & 1.19 & 1.13 & 1.09 \\
\hline & & $(.11)$ & $(.11)$ & $(.29)$ & $(.25)$ & $(.23)$ & $(.22)$ & $(.23)$ & $(.18)$ & (.16) & $(.16)$ & $(.24)$ & $(.24)$ \\
\hline Interes & & & & & & & & & & & & & \\
\hline spread & L & 1.07 & 1.16 & 1.45 & 1.48 & 1.64 & 1.82 & 1.99 & 1.89 & 1.95 & 1.81 & 1.55 & 1.61 \\
\hline & & $(.05)$ & $(.08)$ & $(.24)$ & $(.24)$ & $(.36)$ & $(.47)$ & $(.55)$ & $(.45)$ & $(.44)$ & $(.45)$ & $(.47)$ & $(.56)$ \\
\hline short-term & $\mathrm{L}$ & 1.09 & 1.28 & 1.48 & 1.53 & 1.51 & 1.69 & 1.79 & 1.74 & 1.59 & 1.29 & 1.09 & 1.01 \\
\hline & & $(.24)$ & (.33) & $(.52)$ & $(.58)$ & $(.62)$ & $(.71)$ & $(.78)$ & $(.73)$ & (.67) & $(.53)$ & $(.44)$ & $(.38)$ \\
\hline long-term & $\mathrm{L}$ & 0.88 & 0.89 & 0.89 & 0.82 & 0.77 & 0.83 & 0.83 & 0.83 & 0.79 & 0.76 & 0.71 & 0.69 \\
\hline & & $(.19)$ & $(.23)$ & $(.21)$ & $(.19)$ & $(.19)$ & $(.19)$ & $(.17)$ & $(.15)$ & (.15) & $(.15)$ & $(.17)$ & $(.17)$ \\
\hline Stock prices: & & & & & & & & & & & & & \\
\hline total market index & DLN & 0.84 & 0.97 & 1.13 & 1.20 & 1.17 & 1.36 & 1.30 & 1.26 & 1.19 & 1.10 & 0.91 & 0.98 \\
\hline & & $(.06)$ & $(.11)$ & $(.13)$ & $(.15)$ & $(.16)$ & $(.18)$ & $(.22)$ & $(.19)$ & $(.17)$ & $(.13)$ & $(.16)$ & $(.19)$ \\
\hline price-earnings ratio & $\mathrm{L}$ & 1.07 & 1.72 & 1.94 & 1.69 & 1.45 & 1.34 & 1.29 & 1.14 & 0.97 & 0.93 & 0.81 & 0.84 \\
\hline & & $(.30)$ & $(.38)$ & $(.35)$ & $(.31)$ & $(.28)$ & $(.20)$ & $(.15)$ & $(.15)$ & $(.16)$ & $(.14)$ & $(.17)$ & $(.16)$ \\
\hline dividend yield & $\mathrm{L}$ & 1.07 & 1.38 & 1.85 & 1.87 & 1.81 & 1.90 & 1.86 & 1.76 & 1.56 & 1.41 & 1.25 & 1.20 \\
\hline & & $(.17)$ & $(.22)$ & $(.38)$ & $(.43)$ & $(.45)$ & $(.44)$ & $(.45)$ & $(.36)$ & $(.27)$ & $(.24)$ & $(.28)$ & $(.27)$ \\
\hline eal activity: & & & & & & & & & & & & & \\
\hline real output & DLN & 1.00 & 0.88 & 1.02 & 0.94 & 1.05 & 1.03 & 0.93 & 0.96 & 1.02 & 1.05 & 1.12 & 1.15 \\
\hline & & $(.02)$ & $(.05)$ & $(.05)$ & $(.08)$ & $(.07)$ & $(.13)$ & $(.11)$ & (.11) & $(.09)$ & $(.11)$ & $(.14)$ & $(.13)$ \\
\hline output gap & LN & 1.02 & 0.99 & 1.04 & 1.07 & 0.96 & 0.82 & 0.80 & 0.83 & 0.86 & 0.85 & 0.85 & 0.89 \\
\hline & & $(.04)$ & $(.04)$ & $(.04)$ & $(.04)$ & $(.12)$ & $(.17)$ & $(.15)$ & $(.12)$ & (.11) & $(.09)$ & $(.06)$ & $(.04)$ \\
\hline unempl. rate & L & 1.18 & 1.51 & 2.17 & 1.86 & 1.77 & 1.71 & 1.70 & 1.60 & 1.39 & 1.25 & 1.03 & 0.99 \\
\hline & & $(.21)$ & $(.45)$ & $(.84)$ & $(.76)$ & $(.76)$ & $(.77)$ & $(.85)$ & $(.83)$ & $(.71)$ & $(.64)$ & $(.53)$ & $(.48)$ \\
\hline employment & DLN & 1.16 & 1.16 & 1.35 & 1.21 & 1.02 & 1.05 & 1.16 & 1.22 & 1.08 & 1.06 & 1.09 & 1.12 \\
\hline & & $(.10)$ & $(.17)$ & $(.28)$ & $(.17)$ & $(.15)$ & $(.15)$ & $(.19)$ & $(.20)$ & $(.15)$ & $(.14)$ & $(.12)$ & $(.11)$ \\
\hline Capacity utilization & L & 1.06 & 1.09 & 1.66 & 1.85 & 1.64 & 1.47 & 1.64 & 1.99 & 2.03 & 2.02 & 1.87 & 1.76 \\
\hline & & $(.04)$ & $(.10)$ & $(.40)$ & $(.43)$ & $(.39)$ & $(.43)$ & $(.54)$ & $(.67)$ & (.61) & $(.60)$ & $(.54)$ & $(.51)$ \\
\hline nd prices: & & & & & & & & & & & & & \\
\hline ULC & DLN & 1.09 & 1.27 & 1.77 & 1.74 & 1.41 & 1.55 & 1.57 & 1.43 & 1.28 & 1.23 & 1.15 & 1.10 \\
\hline & & $(.16)$ & $(.21)$ & $(.38)$ & $(.32)$ & $(.26)$ & $(.30)$ & $(.35)$ & $(.29)$ & $(.25)$ & $(.23)$ & $(.24)$ & $(.20)$ \\
\hline wages & DLN & 0.90 & 0.92 & 1.63 & 1.71 & 1.34 & 1.53 & 1.78 & 1.74 & 1.58 & 1.42 & 1.36 & 1.25 \\
\hline & & $(.16)$ & $(.32)$ & $(.68)$ & $(.61)$ & $(.58)$ & $(.67)$ & $(.67)$ & $(.63)$ & $(.55)$ & $(.46)$ & $(.37)$ & $(.29)$ \\
\hline eff. exch. rate & DLN & 1.12 & 1.48 & 1.81 & 1.67 & 1.51 & 1.46 & 1.55 & 1.50 & 1.47 & 1.41 & 1.20 & 1.13 \\
\hline & & $(.11)$ & (.19) & $(.32)$ & $(.25)$ & $(.21)$ & $(.19)$ & $(.20)$ & $(.18)$ & $(.17)$ & $(.14)$ & $(.18)$ & $(.18)$ \\
\hline import deflator & DLN & 1.04 & 0.99 & 1.12 & 1.08 & 1.13 & 1.11 & 1.20 & 1.19 & 1.18 & 1.18 & 1.01 & 0.95 \\
\hline & & $(.11)$ & (.11) & $(.11)$ & $(.13)$ & $(.15)$ & $(.15)$ & $(.17)$ & $(.16)$ & $(.14)$ & $(.16)$ & $(.23)$ & $(.24)$ \\
\hline commodity price & DLN & 1.29 & 1.19 & 1.11 & 1.00 & 0.93 & 0.96 & 1.01 & 1.02 & 0.96 & 0.89 & 0.79 & 0.78 \\
\hline & & $(.14)$ & $(.21)$ & $(.21)$ & $(.20)$ & $(.20)$ & $(.19)$ & $(.18)$ & $(.20)$ & $(.20)$ & $(.15)$ & $(.21)$ & $(.23)$ \\
\hline oil prices & DLN & 1.02 & 1.06 & 1.06 & 0.92 & 1.01 & 1.03 & 1.07 & 0.98 & 0.94 & 1.01 & 1.00 & 1.00 \\
\hline & & $(.03)$ & $(.12)$ & $(.18)$ & $(.14)$ & $(.14)$ & $(.14)$ & $(.13)$ & $(.10)$ & (.11) & $(.07)$ & $(.04)$ & $(.03)$ \\
\hline
\end{tabular}

Notes: see notes to Table 1.a 
Table 2.a: HICP - bivariate forecasts: information content relative to M3

(Model 1 - Period: 1992.1 - 2000.3)

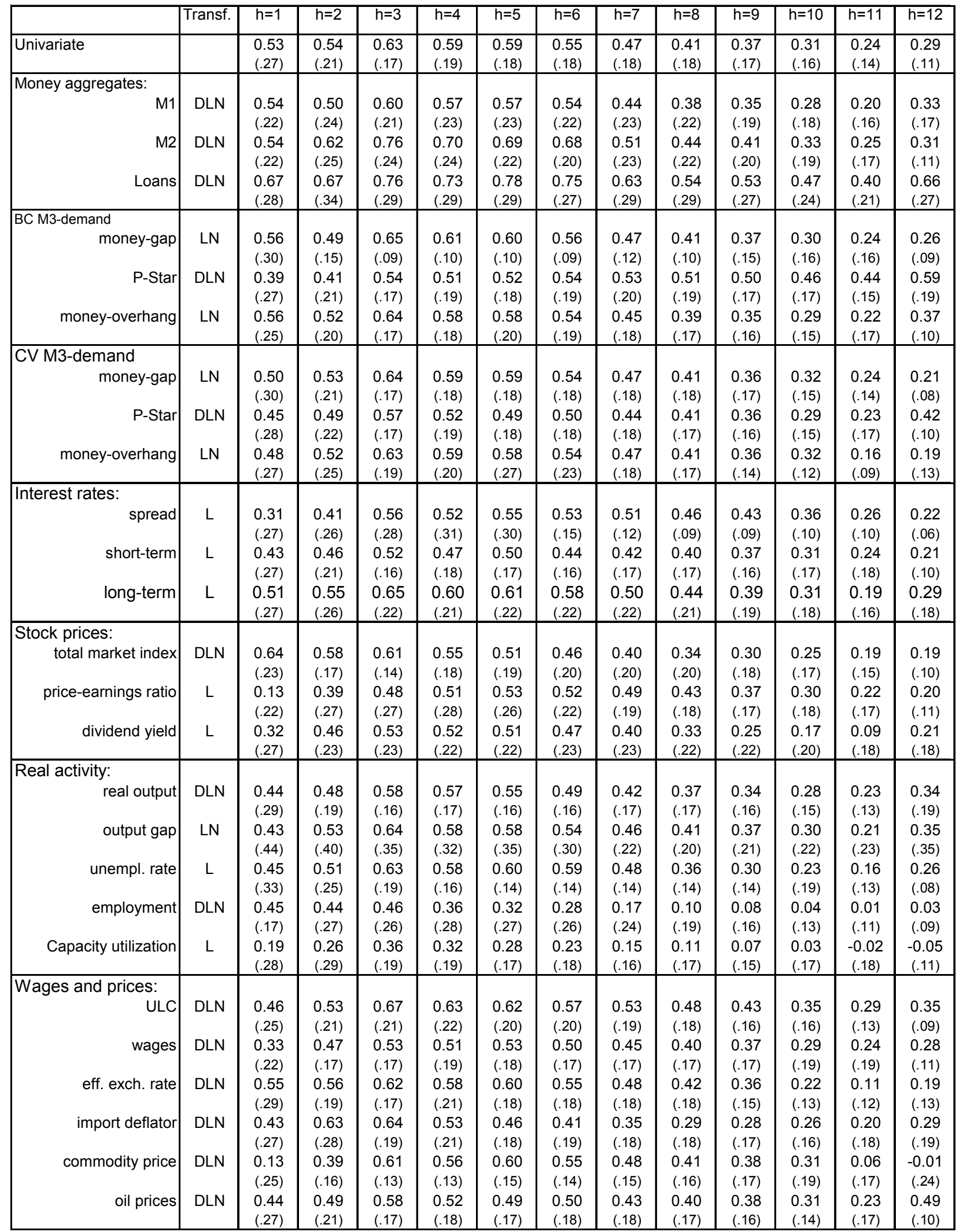

Notes: OLS estimate of lambda coefficient based on equation (11) in the text. HAC standard errors in parenthesis 
Table 2.b: Consumption deflator - bivariate forecasts: information content relative to M3

(Model 1 - Period: 1992.1 - 2000.2)

\begin{tabular}{|c|c|c|c|c|c|c|c|c|c|c|c|c|c|}
\hline & Transf. & $\mathrm{h}=1$ & $\mathrm{~h}=2$ & $\mathrm{~h}=3$ & $\mathrm{~h}=4$ & $\mathrm{~h}=5$ & $\mathrm{~h}=6$ & $\mathrm{~h}=7$ & $\mathrm{~h}=8$ & $\mathrm{~h}=9$ & $\mathrm{~h}=10$ & $\mathrm{~h}=11$ & $\mathrm{~h}=12$ \\
\hline Univariate & & $\begin{array}{l}0.71 \\
(.29)\end{array}$ & $\begin{array}{l}0.56 \\
(.18)\end{array}$ & $\begin{array}{l}0.62 \\
(.18)\end{array}$ & $\begin{array}{l}0.68 \\
(.15)\end{array}$ & $\begin{array}{l}0.64 \\
(.15)\end{array}$ & $\begin{array}{l}0.65 \\
(.14)\end{array}$ & $\begin{array}{l}0.57 \\
(.15)\end{array}$ & $\begin{array}{l}0.47 \\
(.16)\end{array}$ & $\begin{array}{l}0.37 \\
(.16)\end{array}$ & $\begin{array}{l}0.27 \\
(.16)\end{array}$ & $\begin{array}{l}0.20 \\
(.14)\end{array}$ & $\begin{array}{l}0.10 \\
(.13)\end{array}$ \\
\hline \multicolumn{14}{|l|}{ Money aggregates: } \\
\hline & DLN & $\begin{array}{l}0.55 \\
(.32)\end{array}$ & $\begin{array}{l}0.47 \\
(.21)\end{array}$ & $\begin{array}{l}0.53 \\
(.24)\end{array}$ & $\begin{array}{l}0.65 \\
(.19)\end{array}$ & $\begin{array}{l}0.60 \\
(.19)\end{array}$ & $\begin{array}{l}0.62 \\
(.18)\end{array}$ & $\begin{array}{l}0.50 \\
(.21)\end{array}$ & $\begin{array}{l}0.43 \\
\text { (.19) }\end{array}$ & $\begin{array}{l}0.33 \\
(.18)\end{array}$ & $\begin{array}{l}0.23 \\
(.18)\end{array}$ & $\begin{array}{l}0.15 \\
(.16)\end{array}$ & $\begin{array}{l}0.07 \\
(.14)\end{array}$ \\
\hline & DLN & 0.62 & 0.59 & 0.69 & 0.74 & 0.70 & 0.71 & 0.55 & 0.48 & 0.38 & 0.26 & 0.17 & 0.07 \\
\hline & & $(.38)$ & $(.25)$ & $(.25)$ & (.19) & (.19) & $(.18)$ & $(.23)$ & (.22) & $(.21)$ & $(.21)$ & (.19) & $(.17)$ \\
\hline \multirow[t]{2}{*}{ Loans } & DLN & 0.90 & 0.68 & 0.74 & 0.83 & 0.79 & 0.81 & 0.74 & 0.66 & 0.59 & 0.52 & 0.44 & 0.42 \\
\hline & & $(.38)$ & $(.28)$ & $(.32)$ & $(.24)$ & $(.26)$ & (.28) & $(.29)$ & (.28) & $(.27)$ & $(.25)$ & $(.22)$ & $(.16)$ \\
\hline \multirow{3}{*}{$\begin{array}{l}\text { BC M3-demand } \\
\text { money-gap }\end{array}$} & & & & & & & & & & & & & \\
\hline & LN & 0.68 & 0.59 & 0.64 & 0.70 & 0.66 & 0.67 & 0.59 & 0.51 & 0.37 & 0.28 & 0.20 & 0.11 \\
\hline & & $(.25)$ & (.17) & $(.17)$ & (.13) & $(.11)$ & $(.08)$ & $(.14)$ & (.13) & $(.17)$ & $(.20)$ & $(.20)$ & $(.21)$ \\
\hline \multirow{2}{*}{ P-Star } & DLN & 0.18 & 0.44 & 0.47 & 0.44 & 0.45 & 0.51 & 0.52 & 0.59 & 0.65 & 0.54 & 0.61 & 0.37 \\
\hline & & $(.30)$ & $(.20)$ & $(.18)$ & (.16) & $(.21)$ & (.19) & $(.23)$ & (.18) & $(.18)$ & (.18) & $(.16)$ & (.15) \\
\hline \multirow{2}{*}{ money-overhang } & LN & 0.61 & 0.51 & 0.63 & 0.66 & 0.61 & 0.60 & 0.45 & 0.42 & 0.30 & 0.23 & 0.19 & 0.10 \\
\hline & & $(.29)$ & $(.18)$ & $(.17)$ & (.16) & $(.16)$ & $(.15)$ & $(.16)$ & (.15) & $(.13)$ & $(.14)$ & $(.12)$ & $(.12)$ \\
\hline \multicolumn{14}{|l|}{ CV M3-demand } \\
\hline money-gap & LN & 0.70 & 0.57 & 0.63 & 0.68 & 0.65 & 0.64 & 0.57 & 0.46 & 0.36 & 0.27 & 0.17 & 0.11 \\
\hline & & $(.29)$ & $(.18)$ & $(.17)$ & (.14) & $(.14)$ & (.17) & $(.15)$ & (.15) & $(.16)$ & $(.16)$ & $(.15)$ & $(.16)$ \\
\hline \multirow{2}{*}{ P-Star } & DLN & 0.75 & 0.58 & 0.54 & 0.59 & 0.58 & 0.70 & 0.59 & 0.38 & 0.30 & 0.25 & 0.15 & 0.13 \\
\hline & & $(.28)$ & $(.18)$ & $(.25)$ & (.17) & (.19) & (.15) & $(.14)$ & (.14) & $(.16)$ & $(.15)$ & $(.15)$ & $(.14)$ \\
\hline \multirow[t]{2}{*}{ money-overhang } & LN & 0.72 & 0.57 & 0.43 & 0.62 & 0.47 & 0.47 & 0.42 & 0.42 & 0.36 & 0.28 & 0.18 & 0.04 \\
\hline & & $(.22)$ & $(.29)$ & $(.21)$ & (.18) & $(.15)$ & (.15) & $(.14)$ & (.13) & $(.12)$ & (.11) & $(.09)$ & $(.08)$ \\
\hline Interest rates: & & & & & & & & & & & & & \\
\hline \multirow[t]{2}{*}{ spread } & L & 0.44 & 0.47 & 0.59 & 0.62 & 0.61 & 0.66 & 0.62 & 0.55 & 0.51 & 0.43 & 0.32 & 0.17 \\
\hline & & $(.22)$ & (.18) & $(.21)$ & $(.22)$ & (.14) & $(.09)$ & $(.05)$ & $(.02)$ & $(.08)$ & (.10) & $(.17)$ & (.15) \\
\hline short-term & $\mathrm{L}$ & 0.57 & 0.47 & 0.53 & 0.56 & 0.50 & 0.53 & 0.54 & 0.52 & 0.41 & 0.31 & 0.16 & 0.06 \\
\hline & & $(.34)$ & $(.22)$ & $(.20)$ & (.15) & (.14) & (.13) & $(.13)$ & (.15) & (.16) & $(.19)$ & $(.19)$ & $(.21)$ \\
\hline long-term & L & 0.69 & 0.52 & 0.58 & 0.68 & 0.67 & 0.67 & 0.61 & 0.52 & 0.41 & 0.25 & 0.13 & 0.01 \\
\hline & & $(.31)$ & $(.29)$ & $(.28)$ & $(.21)$ & $(.20)$ & $(.20)$ & $(.19)$ & $(.18)$ & $(.17)$ & $(.16)$ & $(.14)$ & $(.11)$ \\
\hline Stock prices: & & & & & & & & & & & & & \\
\hline total market index & DLN & 0.51 & 0.61 & 0.59 & 0.63 & 0.58 & 0.59 & 0.52 & 0.42 & 0.35 & 0.25 & 0.18 & 0.08 \\
\hline & & (.31) & (.11) & (.12) & (.13) & (.14) & $(.14)$ & (.15) & (.17) & (.15) & (.15) & (.13) & (.13) \\
\hline price-earnings ratio & $\mathrm{L}$ & 0.45 & 0.44 & 0.51 & 0.61 & 0.61 & 0.68 & 0.59 & 0.50 & 0.40 & 0.33 & 0.17 & 0.03 \\
\hline & & $(.27)$ & $(.21)$ & $(.23)$ & $(.20)$ & $(.20)$ & $(.17)$ & $(.17)$ & (.17) & $(.17)$ & $(.16)$ & $(.16)$ & $(.21)$ \\
\hline dividend yield & $\mathrm{L}$ & 0.39 & 0.48 & 0.48 & 0.55 & 0.53 & 0.55 & 0.46 & 0.39 & 0.33 & 0.23 & 0.15 & 0.04 \\
\hline & & $(.31)$ & $(.19)$ & $(.19)$ & (.17) & $(.18)$ & (.19) & $(.20)$ & (.19) & $(.18)$ & $(.17)$ & $(.16)$ & $(.16)$ \\
\hline Real activity: & & & & & & & & & & & & & \\
\hline real output & DLN & 0.57 & 0.35 & 0.48 & 0.60 & 0.58 & 0.58 & 0.52 & 0.46 & 0.38 & 0.30 & 0.23 & 0.18 \\
\hline & & (.35) & (.18) & $(.20)$ & (.15) & (.13) & $(.13)$ & (.15) & (.14) & (.15) & (.16) & $(.14)$ & $(.12)$ \\
\hline output gap & LN & 0.39 & 0.49 & 0.56 & 0.64 & 0.63 & 0.63 & 0.54 & 0.47 & 0.37 & 0.24 & 0.17 & 0.07 \\
\hline & & $(.33)$ & $(.33)$ & $(.30)$ & (.34) & $(.32)$ & (.33) & $(.24)$ & (.26) & $(.24)$ & $(.25)$ & $(.26)$ & $(.27)$ \\
\hline unempl. rate & L & 0.74 & 0.61 & 0.68 & 0.72 & 0.70 & 0.69 & 0.61 & 0.42 & 0.30 & 0.19 & 0.13 & 0.02 \\
\hline & & $(.38)$ & $(.28)$ & $(.25)$ & (.17) & $(.18)$ & (.23) & $(.17)$ & (.17) & $(.12)$ & $(.08)$ & $(.05)$ & $(.03)$ \\
\hline employment & DLN & 0.27 & 0.13 & 0.21 & 0.35 & 0.32 & 0.35 & 0.27 & 0.20 & 0.13 & 0.07 & 0.03 & -0.02 \\
\hline & & $(.31)$ & $(.22)$ & $(.24)$ & $(.24)$ & $(.24)$ & (.25) & $(.23)$ & (.19) & $(.17)$ & $(.12)$ & (.10) & $(.08)$ \\
\hline Capacity utilization & L & 0.14 & 0.14 & 0.19 & 0.29 & 0.31 & 0.34 & 0.22 & 0.17 & 0.11 & 0.03 & -0.02 & -0.09 \\
\hline & & $(.31)$ & (.19) & $(.14)$ & $(.14)$ & $(.15)$ & $(.14)$ & $(.17)$ & (.14) & $(.13)$ & $(.15)$ & (.15) & $(.19)$ \\
\hline Wages and prices: & & & & & & & & & & & & & \\
\hline ULC & DLN & 0.63 & 0.62 & 0.70 & 0.75 & 0.68 & 0.69 & 0.64 & 0.56 & 0.44 & 0.35 & 0.22 & 0.10 \\
\hline & & $(.26)$ & $(.17)$ & (.19) & (.17) & $(.16)$ & (.15) & $(.15)$ & (.16) & $(.16)$ & $(.16)$ & $(.14)$ & $(.13)$ \\
\hline wages & DLN & 0.50 & 0.51 & 0.53 & 0.62 & 0.62 & 0.63 & 0.56 & 0.45 & 0.37 & 0.27 & 0.20 & 0.10 \\
\hline & & $(.25)$ & (.13) & $(.15)$ & (.14) & $(.14)$ & (.14) & $(.14)$ & (.15) & $(.16)$ & (.19) & $(.17)$ & $(.18)$ \\
\hline eff. exch. rate & DLN & 0.52 & 0.52 & 0.58 & 0.65 & 0.62 & 0.62 & 0.54 & 0.45 & 0.36 & 0.19 & 0.10 & 0.02 \\
\hline & & $(.26)$ & $(.18)$ & $(.16)$ & (.15) & $(.14)$ & (.12) & $(.13)$ & (.14) & $(.14)$ & $(.13)$ & (.11) & $(.12)$ \\
\hline import deflator & DLN & 0.64 & 0.55 & 0.63 & 0.64 & 0.54 & 0.57 & 0.52 & 0.43 & 0.34 & 0.28 & 0.19 & 0.07 \\
\hline & & $(.30)$ & (.18) & (.18) & (.15) & (.15) & (.14) & $(.15)$ & $(.17)$ & $(.16)$ & (.18) & (.16) & (.19) \\
\hline commodity price & DLN & 0.64 & 0.57 & 0.61 & 0.68 & 0.65 & 0.65 & 0.57 & 0.46 & 0.38 & 0.25 & 0.07 & -0.06 \\
\hline & & $(.34)$ & $(.18)$ & $(.16)$ & (.17) & $(.17)$ & (.18) & $(.26)$ & (.28) & $(.24)$ & $(.16)$ & $(.12)$ & $(.09)$ \\
\hline oil prices & DLN & 0.78 & 0.57 & 0.61 & 0.60 & 0.58 & 0.66 & 0.51 & 0.38 & 0.26 & 0.20 & 0.06 & 0.06 \\
\hline & & $(.28)$ & $(.18)$ & (.19) & (.16) & $(.16)$ & (.14) & $(.13)$ & (.12) & $(.16)$ & $(.15)$ & (.15) & $(.12)$ \\
\hline
\end{tabular}

Notes: OLS estimate of lambda coefficient based on equation (11) in the text. HAC standard errors in parenthesis 
Table 3: HICP - forecast MSE relative to the univariate model for different sub-periods

\begin{tabular}{|c|c|c|c|c|c|c|c|c|c|c|c|c|c|c|c|}
\hline & & \multicolumn{7}{|c|}{ HICP - Period: 1995.1 - 2000.3} & \multicolumn{7}{|c|}{ Consumption deflator - Period: 1998.1 - 2000.2} \\
\hline & Transf. & $h=1$ & $\mathrm{~h}=2$ & $\mathrm{~h}=4$ & $\mathrm{~h}=6$ & $\mathrm{~h}=8$ & $\mathrm{~h}=10$ & $\mathrm{~h}=12$ & $\mathrm{~h}=1$ & $\mathrm{~h}=2$ & $\mathrm{~h}=4$ & $\mathrm{~h}=6$ & $\mathrm{~h}=8$ & $\mathrm{~h}=10$ & $\mathrm{~h}=12$ \\
\hline univariate (\% RMSE) & & 0.43 & 0.55 & 0.58 & 0.63 & 0.74 & 0.84 & 0.96 & 0.46 & 0.59 & 0.68 & 0.74 & 0.81 & 0.93 & 1.11 \\
\hline Money aggregates: & & & & & & & & & & & & & & & \\
\hline M1 & DLN & 1.12 & 1.03 & 1.04 & 1.05 & 1.07 & 1.02 & 1.04 & 0.96 & 1.03 & 1.04 & 1.07 & 1.14 & 1.07 & 1.00 \\
\hline M2 & DLN & 1.08 & 0.96 & 0.87 & 0.89 & 0.85 & 0.78 & 0.76 & 0.92 & 0.87 & 0.78 & 0.76 & 0.91 & 0.85 & 0.77 \\
\hline M3 & DLN & 0.94 & 1.58 & 1.60 & 1.53 & 0.93 & 0.64 & 0.31 & 0.94 & 0.90 & 0.82 & 0.72 & 0.47 & 0.28 & 0.24 \\
\hline $\mathrm{M} 3 \mathrm{mv}$ & DLN & 1.15 & 1.34 & 1.58 & 1.46 & 0.86 & 0.60 & 0.41 & 0.94 & 0.91 & 0.80 & 0.69 & 0.44 & 0.26 & 0.30 \\
\hline Loans & DLN & 1.00 & 0.92 & 0.99 & 0.94 & 0.73 & 0.53 & 0.44 & 0.92 & 0.94 & 1.02 & 0.90 & 1.03 & 0.73 & 0.56 \\
\hline BC M3-demand & & & & & & & & & & & & & & & \\
\hline money-gap & LN & 1.01 & 1.06 & 1.02 & 0.92 & 0.77 & 0.44 & 0.39 & 1.00 & 1.03 & 1.02 & 0.96 & 0.76 & 0.44 & 0.33 \\
\hline P-Star & DLN & 0.78 & 1.04 & 0.76 & 0.63 & 0.45 & 0.54 & 0.59 & 0.89 & 0.94 & 0.67 & 0.66 & 0.52 & 0.57 & 0.52 \\
\hline money-overhang & $\mathrm{LN}$ & 1.01 & 1.04 & 0.99 & 0.95 & 0.71 & 0.52 & 0.39 & 1.00 & 1.05 & 1.03 & 0.97 & 0.78 & 0.65 & 0.50 \\
\hline CV M3-demand & & & & & & & & & & & & & & & \\
\hline money-gap & LN & 1.01 & 1.11 & 1.08 & 1.13 & 1.34 & 1.34 & 1.36 & 1.02 & 1.03 & 1.03 & 1.02 & 1.01 & 0.98 & 1.04 \\
\hline P-Star & DLN & 1.01 & 1.05 & 1.00 & 1.00 & 1.00 & 0.99 & 0.98 & 1.03 & 0.99 & 1.00 & 1.00 & 1.00 & 0.99 & 0.99 \\
\hline money-overhang & $\mathrm{LN}$ & 1.02 & 1.10 & 1.13 & 1.10 & 1.03 & 0.83 & 0.79 & 1.03 & 1.07 & 1.05 & 1.01 & 0.90 & 0.87 & 0.89 \\
\hline Interest rates: & & & & & & & & & & & & & & & \\
\hline spread & L & 1.02 & 1.00 & 0.96 & 0.91 & 1.88 & 2.63 & 4.93 & 1.26 & 1.46 & 1.60 & 1.10 & 0.55 & 0.64 & 0.83 \\
\hline short-term & L & 1.10 & 1.19 & 0.95 & 0.56 & 0.57 & 0.76 & 1.00 & 1.40 & 1.74 & 2.10 & 1.55 & 0.83 & 0.79 & 1.04 \\
\hline long-term & $\mathrm{L}$ & 1.13 & 1.35 & 1.37 & 1.32 & 1.04 & 1.20 & 1.45 & 1.00 & 0.97 & 1.00 & 1.01 & 0.93 & 0.90 & 0.92 \\
\hline $\begin{array}{l}\text { Stock prices: } \\
\text { total market index }\end{array}$ & DLN & 0.97 & 0.88 & 1.02 & 1.01 & 1.08 & 1.18 & 1.21 & 1.02 & 1.01 & 0.95 & 0.95 & 1.01 & 1.07 & 1.08 \\
\hline price-earnings ratio & $\mathrm{L}$ & 1.74 & 1.42 & 1.29 & 0.95 & 0.87 & 0.85 & 0.91 & 1.98 & 1.72 & 1.63 & 1.21 & 0.92 & 0.90 & 0.94 \\
\hline dividend yield & $\mathrm{L}$ & 1.03 & 1.13 & 0.99 & 0.91 & 1.03 & 1.39 & 1.64 & 1.31 & 1.30 & 1.13 & 1.00 & 0.94 & 0.98 & 1.03 \\
\hline Real activity: & & & & & & & & & & & & & & & \\
\hline real output & DLN & 1.01 & 1.00 & 0.98 & 0.97 & 0.88 & 0.91 & 0.92 & 1.00 & 0.97 & 1.00 & 1.01 & 0.93 & 0.90 & 0.92 \\
\hline output gap & LN & 1.00 & 1.02 & 1.06 & 1.06 & 0.94 & 0.94 & 0.87 & 1.00 & 1.02 & 1.05 & 1.04 & 1.05 & 1.02 & 1.00 \\
\hline unempl. rate & L & 0.86 & 0.63 & 0.72 & 0.74 & 0.46 & 0.40 & 0.46 & 0.68 & 0.51 & 0.38 & 0.29 & 0.12 & 0.06 & 0.02 \\
\hline & $\mathrm{DL}$ & 1.01 & 0.95 & 0.99 & 0.96 & 0.97 & 1.01 & 1.01 & 1.01 & 0.97 & 0.98 & 0.93 & 0.96 & 0.93 & 0.93 \\
\hline employment & DLN & 1.03 & 0.98 & 0.94 & 0.90 & 0.75 & 0.75 & 1.22 & 1.00 & 0.98 & 0.95 & 0.87 & 0.90 & 0.85 & 0.83 \\
\hline Capacity utilization & $\mathrm{L}$ & 1.02 & 0.96 & 0.96 & 0.89 & 1.84 & 2.18 & 2.50 & 1.04 & 1.04 & 0.99 & 0.97 & 0.84 & 0.84 & 0.85 \\
\hline Wages and prices: & & & & & & & & & & & & & & & \\
\hline ULC & DLN & 1.13 & 1.15 & 0.91 & 0.84 & 0.83 & 0.80 & 0.85 & 1.42 & 1.25 & 1.04 & 0.98 & 0.83 & 0.85 & 0.88 \\
\hline wages & DLN & 1.25 & 1.16 & 0.93 & 0.87 & 0.78 & 0.80 & 0.88 & 1.34 & 1.39 & 1.11 & 1.09 & 0.82 & 0.84 & 0.88 \\
\hline eff. exch. rate & DLN & 1.10 & 0.98 & 1.06 & 1.06 & 1.03 & 1.02 & 1.01 & 0.50 & 0.78 & 1.14 & 1.08 & 0.98 & 0.97 & 0.96 \\
\hline import deflator & DLN & 0.93 & 0.97 & 0.98 & 0.96 & 0.94 & 1.00 & 0.99 & 0.82 & 0.97 & 1.02 & 0.94 & 0.92 & 0.96 & 0.97 \\
\hline commodity price & DLN & 0.96 & 0.86 & 1.02 & 1.40 & 1.45 & 1.29 & 1.25 & 0.91 & 0.80 & 0.92 & 1.03 & 1.26 & 1.11 & 1.25 \\
\hline oil prices & DLN & 1.64 & 1.25 & 1.02 & 0.96 & 0.99 & 0.98 & 0.98 & 1.88 & 1.56 & 1.22 & 1.04 & 1.00 & 0.98 & 0.98 \\
\hline
\end{tabular}

Notes: see notes to Table 1.a 
Table 4. HICP - model 2 forecast MSE relative to the model 1 univariate model

(Model 2 - Period: 1992.1 - 2000.3)

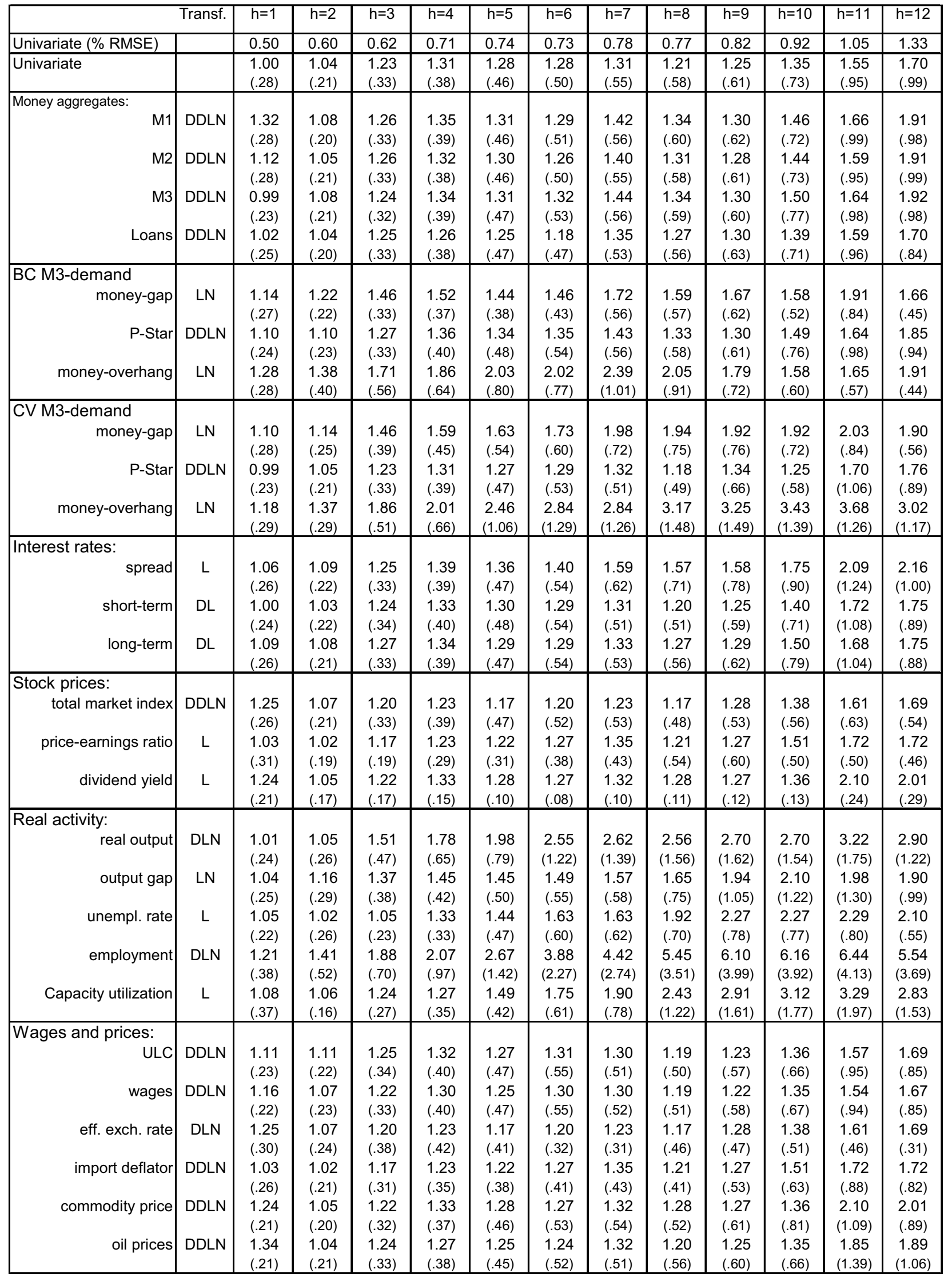

Notes: All results are for simulated out of sample forecasts according to equation (10) in the text. See also notes to Table 1.a. 
Table 5.a. HICP - Multivariate models: forecast MSE relative to the univariate model

(Period: 1992.1 - 2000.3)

\begin{tabular}{|c|c|c|c|c|c|c|c|c|c|c|c|c|}
\hline & $\mathrm{h}=1$ & $\mathrm{~h}=2$ & $\mathrm{~h}=3$ & $\mathrm{~h}=4$ & $\mathrm{~h}=5$ & $\mathrm{~h}=6$ & $\mathrm{~h}=7$ & $\mathrm{~h}=8$ & $\mathrm{~h}=9$ & $\mathrm{~h}=10$ & $\mathrm{~h}=11$ & $\mathrm{~h}=12$ \\
\hline univariate (\% RMSE) & 0.50 & 0.59 & 0.56 & 0.62 & 0.65 & 0.65 & 0.68 & 0.70 & 0.73 & 0.79 & 0.84 & 1.02 \\
\hline \multicolumn{13}{|l|}{ All variables: } \\
\hline \multirow[t]{2}{*}{ Mean } & $\begin{array}{l}0.96 \\
(05)\end{array}$ & 0.92 & 0.92 & 0.91 & 0.91 & 0.91 & 0.89 & 0.90 & 0.93 & 0.95 & 0.99 & 0.96 \\
\hline & & & $(.05)$ & $(.06)$ & $\begin{array}{l}(.07) \\
0.93\end{array}$ & (.07) & $\begin{array}{l}(.08) \\
0.93\end{array}$ & (.10) & $(.13)$ & (.14) & (.15) & $\begin{array}{l}(.11) \\
097\end{array}$ \\
\hline Median & $\begin{array}{l}0.99 \\
(.06)\end{array}$ & $\begin{array}{l}0.94 \\
(.05)\end{array}$ & $\begin{array}{l}0.96 \\
(.05)\end{array}$ & $\begin{array}{l}0.94 \\
(.05)\end{array}$ & $\begin{array}{l}0.93 \\
(.04)\end{array}$ & $\begin{array}{l}0.94 \\
(.05)\end{array}$ & $\begin{array}{l}0.93 \\
(.07)\end{array}$ & $\begin{array}{l}0.94 \\
(.08)\end{array}$ & $\begin{array}{l}0.95 \\
(.09)\end{array}$ & $\begin{array}{l}0.97 \\
(.10)\end{array}$ & $\begin{array}{l}0.97 \\
(.11)\end{array}$ & $\begin{array}{l}0.97 \\
(.19)\end{array}$ \\
\hline \multirow[t]{2}{*}{ Ridge-regression } & 0.99 & 0.90 & 0.93 & 0.99 & 0.76 & 0.72 & 0.90 & 0.89 & 1.00 & 1.27 & 1.42 & 2.22 \\
\hline & $(.08)$ & (.13) & $(.14)$ & $(.21)$ & $(.14)$ & (.14) & $(.26)$ & $(.28)$ & (.38) & $(.55)$ & $(.61)$ & (1.31) \\
\hline \multirow[t]{2}{*}{ Single factor } & 1.27 & 1.46 & 1.32 & 1.35 & 1.55 & 1.36 & 1.29 & 1.34 & 1.39 & 1.31 & 1.26 & 0.98 \\
\hline & $(.34)$ & $(.26)$ & $(.28)$ & $(.39)$ & $(.54)$ & $(.59)$ & $(.61)$ & $(.63)$ & $(.70)$ & $(.71)$ & $(.68)$ & $(.50)$ \\
\hline \multirow[t]{2}{*}{ Multi factors } & 1.03 & 1.12 & 1.31 & 1.31 & 1.29 & 1.24 & 1.27 & 1.31 & 1.29 & 1.30 & 1.20 & 0.93 \\
\hline & $(.20)$ & $(.22)$ & $(.28)$ & $(.33)$ & $(.44)$ & $(.51)$ & $(.52)$ & $(.62)$ & $(.74)$ & $(.85)$ & $(.78)$ & $(.57)$ \\
\hline \multicolumn{13}{|l|}{ Money aggregates: } \\
\hline \multirow[t]{2}{*}{ Mean } & 0.90 & 0.85 & 0.88 & 0.85 & 0.79 & 0.74 & 0.71 & 0.63 & 0.57 & 0.55 & 0.57 & 0.79 \\
\hline & (.10) & (.11) & (.19) & $(.20)$ & (.19) & (.18) & (.19) & $(.22)$ & $(.30)$ & $(.29)$ & $(.34)$ & $(.30)$ \\
\hline \multirow[t]{2}{*}{ Median } & 0.91 & 0.82 & 0.86 & 0.86 & 0.82 & 0.77 & 0.77 & 0.68 & 0.62 & 0.62 & 0.64 & 0.85 \\
\hline & $(.03)$ & $(.02)$ & $(.02)$ & $(.02)$ & $(.03)$ & $(.02)$ & $(.02)$ & $(.02)$ & (.02) & $(.02)$ & $(.02)$ & $(.02)$ \\
\hline \multirow[t]{2}{*}{ Ridge-regression } & 0.90 & 0.88 & 0.94 & 0.93 & 0.81 & 0.72 & 0.84 & 0.72 & 0.65 & 0.67 & 0.68 & 0.83 \\
\hline & $(.18)$ & $(.09)$ & $(.09)$ & $(.10)$ & $(.08)$ & $(.07)$ & $(.11)$ & $(.10)$ & (.11) & $(.13)$ & $(.14)$ & $(.21)$ \\
\hline \multirow[t]{2}{*}{ Single factor } & 0.90 & 0.86 & 0.87 & 0.86 & 0.81 & 0.72 & 0.78 & 0.74 & 0.63 & 0.58 & 0.55 & 0.50 \\
\hline & $(.24)$ & (.10) & (.16) & $(.14)$ & $(.12)$ & $(.09)$ & $(.14)$ & (.11) & $(.09)$ & $(.08)$ & $(.08)$ & $(.05)$ \\
\hline \multirow[t]{2}{*}{ Multi factors } & 0.95 & 0.83 & 0.92 & 0.84 & 0.78 & 0.64 & 0.75 & 0.68 & 0.57 & 0.52 & 0.51 & 0.42 \\
\hline & $(.23)$ & $(.09)$ & $(.14)$ & $(.12)$ & $(.11)$ & $(.09)$ & $(.11)$ & $(.10)$ & $(.08)$ & $(.08)$ & $(.07)$ & $(.05)$ \\
\hline \multicolumn{13}{|l|}{ Real activity: } \\
\hline \multirow[t]{2}{*}{ Mean } & 1.03 & 0.99 & 0.97 & 0.95 & 0.96 & 0.94 & 0.94 & 1.00 & 1.09 & 1.13 & 1.06 & 0.93 \\
\hline & $(.03)$ & $(.02)$ & $(.02)$ & $(.02)$ & $(.03)$ & $(.03)$ & $(.02)$ & $(.02)$ & $(.03)$ & $(.04)$ & $(.04)$ & $(.03)$ \\
\hline \multirow[t]{2}{*}{ Median } & 1.03 & 1.00 & 0.99 & 0.98 & 0.97 & 0.96 & 0.94 & 0.96 & 1.04 & 1.07 & 1.06 & 0.98 \\
\hline & $(.09)$ & (.12) & $(.22)$ & $(.21)$ & (.19) & (.15) & $(.11)$ & (.11) & $(.13)$ & $(.12)$ & $(.12)$ & $(.10)$ \\
\hline Ridge-regression & 1.04 & 0.92 & 0.94 & 0.96 & 0.82 & 0.79 & 0.89 & 0.97 & 1.18 & 1.34 & 1.26 & 1.47 \\
\hline & $(.11)$ & $(.11)$ & (.11) & (.18) & (.13) & (.16) & $(.24)$ & $(.31)$ & $(.46)$ & $(.57)$ & $(.50)$ & $(.73)$ \\
\hline Single factor & 0.97 & 0.99 & 0.93 & 0.90 & 0.86 & 0.77 & 0.80 & 0.91 & 1.01 & 1.08 & 1.04 & 0.93 \\
\hline & (.13) & $(.06)$ & $(.06)$ & $(.06)$ & $(.07)$ & $(.09)$ & $(.09)$ & (.11) & (.19) & $(.27)$ & $(.26)$ & (.13) \\
\hline Multi factors & 1.03 & 0.92 & 0.94 & 0.91 & 0.95 & 1.00 & 0.98 & 1.03 & 1.63 & 1.64 & 1.66 & 1.28 \\
\hline & $(.08)$ & $(.05)$ & $(.04)$ & $(.07)$ & $(.08)$ & (.13) & $(.12)$ & $(.14)$ & $(.63)$ & $(.61)$ & $(.73)$ & $(.38)$ \\
\hline Wages and prices: & & & & & & & & & & & & \\
\hline Mean & 0.96 & 0.97 & 1.00 & 1.00 & 1.00 & 1.02 & 0.98 & 0.99 & 0.99 & 1.04 & 1.22 & 1.12 \\
\hline & $(.14)$ & (.14) & $(.11)$ & $(.08)$ & $(.08)$ & $(.08)$ & $(.13)$ & (.12) & (.11) & $(.12)$ & $(.12)$ & $(.14)$ \\
\hline Median & 0.96 & 0.96 & 1.02 & 1.00 & 0.97 & 0.99 & 0.97 & 0.96 & 0.98 & 1.03 & 1.16 & 1.06 \\
\hline & $(.14)$ & (.14) & $(.11)$ & $(.11)$ & (.11) & $(.07)$ & $(.05)$ & $(.05)$ & $(.07)$ & $(.09)$ & (.09) & $(.18)$ \\
\hline Ridge-regression & 0.98 & 0.90 & 0.95 & 1.02 & 0.88 & 0.89 & 0.97 & 0.98 & 1.02 & 1.23 & 1.57 & 1.74 \\
\hline & $(.09)$ & $(.08)$ & $(.08)$ & $(.10)$ & $(.07)$ & $(.07)$ & $(.10)$ & $(.10)$ & (.11) & $(.21)$ & $(.38)$ & $(.53)$ \\
\hline Single factor & 0.99 & 0.88 & 0.89 & 0.95 & 1.00 & 0.93 & 0.93 & 1.01 & 1.03 & 1.09 & 1.19 & 1.05 \\
\hline & $(.14)$ & $(.08)$ & $(.05)$ & $(.04)$ & $(.03)$ & $(.02)$ & $(.03)$ & $(.02)$ & $(.02)$ & $(.07)$ & $(.17)$ & $(.07)$ \\
\hline Multi factors & 0.99 & 0.81 & 0.86 & 0.88 & 0.90 & 1.01 & 1.04 & 1.06 & 1.07 & 1.09 & 1.10 & 0.92 \\
\hline & $(.15)$ & (.10) & $(.06)$ & $(.06)$ & $(.05)$ & $(.03)$ & $(.03)$ & $(.03)$ & $(.03)$ & $(.03)$ & $(.02)$ & $(.14)$ \\
\hline Int. rates and stock prices: & & & & & & & & & & & & \\
\hline Mean & 1.01 & 0.99 & 1.02 & 1.00 & 1.06 & 1.13 & 1.11 & 1.12 & 1.20 & 1.20 & 1.29 & 1.22 \\
\hline & $(.06)$ & $(.04)$ & $(.01)$ & $(.01)$ & $(.01)$ & $(.02)$ & $(.04)$ & $(.05)$ & $(.04)$ & $(.05)$ & $(.05)$ & (.11) \\
\hline Median & 1.02 & 1.02 & 1.10 & 1.06 & 1.06 & 1.07 & 1.02 & 1.02 & 1.02 & 1.05 & 1.07 & 1.08 \\
\hline & $(.11)$ & $(.07)$ & $(.05)$ & $(.07)$ & (.10) & (.11) & $(.15)$ & (.19) & $(.21)$ & $(.21)$ & $(.56)$ & $(.22)$ \\
\hline Ridge-regression & 1.02 & 0.94 & 1.00 & 1.00 & 0.93 & 0.95 & 1.03 & 1.02 & 1.10 & 1.22 & 1.37 & 1.86 \\
\hline & $(.12)$ & (.14) & $(.23)$ & $(.24)$ & $(.23)$ & $(.21)$ & $(.27)$ & $(.30)$ & (.38) & $(.46)$ & $(.54)$ & $(.93)$ \\
\hline Single factor & 1.08 & 1.23 & 1.25 & 1.13 & 1.23 & 0.99 & 0.90 & 0.94 & 0.94 & 0.93 & 0.96 & 0.79 \\
\hline & $(.24)$ & $(.26)$ & (.38) & $(.38)$ & $(.36)$ & (.29) & (.23) & $(.21)$ & $(.22)$ & $(.20)$ & (.19) & (.17) \\
\hline Multi factors & 0.96 & 1.30 & 1.50 & 1.44 & 1.66 & 1.69 & 1.48 & 1.56 & 1.63 & 1.55 & 1.75 & 1.43 \\
\hline & (.19) & $(.27)$ & $(.39)$ & $(.41)$ & $(.47)$ & $(.55)$ & $(.53)$ & $(.66)$ & $(.75)$ & $(.73)$ & $(.87)$ & $(.67)$ \\
\hline
\end{tabular}

Notes: see notes to Table 1.a and the text in section 4 
Table 5.b. Consumption deflator - Multivariate models: forecast MSE relative to the univariate model

(Period: 1992.1 - 2000.2)

\begin{tabular}{|c|c|c|c|c|c|c|c|c|c|c|c|c|}
\hline & $\mathrm{h}=1$ & $\mathrm{~h}=2$ & $\mathrm{~h}=3$ & $\mathrm{~h}=4$ & $\mathrm{~h}=5$ & $\mathrm{~h}=6$ & $\mathrm{~h}=7$ & $\mathrm{~h}=8$ & $\mathrm{~h}=9$ & $\mathrm{~h}=10$ & $\mathrm{~h}=11$ & $\mathrm{~h}=12$ \\
\hline univariate (\% RMSE) & 0.80 & 0.68 & 0.60 & 0.61 & 0.64 & 0.66 & 0.71 & 0.79 & 0.88 & 0.96 & 0.99 & 1.08 \\
\hline \multicolumn{13}{|l|}{ All variables: } \\
\hline \multirow[t]{2}{*}{ Mean } & 0.95 & 0.90 & 0.87 & 0.86 & 0.82 & 0.77 & 0.79 & 0.76 & 0.73 & 0.71 & 0.78 & 0.80 \\
\hline & $(.04)$ & $(.05)$ & $(.08)$ & (.10) & $(.09)$ & $(.09)$ & $(.09)$ & $(.09)$ & $(.08)$ & $(.08)$ & $(.10)$ & $(.08)$ \\
\hline \multirow[t]{2}{*}{ Median } & 0.96 & 0.91 & 0.89 & 0.88 & 0.87 & 0.87 & 0.87 & 0.87 & 0.86 & 0.84 & 0.86 & 0.89 \\
\hline & $(.02)$ & $(.03)$ & $(.03)$ & $(.04)$ & $(.04)$ & $(.04)$ & $(.04)$ & $(.05)$ & $(.03)$ & $(.02)$ & $(.03)$ & $(.03)$ \\
\hline \multirow[t]{2}{*}{ Ridge-regression } & 0.97 & 0.88 & 0.85 & 0.78 & 0.69 & 0.66 & 0.77 & 0.75 & 0.84 & 0.91 & 1.04 & 1.35 \\
\hline & $(.13)$ & $(.16)$ & (.15) & (.18) & (.16) & $(.17)$ & (.26) & $(.24)$ & $(.31)$ & $(.36)$ & $(.39)$ & $(.57)$ \\
\hline \multirow[t]{2}{*}{ Single factor } & 1.18 & 1.29 & 1.46 & 1.48 & 1.63 & 1.52 & 1.30 & 1.13 & 0.90 & 0.79 & 0.77 & 0.75 \\
\hline & (.35) & $(.34)$ & $(.38)$ & (.45) & $(.60)$ & $(.65)$ & $(.58)$ & $(.52)$ & $(.41)$ & $(.38)$ & $(.37)$ & $(.30)$ \\
\hline \multirow[t]{2}{*}{ Multi factors } & 1.11 & 1.15 & 1.19 & 1.23 & 1.25 & 1.08 & 0.99 & 0.95 & 0.82 & 0.76 & 0.74 & 0.75 \\
\hline & $(.32)$ & $(.32)$ & $(.31)$ & $(.34)$ & $(.40)$ & $(.42)$ & $(.38)$ & $(.42)$ & $(.43)$ & $(.42)$ & $(.43)$ & $(.38)$ \\
\hline \multicolumn{13}{|l|}{ Money aggregates: } \\
\hline \multirow[t]{2}{*}{ Mean } & 0.95 & 0.88 & 0.88 & 0.86 & 0.79 & 0.77 & 0.78 & 0.63 & 0.57 & 0.54 & 0.54 & 0.55 \\
\hline & $(.07)$ & $(.06)$ & $(.08)$ & $(.08)$ & $(.08)$ & $(.07)$ & $(.08)$ & $(.08)$ & $(.07)$ & $(.07)$ & $(.09)$ & $(.09)$ \\
\hline \multirow[t]{2}{*}{ Median } & 0.95 & 0.87 & 0.83 & 0.81 & 0.78 & 0.74 & 0.77 & 0.66 & 0.61 & 0.57 & 0.58 & 0.58 \\
\hline & $(.06)$ & $(.05)$ & $(.05)$ & $(.06)$ & $(.06)$ & $(.07)$ & (.10) & (.10) & $(.09)$ & $(.08)$ & (.09) & $(.08)$ \\
\hline \multirow[t]{2}{*}{ Ridge-regression } & 0.95 & 0.87 & 0.90 & 0.86 & 0.78 & 0.78 & 0.83 & 0.65 & 0.61 & 0.60 & 0.59 & 0.66 \\
\hline & $(.10)$ & $(.10)$ & $(.10)$ & $(.09)$ & $(.08)$ & $(.08)$ & (.11) & $(.08)$ & $(.09)$ & $(.11)$ & $(.10)$ & $(.14)$ \\
\hline \multirow[t]{2}{*}{ Single factor } & 0.95 & 1.01 & 0.92 & 0.94 & 0.81 & 0.79 & 0.93 & 0.76 & 0.65 & 0.57 & 0.53 & 0.52 \\
\hline & (.10) & (.10) & (.13) & (.12) & (.12) & (.10) & (.19) & (.14) & $(.08)$ & $(.06)$ & $(.07)$ & $(.08)$ \\
\hline \multirow[t]{2}{*}{ Multi factors } & 0.88 & 0.70 & 0.92 & 0.89 & 0.74 & 0.62 & 0.65 & 0.54 & 0.42 & 0.39 & 0.39 & 0.34 \\
\hline & $(.07)$ & $(.10)$ & $(.11)$ & (.09) & (.09) & $(.09)$ & (.11) & (.08) & $(.07)$ & $(.06)$ & $(.08)$ & $(.07)$ \\
\hline \multicolumn{13}{|l|}{ Real activity: } \\
\hline \multirow[t]{2}{*}{ Mean } & 1.00 & 1.04 & 1.01 & 1.00 & 0.91 & 0.84 & 0.82 & 0.84 & 0.79 & 0.71 & 0.71 & 0.67 \\
\hline & $(.07)$ & $(.09)$ & (.13) & (.19) & (.16) & $(.17)$ & (.16) & (.18) & $(.17)$ & (.15) & $(.15)$ & $(.12)$ \\
\hline Median & 0.97 & 1.00 & 0.94 & 0.97 & 0.89 & 0.87 & 0.85 & 0.90 & 0.88 & 0.80 & 0.79 & 0.76 \\
\hline & $(.04)$ & $(.07)$ & $(.07)$ & $(.12)$ & $(.09)$ & $(.10)$ & (.12) & (.15) & $(.11)$ & $(.11)$ & $(.11)$ & $(.12)$ \\
\hline Ridge-regression & 1.00 & 1.00 & 0.97 & 0.92 & 0.81 & 0.75 & 0.76 & 0.80 & 0.79 & 0.73 & 0.73 & 0.77 \\
\hline & (.14) & $(.17)$ & $(.18)$ & (.23) & $(.20)$ & $(.21)$ & (.24) & (.26) & $(.27)$ & $(.24)$ & $(.22)$ & $(.24)$ \\
\hline Single factor & 1.03 & 1.04 & 0.97 & 0.90 & 0.87 & 0.84 & 0.80 & 0.79 & 0.87 & 0.93 & 0.91 & 0.83 \\
\hline & (.13) & $(.20)$ & (.14) & (.23) & $(.38)$ & (.38) & $(.25)$ & $(.42)$ & (.53) & $(.59)$ & (.45) & (.41) \\
\hline Multi factors & 1.02 & 1.14 & 1.08 & 1.19 & 1.35 & 1.28 & 1.06 & 1.25 & 1.44 & 1.37 & 1.11 & 1.11 \\
\hline & (.13) & $(.20)$ & $(.14)$ & (.23) & $(.38)$ & $(.38)$ & $(.25)$ & (.42) & $(.53)$ & $(.59)$ & $(.45)$ & $(.41)$ \\
\hline Wages and prices: & & & & & & & & & & & & \\
\hline Mean & 0.97 & 0.94 & 0.91 & 0.92 & 0.96 & 0.94 & 0.93 & 0.90 & 0.88 & 0.92 & 1.12 & 1.14 \\
\hline & $(.04)$ & $(.03)$ & $(.02)$ & $(.02)$ & (.03) & $(.02)$ & $(.03)$ & $(.03)$ & $(.04)$ & $(.05)$ & $(.20)$ & $(.17)$ \\
\hline Median & 0.97 & 0.95 & 0.94 & 0.93 & 0.95 & 0.95 & 0.95 & 0.94 & 0.93 & 0.93 & 1.10 & 1.11 \\
\hline & $(.03)$ & $(.03)$ & $(.02)$ & $(.02)$ & $(.02)$ & $(.01)$ & $(.02)$ & $(.02)$ & $(.03)$ & $(.03)$ & $(.16)$ & $(.15)$ \\
\hline Ridge-regression & 0.95 & 0.87 & 0.84 & 0.85 & 0.87 & 0.87 & 0.92 & 0.92 & 0.99 & 1.12 & 1.44 & 1.65 \\
\hline & $(.05)$ & $(.07)$ & $(.06)$ & $(.08)$ & $(.07)$ & $(.07)$ & $(.11)$ & $(.09)$ & $(.12)$ & (.19) & $(.33)$ & $(.39)$ \\
\hline Single factor & 1.00 & 0.87 & 0.87 & 0.95 & 0.99 & 1.02 & 0.96 & 0.96 & 0.98 & 0.99 & 1.01 & 0.99 \\
\hline & (.14) & (.13) & $(.08)$ & $(.09)$ & $(.06)$ & $(.06)$ & $(.05)$ & $(.06)$ & $(.04)$ & $(.05)$ & $(.04)$ & $(.03)$ \\
\hline Multi factors & 0.89 & 0.77 & 0.83 & 0.91 & 1.02 & 1.05 & 0.98 & 0.92 & 0.92 & 0.93 & 0.95 & 0.87 \\
\hline & $(.16)$ & $(.14)$ & $(.11)$ & (.11) & $(.07)$ & $(.06)$ & $(.06)$ & (.10) & $(.07)$ & $(.04)$ & $(.04)$ & $(.06)$ \\
\hline Int. rates and stock prices: & & & & & & & & & & & & \\
\hline Mean & 0.97 & 0.89 & 0.90 & 0.94 & 0.99 & 0.95 & 1.00 & 0.97 & 0.94 & 0.91 & 1.03 & 1.11 \\
\hline & $(.11)$ & (.15) & (.18) & $(.21)$ & $(.23)$ & $(.21)$ & $(.24)$ & $(.23)$ & $(.24)$ & $(.24)$ & $(.26)$ & $(.24)$ \\
\hline Median & 0.99 & 0.92 & 0.92 & 0.94 & 0.97 & 0.91 & 0.93 & 0.87 & 0.85 & 0.85 & 0.92 & 1.00 \\
\hline & $(.10)$ & $(.16)$ & (.19) & $(.20)$ & $(.20)$ & (.15) & (.15) & (.13) & $(.11)$ & $(.10)$ & $(.11)$ & $(.08)$ \\
\hline Ridge-regression & 0.97 & 0.84 & 0.85 & 0.84 & 0.84 & 0.80 & 0.90 & 0.87 & 0.93 & 0.98 & 1.18 & 1.47 \\
\hline & (.10) & $(.14)$ & $(.21)$ & $(.24)$ & $(.26)$ & $(.24)$ & (.31) & $(.29)$ & $(.35)$ & $(.39)$ & $(.47)$ & $(.59)$ \\
\hline Single factor & 1.25 & 1.29 & 1.37 & 1.43 & 1.48 & 1.20 & 1.04 & 0.89 & 0.72 & 0.70 & 0.74 & 0.74 \\
\hline & $(.39)$ & $(.35)$ & $(.41)$ & $(.53)$ & $(.55)$ & $(.41)$ & (.32) & (.23) & $(.17)$ & $(.15)$ & $(.15)$ & $(.11)$ \\
\hline Multi factors & 1.25 & 1.16 & 1.24 & 1.31 & 1.47 & 1.31 & 1.22 & 1.09 & 1.02 & 0.95 & 1.01 & 1.00 \\
\hline & $(.39)$ & $(.34)$ & $(.37)$ & $(.43)$ & $(.52)$ & $(.52)$ & $(.50)$ & $(.46)$ & $(.46)$ & $(.44)$ & $(.44)$ & $(.36)$ \\
\hline
\end{tabular}

Notes: see notes to Table 1.a and the text in section 4 


\section{European Central Bank Working Paper Series}

I "A global hazard index for the world foreign exchange markets" by V. Brousseau and F. Scacciavillani, May 1999.

2 "What does the single monetary policy do? A SVAR benchmark for the European Central Bank" by C. Monticelli and O. Tristani, May 1999.

3 "Fiscal policy effectiveness and neutrality results in a non-Ricardian world" by C. Detken, May 1999.

4 "From the ERM to the euro: new evidence on economic and policy convergence among EU countries" by I. Angeloni and L. Dedola, May 1999.

5 “Core inflation: a review of some conceptual issues" by M. Wynne, May 1999.

6 "The demand for M3 in the euro area" by G. Coenen and J.-L. Vega, September 1999.

7 “A cross-country comparison of market structures in European banking” by O. de Bandt and E. P. Davis, September 1999.

8 “Inflation zone targeting” by A. Orphanides and V. Wieland, October 1999.

9 "Asymptotic confidence bands for the estimated autocovariance and autocorrelation functions of vector autoregressive models" by G. Coenen, January 2000.

10 "On the effectiveness of sterilized foreign exchange intervention" by R. Fatum, February 2000.

II "Is the yield curve a useful information variable for the Eurosystem?" by J. M. Berk and P. van Bergeijk, February 2000.

12 “Indicator variables for optimal policy" by L. E. O. Svensson and M. Woodford, February 2000.

I3 “Monetary policy with uncertain parameters” by U. Söderström, February 2000.

14 "Assessing nominal income rules for monetary policy with model and data uncertainty" by G. D. Rudebusch, February 2000.

15 “The quest for prosperity without inflation” by A. Orphanides, March 2000.

16 "Estimating the implied distribution of the future short term interest rate using the LongstaffSchwartz model” by P. Hördahl, March 2000.

17 "Alternative measures of the NAIRU in the euro area: estimates and assessment" by S. Fabiani and R. Mestre, March 2000.

18 "House prices and the macroeconomy in Europe: Results from a structural VAR analysis" by M. lacoviello, April 2000. 
19 "The euro and international capital markets" by C. Detken and P. Hartmann, April 2000.

20 "Convergence of fiscal policies in the euro area" by O. De Bandt and F. P. Mongelli, May 2000.

21 "Firm size and monetary policy transmission: evidence from German business survey data" by M. Ehrmann, May 2000.

22 "Regulating access to international large value payment systems" by C. Holthausen and T. Rønde, June 2000.

23 “Escaping Nash inflation” by In-Koo Cho and T. J. Sargent, June 2000.

24 "What horizon for price stability” by F. Smets, July 2000.

25 "Caution and conservatism in the making of monetary policy" by P. Schellekens, July 2000.

26 "Which kind of transparency? On the need for clarity in monetary policy-making" by B. Winkler, August 2000.

27 "This is what the US leading indicators lead" by M. Camacho and G. Perez-Quiros, August 2000.

28 "Learning, uncertainty and central bank activism in an economy with strategic interactions" by M. Ellison and N. Valla, August 2000.

29 "The sources of unemployment fluctuations: an empirical application to the Italian case" by S. Fabiani, A. Locarno, G. Oneto and P. Sestito, September 2000.

30 "A small estimated euro area model with rational expectations and nominal rigidities" by G. Coenen and V. Wieland, September 2000.

3I "The disappearing tax base: Is foreign direct investment eroding corporate income taxes?" by R. Gropp and K. Kostial, September 2000.

32 "Can indeterminacy explain the short-run non-neutrality of money?" by F. De Fiore, September 2000.

33 "The information content of M3 for future inflation" by C. Trecroci and J. L. Vega, October 2000.

34 "Capital market development, corporate governance and the credibility of exchange rate pegs" by O. Castrén and T. Takalo, October 2000.

35 “Systemic risk: A survey” by O. De Bandt and P. Hartmann, November 2000.

36 "Measuring core inflation in the euro area" by C. Morana, November 2000.

37 "Business fixed investment: Evidence of a financial accelerator in Europe" by P. Vermeulen, November 2000. 
"The optimal inflation tax when taxes are costly to collect" by F. De Fiore, November 2000.

39 “A money demand system for euro area M3" by C. Brand and N. Cassola, November 2000.

40 "Financial structure and the interest rate channel of ECB monetary policy" by B. Mojon, November 2000.

4I "Why adopt transparency? The publication of central bank forecasts" by P. M. Geraats, January 200I.

42 "An area-wide model (AWM) for the euro area" by G. Fagan, J. Henry and R. Mestre, January 200I.

43 "Sources of economic renewal: from the traditional firm to the knowledge firm" by D. R. Palenzuela, February 200 I.

44 "The supply and demand for eurosystem deposits - The first 18 months" by U. Bindseil and F. Seitz, February 200 I.

45 "Testing the Rank of the Hankel matrix: a statistical approach" by G. Camba-Mendez and G. Kapetanios, February 200I.

46 "A two-factor model of the German term structure of interest rates" by N. Cassola and J. B. Luís, February 2001.

47 "Deposit insurance and moral hazard: does the counterfactual matter?" by R. Gropp and J. Vesala, February 2001.

48 "Financial market integration in Europe: on the effects of EMU on stock markets" by M. Fratzscher, March $200 \mathrm{I}$.

49 "Business cycle and monetary policy analysis in a structural sticky-price model of the euro area" by M. Casares, March 2001.

50 "Employment and productivity growth in service and manufacturing sectors in France, Germany and the US" by T. von Wachter, March 2001.

$5 \mathrm{I}$ "The functional form of the demand for euro area MI" by L. Stracca, March $200 \mathrm{I}$.

52 "Are the effects of monetary policy in the euro area greater in recessions than in booms?" by G. Peersman and F. Smets, March $200 \mathrm{I}$.

53 "An evaluation of some measures of core inflation for the euro area" by J.-L. Vega and M. A. Wynne, April 200 I.

54 “Assessment criteria for output gap estimates" by G. Camba-Méndez and D. R. Palenzuela, April 2001.

55 "Modelling the demand for loans to the private sector in the euro area" by A. Calza,

G. Gartner and J. Sousa, April 200I. 
56 "Stabilization policy in a two country model and the role of financial frictions" by E. Faia, April 200I.

57 "Model-based indicators of labour market rigidity" by S. Fabiani and D. Rodriguez-Palenzuela, April 200I.

58 "Business cycle asymmetries in stock returns: evidence from higher order moments and conditional densities" by G. Perez-Quiros and A. Timmermann, April 2001.

59 "Uncertain potential output: implications for monetary policy" by M. Ehrmann and F. Smets, April 200I.

60 "A multi-country trend indicator for euro area inflation: computation and properties" by E. Angelini, J. Henry and R. Mestre, April 200 I.

6I "Diffusion index-based inflation forecasts for the euro area" by E. Angelini, J. Henry and R. Mestre, April 200I.

62 "Spectral based methods to identify common trends and common cycles" by G. C. Mendez and G. Kapetanios, May 2001.

63 "Does money lead inflation in the euro area?" by S. Nicoletti Altimari, May 200I. 